\title{
Best practice guidelines for cetacean tagging
}

\author{
Russel D. Andrews ${ }^{1}$, Robin W. Baird ${ }^{2}$, John Calambokidis ${ }^{2}$, Caroline E.C. Goertz ${ }^{3}$, Frances M.D. Gulland ${ }^{4}$, \\ Mads Peter Heide-Jørgensen ${ }^{5}$, Sascha K. Hooker ${ }^{6}$, Mark Johnson ${ }^{6}$, Bruce Mate ${ }^{7}$, Yoko Mitani ${ }^{8}$,

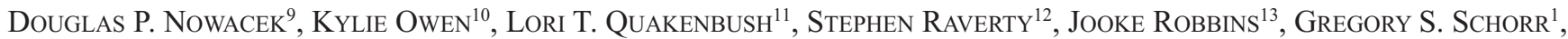 \\ Olga V. Shpak ${ }^{14}$, Forrest I. Townsend, JR. ${ }^{15}$, Marcela UharT ${ }^{4,16}$, Randall S. Wells ${ }^{17}$ And AleXandre N. ZerbinI ${ }^{1,2,18}$
}

Contacte-mail: russ@marecotel.org

\begin{abstract}
Animal-borne electronic instruments (tags) are valuable tools for collecting information on cetacean physiology, behaviour and ecology, and for enhancing conservation and management policies for cetacean populations. Tags allow researchers to track the movement patterns, habitat use and other aspects of the behaviour of animals that are otherwise difficult to observe. They can even be used to monitor the physiology of a tagged animal within its changing environment. Such tags are ideal for identifying and predicting responses to anthropogenic threats, thus facilitating the development of robust mitigation measures. With the increasing need for data best provided by tagging and the increasing availability of tags, such research is becoming more common. Tagging can, however, pose risks to the health and welfare of cetaceans and to personnel involved in tagging operations. Here we provide 'best practice' recommendations for cetacean tag design, deployment and follow-up assessment of tagged individuals, compiled by biologists and veterinarians with significant experience in cetacean tagging. This paper is intended to serve as a resource to assist tag users, veterinarians, ethics committees and regulatory agency staff in the implementation of high standards of practice, and to promote the training of specialists in this area. Standardised terminology for describing tag design and illustrations of tag types and attachment sites are provided, along with protocols for tag testing and deployment (both remote and through capture-release), including training of operators. The recommendations emphasise the importance of ensuring that tagging is ethically and scientifically justified for a particular project and that tagging only be used to address bona fide research or conservation questions that are best addressed with tagging, as supported by an exploration of alternative methods. Recommendations are provided for minimising effects on individual animals (e.g. through careful selection of the individual, tag design and implant sterilisation) and for improving knowledge of tagging effects on cetaceans through increased post-tagging monitoring.
\end{abstract}

KEYWORDS: BIO-LOGGING; RADIO-TAGGING; SATELLITE TAGGING; TELEMETRY

\section{INTRODUCTION*}

The understanding of the biology of cetaceans and their habitat requirements, and our ability to mitigate threats to them, are challenged by the difficulty of observing animals that spend most of their time beneath the water surface, often in remote areas. This challenge can be at least partly overcome by using animal-borne monitoring instruments (bio-logging tags; hereafter referred to as 'tags'). Depending on the design, these tags can provide a variety of data, such as environmental (e.g. water temperature, salinity), physiological (e.g. heart rate, body temperature) and

*Note: In-text references have been used sparingly here as we aim to offer recommendations broad enough to be relevant to all those interested in cetacean tagging, to be as concise as possible, and also to aid readability. An exhaustive list of references (over 500) related to cetacean tagging is provided in the Supplementary Bibliography (see Appendix B). behavioural (e.g. dive depth and duration, acceleration, geographic position). Although the first time a tag of this type was applied to a cetacean was as early as the 1930s (Scholander, 1940), it took several decades and the advent of VHF transmitters, digital time-depth-recorders and eventually satellite-linked transmitters, for these tags to be regularly used in the study of wild cetaceans. Modern tags can archive data for eventual recovery and downloading, or they can transmit data via electromagnetic and/or sound waves. Tags are now a critical component in advancing cetacean science. Compared with other types of observations, tags can provide nearly continuous data as opposed to snapshots in time and are observer-independent. They have yielded data important for answering basic science and life history questions and for the management and conservation of cetaceans, including data on population

\footnotetext{
${ }^{1}$ Marine Ecology and Telemetry Research, 2468 Camp McKenzie Tr NW, Seabeck, WA 98380, USA.

${ }^{2}$ Cascadia Research Collective, 218 1/2 W 4th Avenue; Olympia, WA 98501, USA.

${ }^{3}$ Alaska SeaLife Center, P.O. Box 1329, Seward, AK 99664, USA.

${ }^{4}$ Wildlife Health Center, UC Davis School of Veterinary Medicine, Davis, CA 95616, USA.

${ }^{5}$ Greenland Institute of Natural Resources, Strandgade 91,2, DK-1401 Copenhagen K, Denmark.

${ }^{6}$ Sea Mammal Research Unit, Scottish Oceans Institute, School of Biology, University of St Andrews, St Andrews, Fife, KY16 8LB, UK.

${ }^{7}$ Oregon State University Marine Mammal Institute, Hatfield Marine Science Center, 2030 SE Marine Science Dr, Newport, OR 97365, USA.

${ }^{8}$ Field Science Center for Northern Biosphere, Hokkaido University, Hakodate Research Center for Fisheries and Oceans, 20-5 Benten-cho, Hakodate, Hokkaido 040-0051, Japan.

${ }^{9}$ Duke University Marine Lab, Nicholas School of the Environment, 135 Duke Marine Lab Rd, Beaufort, NC 28516, USA

${ }^{10}$ Cetacean Research Unit, School of Veterinary and Life Sciences, Murdoch University, Murdoch, WA, 6150, Australia.

${ }^{11}$ Arctic Marine Mammal Program, Alaska Department of Fish and Game, 1300 College Road, Fairbanks, AK 99701, USA.

${ }^{12}$ Animal Health Center, British Columbia Ministry of Agriculture and Lands, 1767 Angus Campbell Rd, Abbotsford, BC, V3G 2M3, Canada.

${ }^{13}$ Center for Coastal Studies, 5 Holway Avenue, Provincetown, MA 02657, USA.

${ }^{14}$ Severtsov Institute of Ecology and Evolution, Russian Academy of Sciences, Moscow, Russia.

${ }^{15}$ Bayside Hospital for Animals, 251 Racetrack Road, NE, Fort Walton Beach, FL 32547, USA.

${ }^{16}$ Programa de Monitoreo Sanitario Ballena Franca Austral, Puerto Madryn, Chubut, Argentina.

${ }^{17}$ Chicago Zoological Society, Sarasota Dolphin Research Program, clo Mote Marine Laboratory, 1600 Ken Thompson Parkway, Sarasota, FL 34236, USA.

${ }^{18}$ Marine Mammal Laboratory, Alaska Fisheries Science Center, 7600 Sand Point Way NE, Seattle, WA, 98115, USA.
} 
structure and stock discreteness. Tag data have also been valuable in the development of mitigation measures to protect cetacean species. For example, they have been used to document previously unknown migratory routes and important habitats, to determine the fate of stranded and rescued animals post-release and responses to human disturbance, as well as to provide basic knowledge about cetacean physiology, behaviour and ecology (see Appendix B for a comprehensive list of references that document such studies).

The use of tagging in cetacean research has increased considerably in the past 20yrs (Fig. 1). With tags designed specifically for cetaceans becoming commercially available only recently, their use is likely to further increase and continue to expand our knowledge of cetacean biology. Tagging does, however, present potential risks to tagged individuals, so users need to be aware of possible health and welfare concerns. Tags have the potential to alter the physiology and behaviour of the tagged animal, and thus the validity of the interpretation of the data collected. As tag designs and tagging methods develop, information about the most successful refinements and innovations should be shared to facilitate the use of techniques that are most appropriate for a project and that minimise any potential adverse effects on tagged animals. The objectives of this paper are to provide a summary of key topics to consider before tagging cetaceans and best practice recommendations based on the experience of the authors and reviews of the literature. Whilst the intention is that these recommendations are applicable globally, we recognise that not all of them may be feasible in all situations. Variations in local laws, customs and cultures, and the challenges of fieldwork in remote and difficult environments, can all require adjustments to the recommendations we propose. Therefore, the recommendations presented here should not be interpreted as mandatory but rather as standards to strive for. The text preceding the key recommendations for each section of this document is intended to provide additional context and detail to assist with the adjustment of protocols as possible.

No previous single document has provided guidelines for cetacean tagging, but there are a few highly relevant resources that the guidelines presented here are intended to build upon. The Society for Marine Mammalogy has published 'Guidelines for the Treatment of Marine Mammals in Field Research' (Gales et al., 2009) that scientists contemplating tagging of cetaceans should follow. Morton et al. (2003) provided useful recommendations for refining telemetry procedures, and although their focus was on laboratory animals, many of the recommendations are relevant to cetacean tagging. Casper (2009) provided a valuable framework for minimising the negative effects of instrumenting wild birds and mammals, and Mulcahy (2011; 2013) reviewed asepsis and antibiotic usage associated with implanted electronic tags. Two recent documents have provided best practice recommendations for the use of tags with pinnipeds; one for implanted tags (Horning et al., 2017), and one for external tags (Horning et al., 2019). Specific recommendations for cetacean tagging can be found in some recent book chapters (e.g. Lander et al., 2018; McConnell et al., 2010) and workshop reports (ONR, 2009; Weller, 2008;

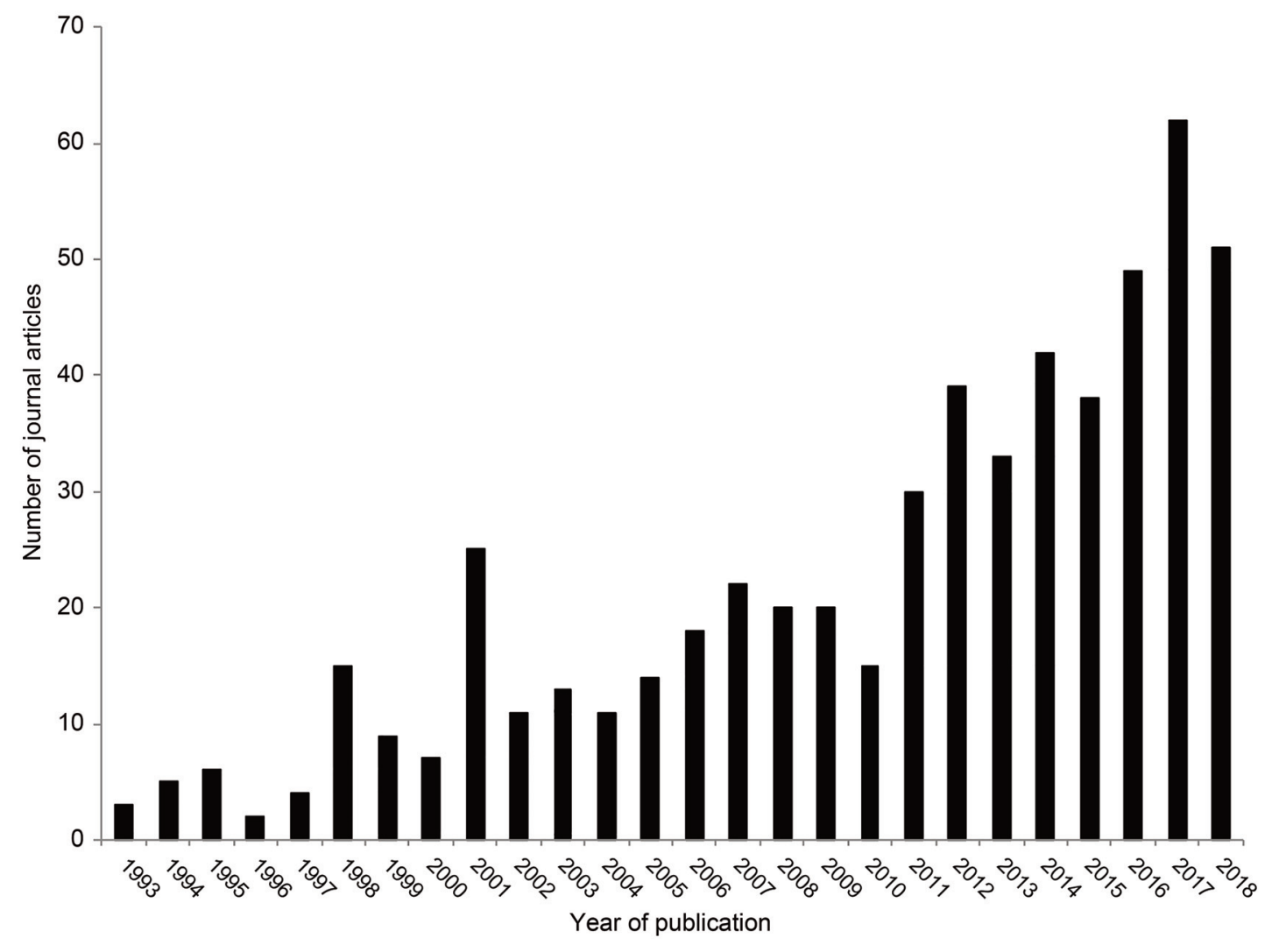

Fig. 1. Number of journal articles published between 1993 and 2018 that included some aspect of cetacean tagging. Web of Science, Scopus and Google Scholar were searched using a broad list of key words to identify scientific papers that included any aspect of the topic of cetacean tagging, including development of tags, deployment of tags and studies of effects of tags. The full reference list is provided in the Supplementary Bibliography (see Appendix B). 
Wells, 2005). This document will focus on updating and clarifying key topics important for cetacean tagging to provide a resource for researchers, veterinarians, ethics boards and regulatory agency staff to interpret and implement high standards of practice, and to identify necessary training. We hope that this paper will further efforts to improve tags, attachments and techniques.

\subsection{Approach}

These guidelines originated with the Cetacean Tag Design Workshop sponsored by the Office of Naval Research in 2009 (ONR, 2009) and were further developed at the Workshop on Living Whales in the Southern Ocean in 2012 (Baker et al., 2012), at the 20th Biennial Conference on the Biology of Marine Mammals in 2013, and at the Workshop on Cetacean Tag Development, Tag Follow-up and Tagging Best Practices sponsored by ONR, the International Whaling Commission (IWC) and the National Marine Fisheries Service/National Oceanic and Atmospheric Administration (NMFS/NOAA) in September 2017 (IWC, in press). Each author has expertise in one or more of the following disciplines as it relates to cetaceans: general biology, capture and release, tagging, veterinary medicine and tag technology. Each author volunteered to participate and has contributed significantly to the development of the guidelines by identifying, evaluating and summarising the most current information on cetacean tagging. The guidelines are not meant to be a detailed description (or instruction manual) of methods, but rather provide key recommendations to inform practitioners and regulators (e.g. animal welfare/ethics and permitting authorities) about appropriate methods and circumstances for tagging cetaceans.

To be most effective, such guidelines need to be readily available and up-to-date. Therefore, in addition to this publication, the guidelines will be available on the cetaceantagging.info website, where a forum will be hosted for the discussion of modifications and additions to ensure the document and recommendations reflect current best practices.

\section{KEY TOPICS AND RECOMMENDATIONS}

\subsection{Ethical and legal considerations of tagging}

While there are scientific and conservation benefits of tagging cetaceans (see Supplementary Bibliography in Appendix B), there can also be negative effects on individuals (Section 2.7). Therefore, prior to any decision to use tags, researchers should weigh the positive and negative factors to determine if tagging is scientifically and ethically justified. The Bateson cube, comparing animal suffering with research merit and population benefit, is one good approach to this decision-making process (McMahon et al., 2012). All methods available to address identified research questions (including thorough examination of existing data), should be evaluated prior to the decision to use tags to ensure that the data required can best be provided by these instruments. To help guide those that are considering a cetacean tagging study, a flow chart of an example decision process is presented in Fig. 2.

If tagging is justified, effects on the target animals should be minimised by following the best principles of research design (Gales et al., 2009). Refinements in tagging

\section{Tagging Study Decision Process}

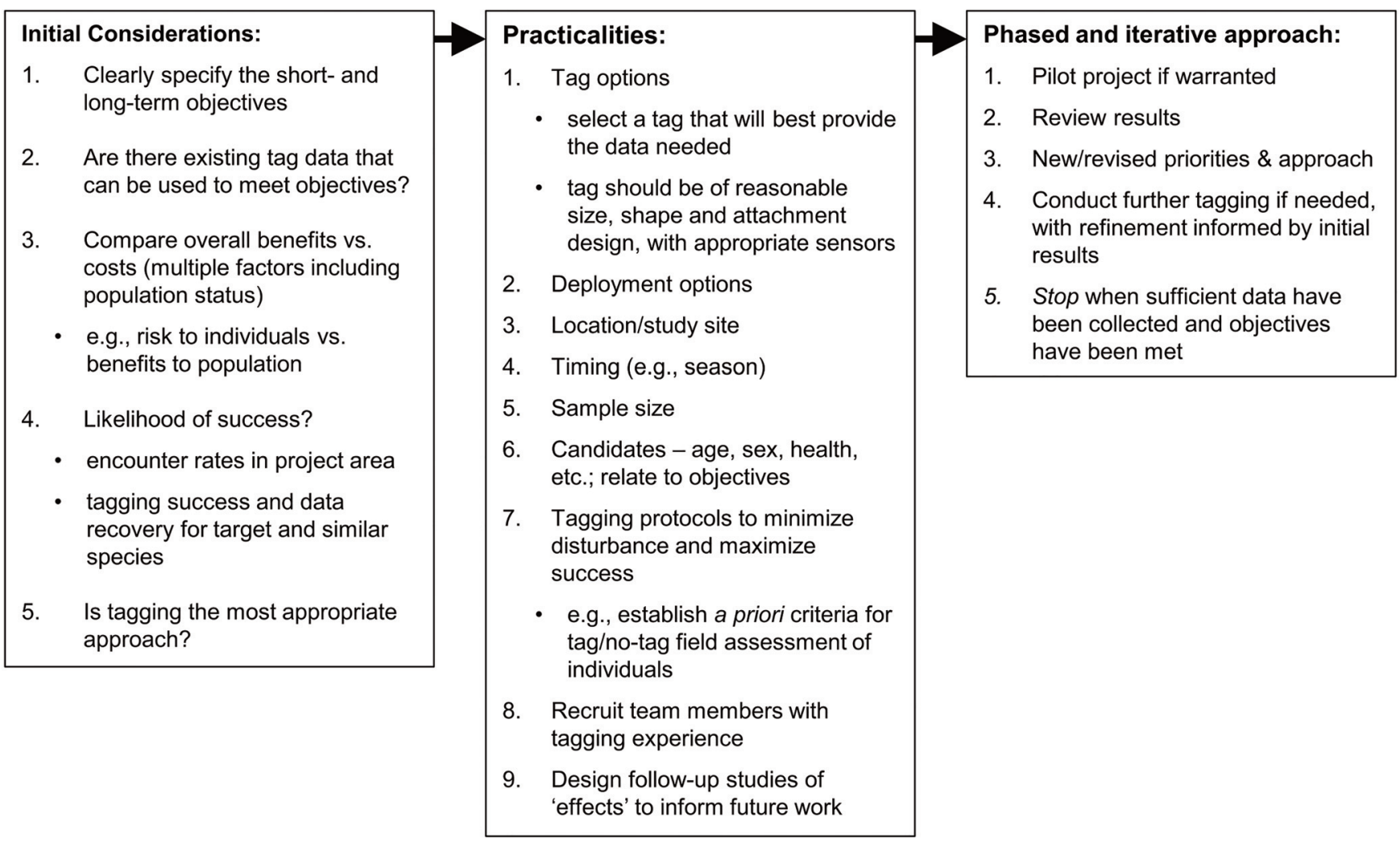

Fig. 2. A recommended approach to guide the decision process for those considering a cetacean tagging study. Additional details are presented in Section 2.2, including an explanation of what constitutes a 'reasonable' tag design for a species. 
procedures, such as using methods that cause no more than momentary pain or discomfort, reflect elements of good experimental design encapsulated in the principle of the Three Rs (Russell and Burch, 1959): Replacement (with procedures not using animals), Reduction (in the number of animals used) and Refinement (using methods which decrease any adverse effect). Tagging studies should only be conducted when the research or management questions require new data from live animals, so it is the latter two Rs that are relevant. For example, researchers must identify a sample size that minimises animal use while answering the study objective. In many types of cetacean studies, ideal sample size is not easily determined or attainable. This is especially true in tagging studies because of difficult logistics (e.g. animals that can be hard to find and approach). Further, estimating the appropriate sample size in advance is complicated by our limited knowledge of the natural variability of most of the parameters that tags are being used to measure. As for any technique, whether the likely achievable sample size will be sufficient to answer the research question must be considered before deciding to use tags. Given how little is known about some species however, even a sample size of one may provide valuable information that will inform future research designs or management questions. Further, due to the wide variation in tag attachment duration, a larger number of deployments may be required to obtain the target number of tags with sufficient attachment duration to answer the research questions. Nevertheless, when possible, scientists should address sample size questions with statistical power analyses. Tagging data collected from similar species will likely be useful for estimating parameter variability.

This paper assumes that researchers will comply with all laws and regulations that govern animal care and welfare at the local, national and international levels. Tagging procedures may have effects on animals during all phases (i.e. approach, deployment, on-animal operation, detachment and post-detachment). Effects should be identified, and if significant, mitigated where possible and justified to administration/regulatory/ethical oversight authorities. Scientists planning to tag cetaceans must also consider possible unintended effects of tagging activities on the environment, including capture-release operations and inadvertent animal disturbance, especially when conducting research in protected or sensitive areas. Furthermore, tags include electronics that may be regulated at the local or federal level, and even though a tag is available commercially, it may not be legal to use it in some locations without permits. Other laws and regulations that apply to cetacean tagging include those that protect the health and safety of the human participants. Tagging large, wild animals from small boats is challenging and poses risks to humans and animals, therefore it is critical that researchers maintain high safety standards to protect themselves, their study subjects, other animals and bystanders. Adequate preparation includes a thorough risk assessment, possession of, and competency in the use of appropriate safety equipment, and a contingency plan for emergencies involving either humans or the study animals. Detailed recommendations regarding training and qualifications are found in Section 2.5.
Researchers should consider the importance of cetaceans to various groups of people for subsistence, cultural, scientific and economic reasons. Stakeholders interested in cetacean tagging projects may include subsistence and commercial whalers, fishers, cultural leaders and participants in wildlife tourism. There is, therefore, a need to identify and work with members of interested communities at all stages of a project, to convey the research objectives and possibly to solicit and include research questions raised by local stakeholders. This may encompass coordination during the planning stages and, just as importantly, communication of results both as the project proceeds and at its end. Consideration of the rights, concerns and interests of indigenous peoples can be regionally critical, as is recognition of the value of local and traditional knowledge. One example of the international acceptance of these principles is the 'Agreement on Enhancing International Arctic Scientific Cooperation', signed at the 10th Arctic Council Ministerial meeting in Fairbanks, Alaska, 11 May 2017. Although local and traditional knowledge and use of cetaceans are important issues far beyond the Arctic, a good example of guidance for outreach to local stakeholders can be found in the US National Science Foundation's 'Principles for the Conduct of Research in the Arctic' (https://www.nsf.gov/od/opp/arctic/conduct.jsp).

At the end of this section, as in all subsequent sections of these guidelines, the main recommendations are summarised for the section topic in bullet points.

\subsubsection{Recommendations for ethical and legal considerations of tagging}

- Determine if tagging is appropriate.

- Consider alternative methods for addressing research questions.

- Review relevant existing data for the species and area of consideration.

- Ensure that there is a scientific or conservation justification for obtaining new data and that those data are best provided by tags.

- Follow best practices of research design.

- Develop the research plan with animal welfare as a high priority.

- Evaluate equipment options and choose the instrument and attachment that provide the data needed.

- As much as possible, ascertain required samples sizes and statistical approaches in advance, obtaining expert advice if needed.

- Tag the fewest number of individuals necessary in the least invasive and impactful manner possible to achieve the project goals.

- Prepare adequately for field work.

- Conduct a thorough risk assessment in advance.

- Prepare for unexpected risks to the safety of animals and humans.

- Ensure the capture/tagging team is trained in the safe and proper procedures for boat approaches (and capture-release techniques if required) and use of tagging equipment. 
- Comply with all applicable local, national and international legal requirements.

- Obtain review and approval by an animal ethics committee, even if not locally required.

- Reach out to stakeholders, including those with subsistence, cultural and economic interests in the study subjects, by:

- sharing research goals and soliciting input;

- coordinating during planning; and

- communicating results throughout and at the completion of the study.

\subsection{Tag design and deployment}

The first known bio-logging tags deployed on cetaceans were capillary manometers, which provided a single data point for the depth of the deepest dive while attached. In the 1930s, Scholander (1940) and colleagues secured such a tag to a harness on a harbor porpoise (Phocoena phocoena) and placed one on a harpoon line to measure the dive depth of a harpooned fin whale (Balaenoptera physalus). Since then, both the tags and the methods for attaching them have improved significantly. However, refinements are still needed, especially in the way instruments are attached to cetaceans, so that attachment durations are more consistent, and therefore more predictable, and provide the required duration of observations while minimising effects on the tagged individuals. There is a wide variety of tag designs, including custom-made tags such as those with external leads for monitoring physiological parameters, and those that transmit data from one part of the body to another device secured elsewhere. Here, the focus is on tags considered a single unit for deployment which, based on the method of attachment, can be either invasive or non-invasive. Invasive is defined here as a tag attachment that intentionally breaks the skin, regardless of the degree of the break.

\subsubsection{Invasive tags}

There are currently three common configurations of invasive tags (Fig. 3). Each of these include percutaneous implants (i.e. implants that create and maintain a hole through the skin until the tag is lost).

Type $\mathrm{A}=$ Anchored. Anchored tags are tags with the electronics package external to the skin, attached by one or more anchors that puncture and terminate below the skin. The anchors, often solid shafts with retention barbs or petals, are designed to terminate in the internal tissue of the dorsal fin or in dermal or hypodermal tissue along the dorsum. Anchored tags are usually deployed using remote-attachment methods that do not require restraint of the animal, such as projection from a crossbow or air-gun, or placement with a pole.

Type $\mathrm{B}=$ Bolt-on. Bolt-on tags have external electronics and one or more piercing anchors. An element of the tag is attached to the external end(s) of one or more 'bolts' that pierce tissue, creating a tunnel around the bolt with an entry and exit site (like a human ear-ring or a pinniped flipper tag). For example, single-point dolphin tags that trail behind a v-shaped piece that is 'bolted' to the dorsal fin, or the three-pin design with the tag
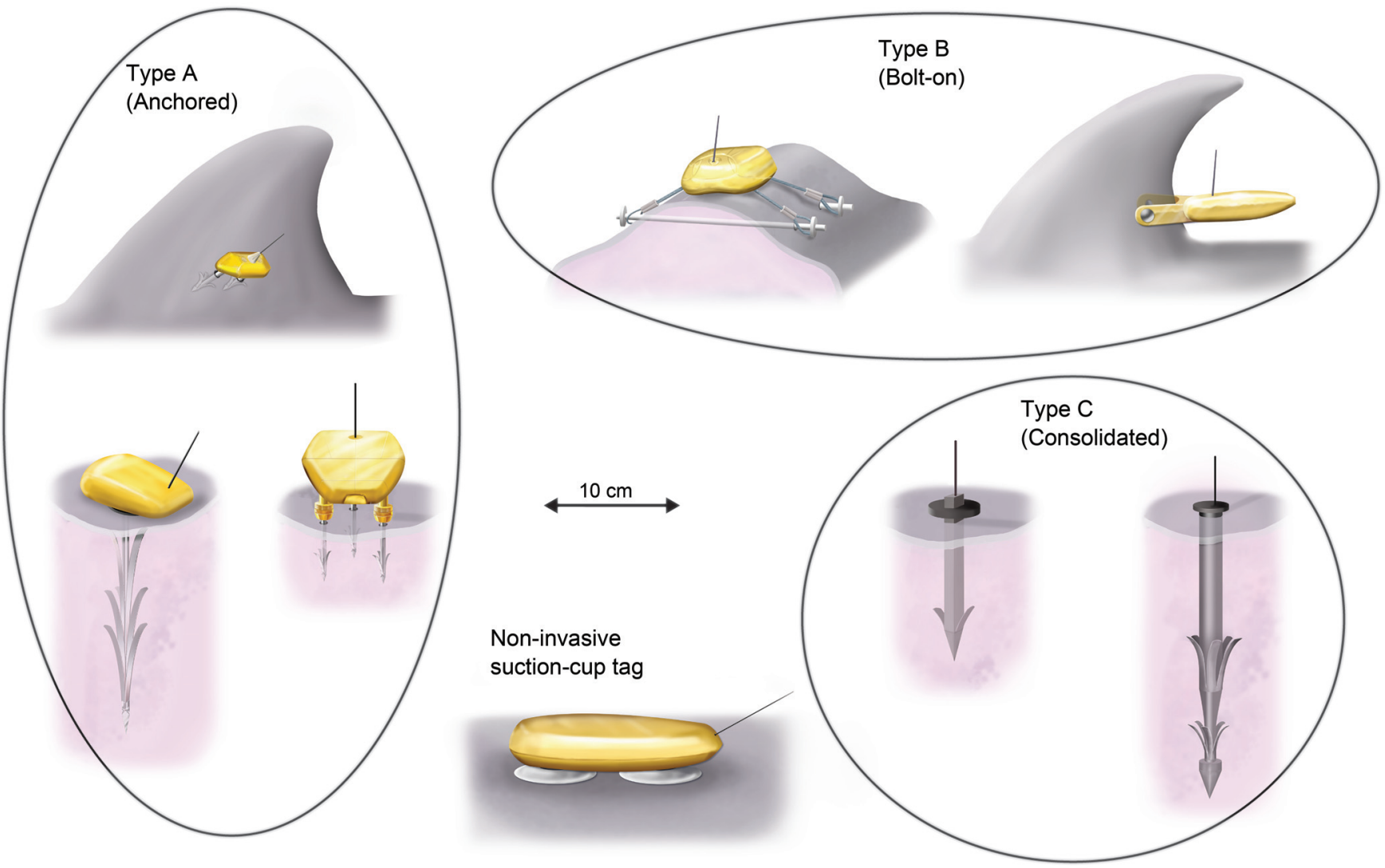

Fig. 3. Illustrations of a non-invasive (= no break in the skin) suction cup tag (bottom center) and the three most common configurations of invasive tags, Type A: Anchored; Type B: Bolt-on; Type C: Consolidated. [Illustrations by Michael Ortiz] 
bolted on one side and a flat plate held on the opposite side. Another example of a bolt-on design is sometimes called a 'spider-legs' tag, where the tag sits as a saddle over or near the dorsal ridge, connected via cables to piercing pins, rods or bolts. Creating the hole for the bolt currently requires capture and restraint of the animal, and manual contact with the skin.

Type $\mathrm{C}=$ Consolidated. The electronics and retention elements are consolidated into a single implanted anchor. The electronics are typically inside a metal case, usually a cylinder, designed to be partially implanted in the body, with only a small part of the top of the tag and antenna and/or sensors projecting above the skin. Retention barbs, or petals, are connected directly to the implanted package. Puncture of the skin typically occurs on the body or the base of the dorsal fin (not the central part of the dorsal fin), and the distal end of the tag sometimes terminates internally to the muscle/blubber interface. Application of these tags does not require restraint and they are deployed with remote methods.

\subsubsection{Non-invasive tags}

Non-invasive tag attachments include harnesses, peduncle belts and suction cups. Suction cups (Fig. 3) are the most common non-invasive attachment and have been used with success in many species. Suction cups pose little to no negative impact on the study animal, but their duration of attachment typically ranges from a few hours to at most a few days.

\subsubsection{Choice of tag type}

When selecting tags and attachment systems, scientists should explore all design and deployment options, using scientific journal articles, reports from vendors and by contacting researchers with extensive tagging experience. Direct communication is the most valuable way to obtain the information needed and to access results from unpublished work.

Key criteria for determining whether a tag is appropriate for a particular research project include:

(1) ability to provide the type, quantity and resolution of data required;

(2) being of a reasonable size, shape and configuration for the species and sex/age class to be studied; and

(3) having the least impact possible on the animals.

\subsubsection{Tag design}

A reasonable tag design is one that does not pose unacceptable risks to the health, welfare and reproductive success of the tagged individual, and that does not significantly alter behaviour or otherwise affect the tagged animal in a way that could bias the results. A reasonable tag should also not interfere with body movements or appreciably increase energy expenditure. The latter can partly be addressed by minimising the external dimensions and the forces imposed by the tag, primarily drag and lift. This applies to all parts of non-invasive tags and the external parts of invasive ones. Design features that improve hydrodynamics will reduce metabolic cost and may also reduce predation risk and the possibility of entanglement or premature tag detachment or failure. The shape and characteristics that result in minimal drag are not necessarily obvious, so focussed testing of different designs is recommended, which can be done empirically and/or by simulation using computational fluid dynamics. In environments where bio-fouling is likely to occur and long attachment durations are needed, making the external portion of tags smooth (e.g. with a slick coating) can reduce attachment ability of marine organisms (bio-fouling) and therefore prevent an increase in drag while protecting external sensors on the tag. An external part of the tag should be labeled with an ID\# and researcher contact information to facilitate identification by beach combers in case a tag washes up on shore, or by stranding responders if a tag is still attached to a cetacean that strands while carrying a tag.

Tags that generate sound, e.g. to transmit data underwater or to facilitate acoustic tracking, may have unanticipated effects on cetaceans. Despite having a low duty cycle, these transmitters may be audible to the tagged animal (and possibly also to its predators) and could cause startle or other behavioural responses. The sounds generated by these tags should be assessed in the context of the hearing range, sensitivity and integration time of the target species and their predators, as well as the likely ambient noise level, to the extent that these are known. Pilot trials with cetaceans in captivity and with devices containing additional behavioural sensors may help to evaluate the acceptability of the acoustic output.

Non-invasive tag attachments are those that are not designed to penetrate the skin. These include suction cups, harnesses and peduncle belts. Non-invasive tags, especially those attached with suction cups, may often be the best choice when short-term tag attachment is all that is required. However, even though these tags are classified as noninvasive, some of these methods can nevertheless cause negative effects on animals, so a reasonable non-invasive tag design should aim to minimise adverse effects, such as excessive drag. Harnesses that encircle the body can impose significant drag loads, an increased risk of entanglement and lead to skin chafing (Scott et al., 1990). Therefore, the use of harnesses is not recommended with free-ranging cetaceans. Peduncle belts are still experimental but placing an object on part of the body that moves as much as the caudal peduncle presents obvious challenges that have yet to be resolved, including the potential for altering the biomechanics of swimming and/or skin chafing. In many cetaceans, the peduncle is laterally compressed with a hydrodynamically efficient shape, the drag of which could be strongly affected by a belt. Non-invasive tags are most commonly attached with suction cups, and the number and arrangement of the cups should be part of the design and testing. The shore hardness or durometer of the material used to make the suction cups is important as attaining the best suction is a balance between stiffness to maintain shape and softness to achieve a good seal with the skin. The volume of 
the cup should be considered as this relates to the suction, or vacuum, pressure that can be achieved inside the suction cup. Although a greater vacuum pressure is likely to allow the tag to resist greater external forces that might dislodge a suction cup, it is important to consider whether excessive vacuum pressure can cause complications such as blistering or hematomas below the cup (Shorter et al., 2014). A suction cup that does not cause significant discomfort is also likely to reduce the possibility that the tagged animal will intentionally remove the tag.

Many non-invasive tags are archival and must be retrieved to recover the data; the tag must therefore float upon release and some system(s) to track the tag must be incorporated (e.g. VHF beacon and/or Argos transmitter). The tracking antenna needs to be oriented correctly, i.e. free of the water surface, after the tag releases, requiring that floatation is integrated strategically into the tag package. Finally, while non-invasive tags are sometimes dislodged by other animals, they can remain attached for relatively long periods of time (e.g. 24+ hrs), so many of these tags incorporate an automatic release system to facilitate retrieval.

For invasive tags, whilst it is generally preferable to use the smallest sizes possible for both external and internal parts, smaller is not always better. For example, the ability of an implanted anchor or bolt to resist withdrawal by external forces is likely to be positively related to its length. Further, the retention elements for anchored or consolidated tags are typically designed to anchor in or under a particular tissue and therefore need to be long enough to reach the target tissue, whether it be blubber, muscle or in the central tissue of the dorsal fin or ridge. However, the maximum depth of penetration and placement on the body require careful consideration to ensure the sharp, rigid elements of the anchor do not damage bones or internal organs. Most tags are implanted on the dorsal surface of cetaceans where the closest bones are the vertebral processes (neural spines and transverse processes) and the ribs (Fig. 4). In small cetaceans, these structures may only be a few centimeters below the skin. In larger cetaceans the distances are greater, but age, season and body condition can alter these distances within a species. Therefore, attention to a tag's intended maximum depth of penetration and the anatomy, size and body condition of the target animal is critical. Figs 4 and 5 illustrate the basic anatomical features to be aware of when placing tags in the typical places on a representative mysticete (humpback whale) and an odontocete (killer whale).

Tags should be constructed of materials that are biocompatible and safe for skin contact (for external parts) or long-term implantation in mammalian tissue (for implanted parts), regardless of the anticipated retention time. Although most tags with implanted parts are likely to be fully shed within a few months, there are reports of implanted tags or parts of tags that have been retained within the tissue of cetaceans for many years. Therefore, for the implanted parts of tags it would be prudent to choose materials that are not likely to cause significant complications that could harm the tagged cetacean if retained permanently. Material choices should also consider the corrosive nature of the tag
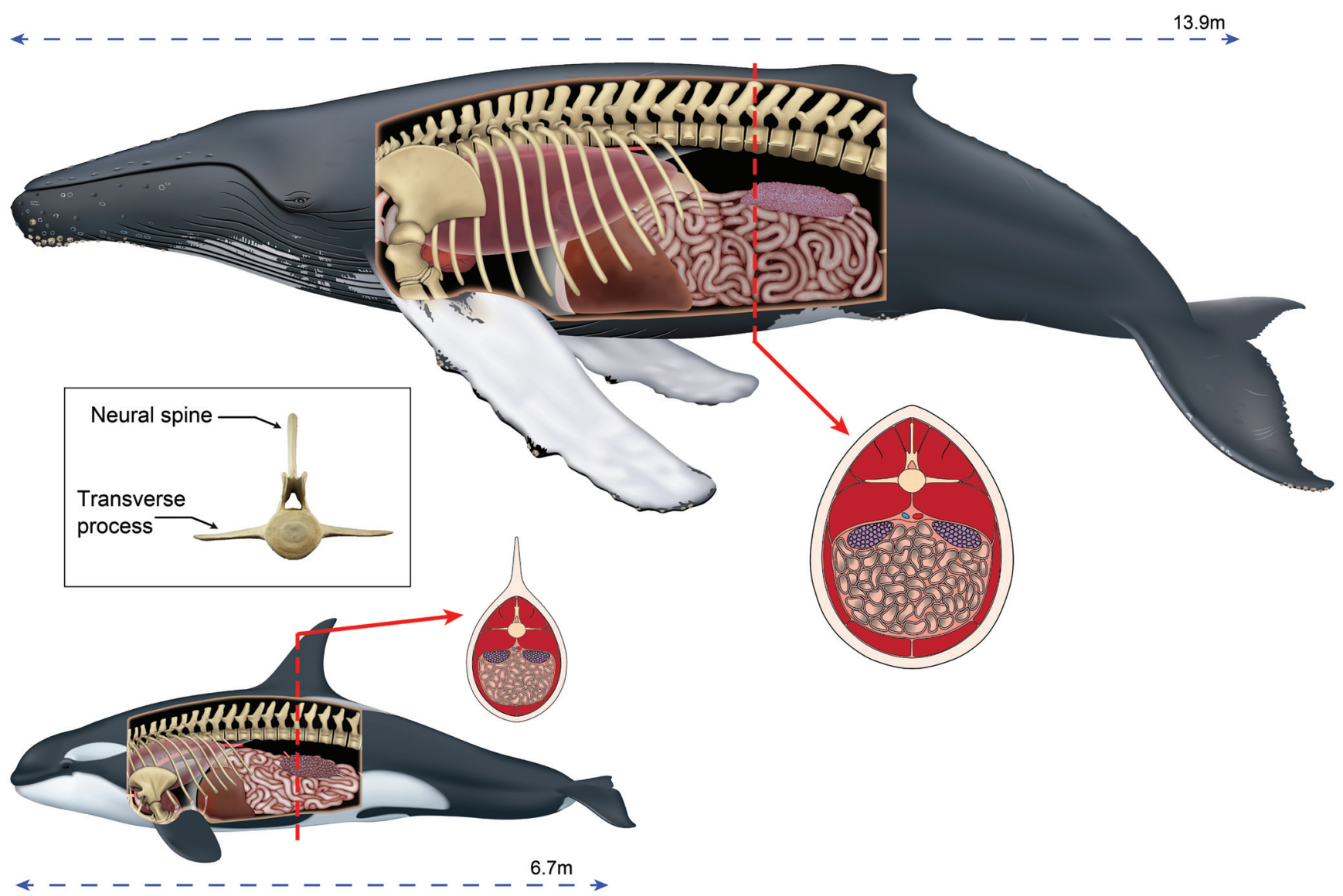

Fig. 4. Schematic illustrations of a humpback whale (top) and killer whale (bottom); both based on non-pregnant adult females. Anatomical features are shown in a cut-away sagittal section and a transverse section at the level of the body where invasive tags are most often attached. In the sagittal sections, many tissues, including muscles and connective tissue, have been omitted for clarity. [Illustrations by Uko Gorter] 


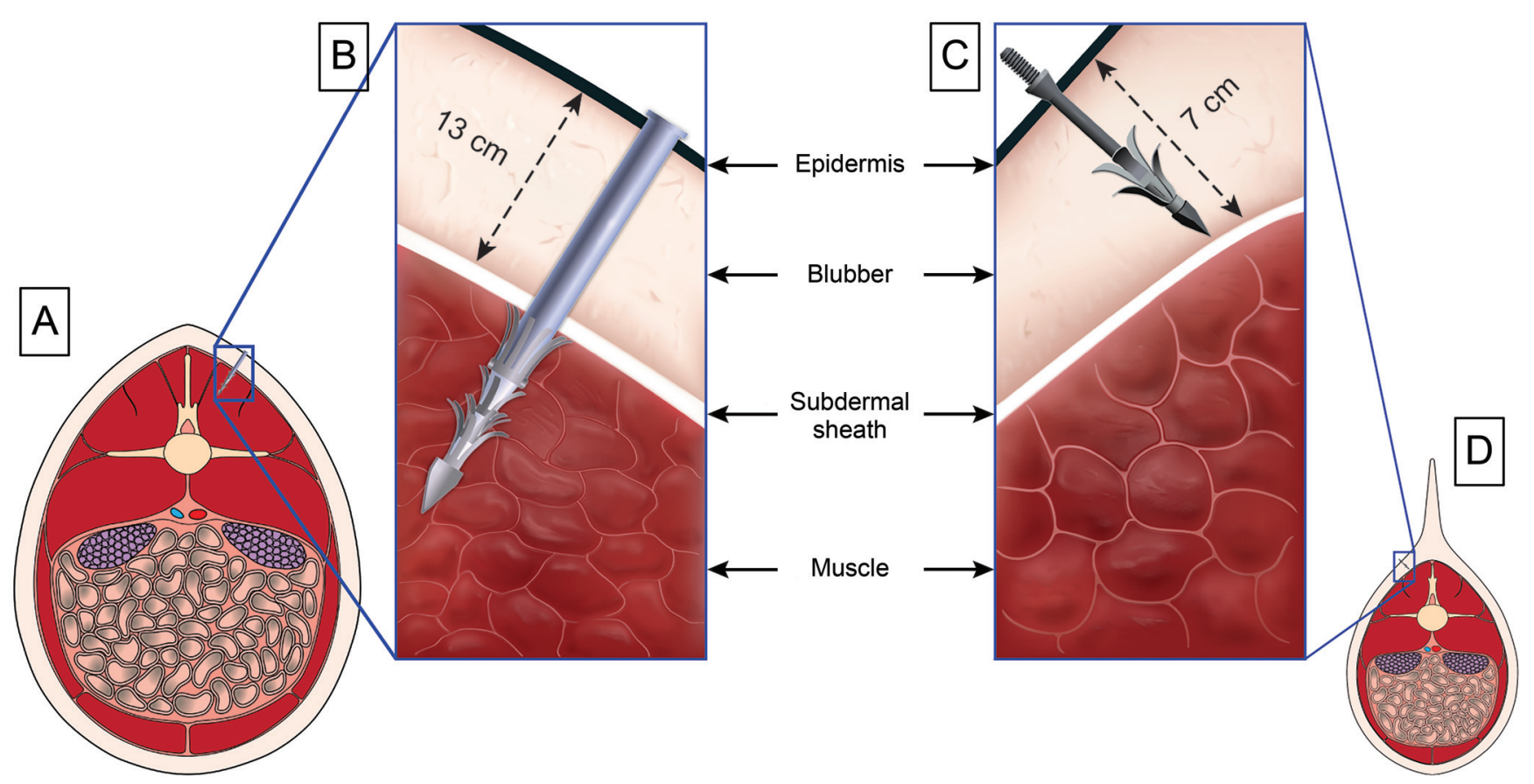

Fig. 5. Schematic illustrations of representative tag implants in situ, based on the transverse sections of a humpback whale (A) and a killer whale (D), drawn to the same scale, as illustrated in Fig. 4. Left (A and B): The humpback whale transverse section with an implanted Type C (Consolidated) tag. Right (C and D): The killer whale transverse section with an implanted dart from a Type A (Anchored) tag. Note that the expanded boxes (B and C) are not drawn to the same scale; they have been scaled so that the blubber layer thicknesses, which are different for the two species, appear at the same size in B and C. The implants are drawn here as if they entered the tissue at a $90^{\circ}$ angle to the plane of the penetrated skin, which results in the maximum possible depth of penetration, even though most Type $\mathrm{C}$ tags and Type $\mathrm{A}$ anchors enter at a smaller angle. The term blubber includes the dermal and hypodermal layers of the integument. The subdermal sheath is the fascia layer of interwoven collagen fibers surrounding the axial musculature (Pabst et al., 1990). [Illustrations by Uko Gorter]

environment, inside and outside of the body. Comprehensive guidance on the topic of biomaterials can be found in Ratner et al. (2013), and recommendations for conducting biocompatibility evaluations for implant devices are presented in the International Standard ISO 10993-1:2018, 'Biological evaluation of medical devices - Part 1: Evaluation and testing within a risk management process'.

\subsubsection{Sterilisation}

All implanted parts of a tag must be thoroughly cleaned of particles and chemical contaminants (e.g., machining oils that are often not removed by manufacturers) by washing and rinsing, and then must be sterilised before implantation. In the past, disinfection (reduction, but not complete elimination, of pathogen contamination) of implanted tags was common practice, yet likelihood of infection at tag sites was unknown due to minimal opportunity for post-tagging assessment of animals. Sterilisation means the killing or removal of all microorganisms, including viruses, fungi, protozoa and bacterial spores. Low level disinfection can only kill most vegetative bacteria, some (enveloped) viruses and some fungi; intermediate level disinfection can eliminate most bacteria (vegetative and mycobacteria), most fungi and most viruses; and high level disinfection (HLD) can destroy all microbes, with the exception of some bacterial spores (see Govindaraj and Muthuraman, 2015). With enhanced understanding of the response of tissues to tag insertion (see Fig. 6), coupled with improved animal welfare standards globally, full sterilisation, as required for surgical implants used in humans and domestic and laboratory animals, is now recommended. Although infection at tag sites can result from organisms entering the tag site at any time after insertion, sterility at the time of implantation is important, as this is the time when blood vessels can be cut during tag insertion, allowing direct entry of pathogens into the blood stream should they be present. As improvements are made to attachment methods, attention should be paid to developing anchors that are not likely to carry skin and its associated microbes deep into the implant site.

Sterilisation of all implantable tag parts is recommended, while any other part of the tag that contacts the implantable pieces of the tag or the whale should be treated with HLD. A variety of sterilisation methods exist, based on heat, radiation or chemical exposure, but dry heat and steam sterilisation are not safe for most electronics. Chemical gas sterilisation is thus a good choice for tag sterilisation. Gas sterilisation with ethylene oxide (EtO) can be used and is widely available in human and veterinary clinics. After EtO sterilisation, approximately $24 \mathrm{hrs}$ of off-gassing is required before tag deployment because EtO is toxic. Additional chemical sterilants include hydrogen peroxide, peracetic acid, glutaraldehyde and hydrogen peroxide/peracetic acid mixtures (FDA, 2015; Rutala et al., 2008), but care must be taken when using these on tags to ensure that all exposed parts of the tags are compatible with the chosen chemical. For example, HLD concentrations of hydrogen peroxide and peracetic acid can degrade Buna N (nitrile rubber), but Viton rubber and EPDM are resistant to these chemicals. Each chemical must be used at a specific temperature, concentration and contact time period for effective disinfection or sterilisation. For example, when soaking devices by immersion in a $2.4 \%$ glutaraldehyde solution, HLD conditions will be reached in $45 \mathrm{mins}$ at $25^{\circ} \mathrm{C}$, but $10 \mathrm{hrs}$ of soaking is required to achieve sterilisation (FDA, 2015). 
Tag insertion

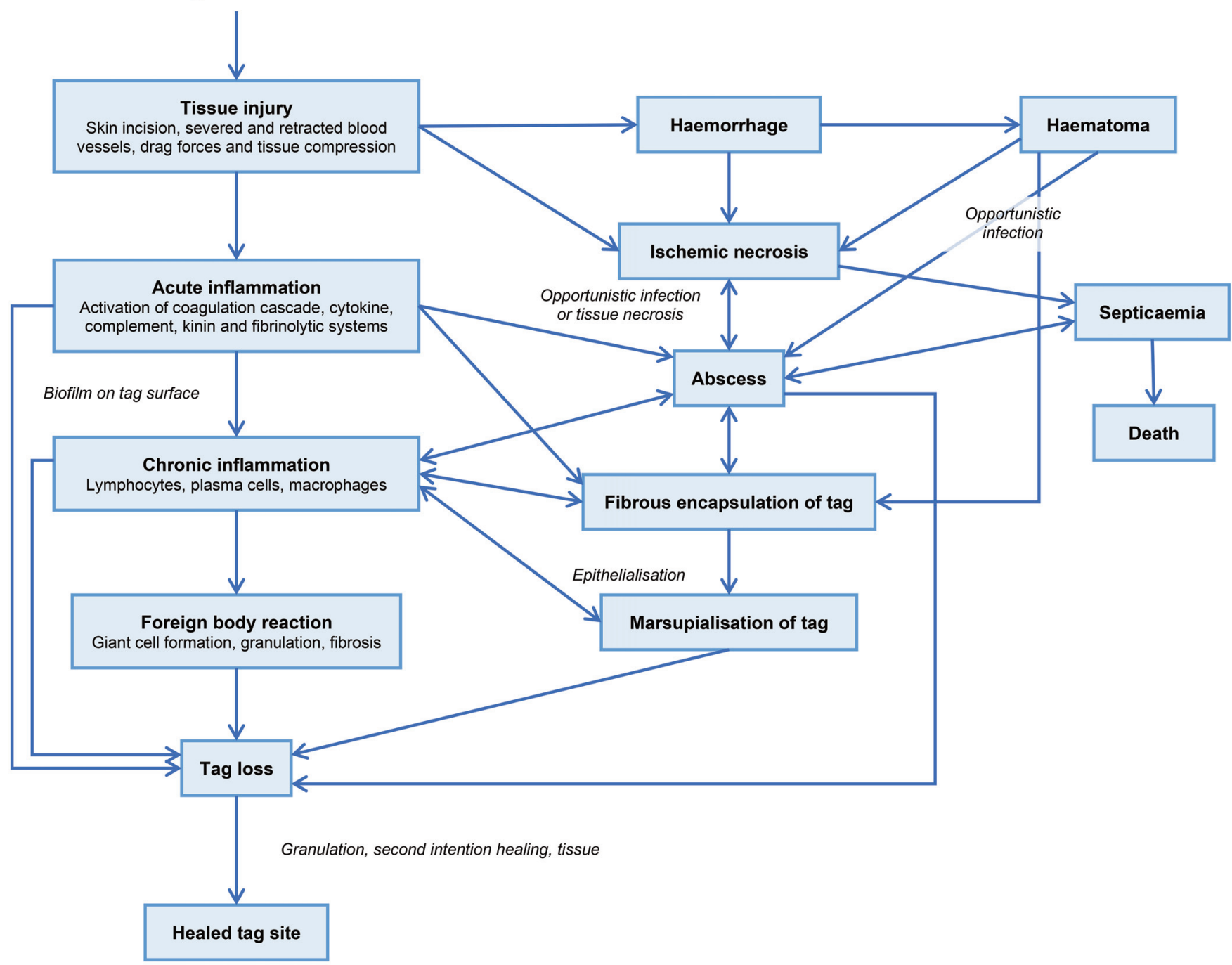

Fig. 6. Schematic diagram of the succession of potential physiological responses to application of an invasive tag. Text in the demarcated boxes describes stages of responses, italic text describes the processes occurring during progression between these stages.

Ideally, the sterility of the implanted parts of a tag should be maintained until deployment. This is often difficult in field situations, but with care and forethought, sterility can be maximised (Mulcahy, 2013). Shrouds, hoods, bags, sheaths or other sterile covers, and sterile gloves can be used to minimise environmental contamination of the tag. Additionally, packaging or containers with peripheral handles could be designed to facilitate easy, aseptic handling of implantable components without sterile gloves. Training, practice and experience with aseptic technique will help ensure compliance. As soon as sterile wrappings are removed, surfaces begin to accumulate contaminants in a time-dependent fashion, at a rate influenced by the environment in which they are being used (Dalstrom et al., 2008). At some point, the surfaces may become contaminated enough to require HLD or re-sterilisation. The length of time that adequate sterility is maintained can be extended by protecting the implantable surfaces with waterimpermeable sterile drapes, wrappings or containers until immediately prior to use. We suggest that a conservative approach is to disinfect or re-sterilise after a few hours of exposure to air. In field situations, availability of sterile gloves, bags, tape and handling instruments, as well as baths for HLD solution immersion, can be useful in maintaining sterility of tags. If the penetrating elements of a tag become contaminated (e.g. implant parts come into direct contact with nonsterile surfaces, including missing the target animal and landing in seawater), they should be re-sterilised prior to use.

To address the potential for infection associated with percutaneous tag deployment, antibiotic coatings have been added to some tags with implanted parts (Mate et al., 2007). The efficacy of antibiotic use in reducing tag site infection is unclear (due to the spectrum of potential organisms involved, including fungi). It may potentially have deleterious effects on beneficial flora and can enhance development of specific antibiotic resistance, and thus use should be conducted with caution and be subsequently evaluated. Any use should only occur after thorough research and in conjunction with improvements in implant preparation and implant technique, use of microbial resistant materials and implant sterilisation. The choice of antibiotic agents and dosage should be determined in consultation with a veterinarian and be effective in killing the range of organisms of concern. A comprehensive review of antibiotic use with electronic tag implants in fish provides recommendations 
that are applicable to tag implants in cetaceans (Mulcahy, 2011). The use of antimicrobials does not preclude the need to sterilise the implantable portions of a tag.

\subsubsection{Tag operation}

Researchers should check that tags are operating properly after receiving them from the manufacturer, and again in the field, prior to deployment. For multi-sensor tags, researchers should develop a protocol for testing each sensor in the tag for correct operation prior to deployment. For all types of transmitting tags, researchers are encouraged to carry receivers to check for transmissions from the tag immediately after deployment, which is important for troubleshooting problems later. Well-documented field procedures greatly aid in diagnosing problems. All relevant deployment data should be recorded in real-time (Section 2.8), either on 'traditional' data sheets or by electronic means. Photographs and videos should be taken of the tag deployment to document the tag attachment site on the body of the animal in sufficient resolution for subsequent evaluation of the condition and placement of the tag (see Section 2.7).

Dedicated follow-up studies should be conducted whenever possible, to assess tag effects and the fate of tags. This is especially important when using new or significantly modified tags and attachment designs (see below). However, even designs with a long history of successful performance have some probability of failure. Tags that transmit data or use a radio beacon to aid recovery may cease transmissions for a variety of reasons, including failure of the tag electronics or battery, tag damage or loss, or animal mortality (Hammerschlag et al., 2014; Hays et al., 2007). Sometimes it is possible to infer the likely cause from data that were transmitted prior to cessation or it is obvious from visual evidence (either from direct observations or photographs). However, in most cases, tags cease transmitting and the cause is never known. Table 1 lists some of the possible causes for lack of transmissions and observable signs or clues that are sometimes found in data or diagnostic messages transmitted by the tag, or from analysis of photographs (also see Section 2.7).

Tag failure can be defined as those events other than the cessation of transmissions at the expected end of the battery life or tag loss by the expected foreign body response with eventual tag detachment or outward migration of retention elements (or the whole tag in the case of Type C tags). The possibility of tag failure (i.e. cases where there is evidence that the tag electronics or mechanicals, including the retention elements, have failed; Table 1), should be discussed during the planning stage. An acceptable tag failure rate should be decided in advance, and if that failure rate is exceeded, a comprehensive review of technology and procedures should be conducted (Morton et al., 2003). The conditions under which most cetacean tags will operate are extreme, and therefore what constitutes an acceptable failure rate for each cetacean tagging study should be evaluated in advance and published with the other study results (Section 2.8). A summary of any tag failures experienced during the study along with the suspected causes should also be published.

\subsubsection{Tag deployment}

Protocols for the successful deployment of tags are as important as the appropriate design, selection and preparation of equipment. Those considering tagging cetaceans should carefully research attachment methods, fully plan their research design including the selection of which individuals should be tagged (Section 2.6) and obtain adequate training (Section 2.5). Whether tagging free-swimming cetaceans (Section 2.3) or captured and restrained animals (Section 2.4), a plan for the tagging operations should be developed in advance and shared with all participating personnel.

Tags should be deployed using methods and equipment that are appropriate to the study species and the sex and age class of targeted individuals. For tags that are deployed on unrestrained animals where there is incomplete control over attachment location, suitability of the penetration depth of anchors over the entire potential attachment surface of the body should be considered. Planning, patience and practice are necessary to ensure that tags are applied where intended.

Projectile devices, such as pneumatic or chemical propellant rifles and crossbows are commonly used to deploy tags onto free-swimming (unrestrained) animals. Projectile devices can be quite powerful; therefore, it is important to adjust the force according to the weight and aerodynamics of the tag and distance to the animal. Poles, whether held or thrown, can also result in tags being delivered with a substantial amount of force. With many pneumatic and chemical propellant devices, adjustments can be made during an approach. Projection force should be no more than required for accurate flight and sufficient implantation. Implant force, whether on a tag at the end of a pole or the end of a projected tag carrier, should not exceed that required for the implanted parts of the tag to reach their designed penetration depth when launched from the expected distance. Projected tag packages are typically not very aerodynamic in the deployment configuration, meaning that their velocity will slow significantly over the range of likely distances between the tagger and the target animal. Therefore, if no adjustments are made to the initial projection velocity, then the impact force at close tagging distances will be much greater than at longer distances. Too much force can cause excessive tissue trauma, limiting retention, exacerbating wounds and potentially damaging the electronics. Consolidated tags should have an adequate section of increased dimension (like the head of a nail) to limit penetration depth, so that excessive deployment force does not cause the tag to implant deeper than designed. Excessively deep implantation can cause unacceptable injury to the animal and prevent tag transmission if the wet/dry sensors or the base of the antenna are also implanted. However, using too little force will result in incomplete penetration, causing shorter retention duration. More detail is presented in Section 2.3 on boat approach for tagging freeswimming cetaceans.

Tag deployments on captured and temporarily-restrained animals are performed under controlled conditions, allowing accurate and consistent tag placement. Restraint and manual placement of tags allows researchers to choose an exact attachment site, but even for well-studied species, there is currently no consensus on what part of the dorsal fin or body 
Table 1

Ultimate causes of lack of transmissions from telemetry tags. Possible proximate causes of each category of unexpected failure are also provided, along with signs or sequelae that may be observed in previously transmitted messages or in photographs or follow up field observations (some may be obvious, like broken dart shafts, others inferred from visual signs, such as purulent discharge suggesting infection, or even less obvious signs, such as swelling). The causes of loss of transmissions listed are not mutually exclusive and there may be multiple issues that occur either simultaneously or in succession after tag deployment.

\begin{tabular}{lll}
\hline Ultimate cause & Proximate cause & Notes re: Signs or consequences \\
\hline Undetermined & Any of the below & $\begin{array}{l}\text { Typically, transmissions are suddenly lost with no warning messages and no } \\
\text { resightings of the tagged animal. Evidence from follow-up studies demonstrates } \\
\text { that this is rarely because of mortality. Therefore, dedicated follow-up studies } \\
\text { can be critical for diagnosing problems and improving tag design and } \\
\text { deployment methods. }\end{array}$
\end{tabular}

Tag electronics Battery failure failure

Antenna breakage

Wet-dry sensor fouling or breakage

Firmware bug

Tag attachment Improper attachment failure (tag loss)

Failed attachment

Mechanical breakage

Typical foreign body response

Secondary infection

Large external force

Mortality

Natural

Tag-related
Migration of bolt, pin or rod

Tag package breakage

Implanted element breakage

Puncture of bone or internal organ

Introduction of secondary infection

Entanglement

Tag-induced predation
Unexpectedly low battery voltage or high rate of decreasing voltage

Poor signal strength or visual confirmation of frayed or broken antenna

Unexpectedly high rate of transmissions due to transmission underwater (corrosion or biofouling will increase the resistance between the electrodes, mimicking surfacing). Alternatively, water absorption in the tag material may decrease the resistance leading to apparent continuous immersion.

Unlimited variety of disappointing revelations.

Retention elements fail to implant at all or to an adequate depth, or tag fails to attach to the desired target anatomic location (due to animal behavior, environmental conditions, operator issues, or other challenges of deploying onto moving animals from unstable platforms).

In Type B (bolt-on) tags, if attachment rod(s) migrate caudally through dorsal fin tissue, drag may increase dramatically, resulting in progressive changes in swimming and dive behavior.

Lacking visual confirmation, fractures can result in water intrusion which may manifest in unexpected sensor readings, accelerated battery voltage decline, or just sudden electronics failure.

Retention of observable parts after tag loss. Migration to the surface may take weeks to years.

Type A (anchored): visual evidence of retained dart shafts snapped or separated from electronics package;

Type B (bolt-on): pierced elements (e.g., bolts/pins/rods) snapped or connections to tag severed.

Type C (consolidated): anchors separated from main tag package.

Wound margins well delineated and even with adjoining skin, healthy granulation tissue visible at surface; typically results in complete wound healing, although in some species, repigmentation of the tagged area may not occur.

Swelling and retraction of the penetrating site margins, dependent swelling, blood or discharge either overlying or draining from the tag site and secondary effects, such as loss of condition and potential behavioral changes.

Wound and surrounding epidermis may appear similar to normal foreign body response; in some cases, retention elements can leave tell-tale scratch marks, or cause unusual wound margins. Recovered tags can also show evidence of being scraped against another animal or some object, including the seafloor.

Possibly unusual movement or other behaviors leading up to time of death; body temperature sensors may reveal abnormally high temperature due to inflammation, infection or an unexplained cause of hyperthermia

Never reported in tagged cetaceans (but only a few dead tagged animals have had full post mortem examination). Depending on the extent of injury, organ involved and possible secondary microbial invasion, clinical signs may be inapparent on external exam or there may be swelling or depression and discharge from tag site, subcutaneous swelling within the vicinity of the penetrating wound, loss of nutritional condition, difficulty with swimming and other factors.

Not likely confirmed without fresh carcass recovery and thorough necropsy. Taggers should coordinate with stranding networks so tag sites can be assessed during stranding responses. Based on external lesions alone, it is difficult to infer either a localized abscess or granuloma at the tag site, vs widespread or systemic infection. Overall nutritional condition, activity and behavior prior to death may provide clues to the health status of the animal.

We are unaware of any occurrence in cetaceans, but anecdotes from fish tagging studies have been reported.

Never reported in cetaceans, but uncommonly observed in fish studies. This should be considered if contemplating the attachment of ultrasonic tags to cetaceans that are prey of other cetaceans. 
is optimal for attachment, so additional research on morphology, physiological function and hydrodynamics of potential attachment sites is required. Trocars, drill bits or other instruments used to pierce tissue should be cleaned and sterilised before each use consistent with the sterilisation of implantable tag components described in Section 2.2.5. Other opportunities for sampling (blood, morphometrics, tissues) are available with a temporarily-restrained animal, and the pros and cons of longer holding times should be considered in deciding whether to collect health assessment data when tagging is the primary purpose. Likewise, when the primary purpose of capture and temporary restraint is to collect health assessment or physiological data, the purpose, type and pros and cons of tagging should be thoroughly considered before deciding to include tagging in the project. More detail is presented below in Section 2.4 on capturerelease methods.

\subsubsection{Identification of tagged individuals}

Whenever possible, researchers should obtain data so that the tagged individual can be identified in the future, especially after the tag has detached. For many individuals, this can be done with photographs or video of the anatomical features that allow individual recognition in that species, such as the dorsal fin, saddle patch, fluke, callosity, barnacle, or colouration patterns. For poorly marked animals, photographs are more likely to produce recognisable images than video, but a genetic sample may be the only way to identify an individual later. Genetic sampling has the advantage that it can permit sex determination, and it can allow identification even when post-mortem decomposition makes visual recognition impossible, or if markings change such that the individual may not be recognisable from subsequent photos. Biopsy dart sampling and tagging can sometimes be performed at nearly the same time (by two different operators) and some tag deployment devices (e.g. a tag holder on the end of an arrow or pole mounted next to a biopsy dart) perform simultaneous tagging and skin collection. In other cases, multiple approaches can be made to collect skin samples by biopsy dart sampling during a separate approach from tagging, but the additional stress to the animal of another close approach should be considered. This consideration may be especially relevant for noninvasive short-term (e.g. suction cup attached) tags for which the period of disturbance could represent an important fraction of the deployment time.

\subsubsection{Development of new equipment and methods}

Refinements of all aspects of cetacean tagging are important, and innovation in tag attachment technology and procedures is encouraged. However, new equipment must be tested, and its effective and consistent operation should be demonstrated before use on live animals. For attachment elements, especially invasive ones, testing should include tissue surrogates (such as fiber-reinforced rubber or foam blocks) and carcass tissue. For equipment that will be deployed by projectile devices, testing using whole carcasses, or at least large tissue blocks representative of the characteristics of in situ tissue, should be conducted. Such tests will allow for the determination of the appropriate projection velocity at a given distance to the animal, which is necessary to ensure proper implantation while minimising tissue damage and tag breakage.

Innovation is also required for non-invasive attachments. Many multi-sensor tags, especially those recording audio and video, can record for a longer duration than most suction cups will remain attached. Therefore, increasing the duration of suction-cup attachments would be valuable. To address this need, suction cups with microtextures and adhesives are being considered, but these may still have effects that should first be explored with tissue surrogates. For all non-invasive tags, initial deployments on cetaceans under human care are encouraged because detailed observations of tag performance and effects on the animals can be more easily conducted.

Efforts to improve tag electronics, sensors, batteries and antennas, while much needed, can introduce unanticipated failures. New tag designs should be tested in a manner that replicates, as closely as reasonably possible, the conditions under which they will be used in the field (e.g. temperature, pressure, salt water and UV light exposure). The effects of rapid acceleration and deceleration on the tag during tag deployment should also be evaluated.

Researchers should be extremely cautious when deploying a new tag attachment design on individuals sensitive to disturbance, especially endangered populations. Most refinements and improvements in tagging equipment and methodology build on previous knowledge and are therefore often modifications of proven technology, limiting the potential for unanticipated effects. However, more substantial innovations may be necessary to provide longer attachment durations to address research questions without increasing the effects on tagged individuals. After thorough testing in the laboratory and under simulated field conditions with tissue surrogates and/or carcass tissue, radically new attachment designs must be shown to be safe and effective on a similar species/population before being applied to one at risk. In such pilot studies, the opportunity for resight observations is critical (see Section 2.7 for more details on the need for pilot and follow-up studies and how they should be designed).

\subsubsection{Recommendations for tag design and deployment}

- Researchers must choose appropriate tags, tools and methods by reviewing previous work and obtaining advice from others with hands-on experience in cetacean tagging, preferably with similar species.

- All elements of the tags must be a reasonable (detailed above) size, shape and configuration for the species, sex and age class that will be targeted.

- Tag configurations should produce the desired data with the least impact possible to the tagged individual for the necessary duration of attachment.

- Tags should minimise: trauma; energetic costs; interference with body movements; predation risk; risk of entanglement; and interference with social interactions.

- Implanted elements should be:

- constructed only of materials known to be biocompatible and safe for long-term implantation (regardless of the intended duration of implantation); 
- thoroughly cleaned and sterilised (not simply disinfected) and maintained sterile until deployment; and

- be of a small enough size and placed appropriately so there is no risk of contact with bones or internal organs upon deployment.

- Researchers should ensure that tags are operating before heading to the field, and if possible, shortly before and after deployment.

- Tagged individuals should be identified.

- Obtain photographs of the tag attachment site and of identifying features of the animal, provided this does not greatly extend the disturbance to the animal.

- Whenever possible, obtain a tissue sample for genetics to aid future identification.

- Refinement and innovation of tags and tagging methods are strongly encouraged but should proceed with caution.

- Testing of new equipment and methods should be thorough and should include tissue surrogates and/or carcass testing before application to live animals. When feasible, such as for non-invasive tags, consider deployments with cetaceans under human care.

- New tags and attachment designs that are so substantially different from previously deployed designs that effects cannot be predicted must be shown to be safe and effective on a similar species before applying to endangered species or populations.

- Dedicated follow-up observations should be conducted whenever feasible, but especially when using new or significantly modified attachment designs.

- An acceptable tag failure rate should be determined before tagging, and if exceeded, protocols should be reviewed.

\subsection{Boat approach for tagging free-swimming cetaceans}

The protocols for boat approaches will vary depending on multiple factors, including species, weather conditions, the type of tagging and the type of boat. However, vessel approaches for tagging are typically closer to the animals than vessel approaches for other cetacean research activities (e.g. photo-identification and biopsy sampling), and thus there is an increased risk of disturbance (and potential injury) to the cetaceans being approached, as well as risks to human safety. Serious accidents have occurred during tagging operations and appropriate caution must be taken. There are several basic principles that should be applied to all boat approaches for tagging free-swimming animals. All crew should be prepared for accidents, including being familiar with safety gear, as well as emergency communication and rescue protocols. The appropriate safety equipment will vary, but key items such as personal floatation devices, helmets for those operating in small boats and rough seas, and emergency locator beacons should be considered. For boats tagging larger whales in remote areas, operation of a second, safety/support boat should be considered. When the use of a second vessel is not feasible, a float plan should be filed and check-in times with someone on shore should be scheduled.
When operating in challenging environments, such as in cold waters or rough seas, even more stringent safety protocols should be considered, such as limits on the distance from an assistance vessel.

Boat approaches should be undertaken in a way to minimise risk to both the cetacean and the personnel on board. Vessel/cetacean collisions could occur either by the vessel striking the animal or by the animal striking the vessel, including potentially breaching onto a vessel. Both possibilities can be minimised with the use of a boat driver with extensive experience in driving in close proximity to cetaceans as well as familiarity with the behaviour of the species being approached. Cetacean responses to vessel approaches vary dramatically by species, by population, by age or sex, and even by individual. Thus, the experience of the boat driver with the behaviour of the target and similar species is key to minimising harassment and ensuring safety. Such experience can improve deployments and reduce risk by providing more steady approaches involving the slowest possible speed, minimal throttle adjustments and fewest course changes while near the animal. Furthermore, the ability of the crew to recognise behaviours or escalating patterns that may indicate the potential for the animal striking the vessel can be as important as familiarity with the vessel controls to minimise the chances of the vessel striking the animal.

Good communication between the boat driver and tagger (e.g. direct concise dialogue, hands-free headsets) and other crew members is paramount for the boat driver to be aware of other animals in a group or behaviour of individuals not visible to the driver beyond the target individual. Such communication also increases general safety aboard the vessel. The tagger will usually have both hands on the deployment device, thus may not be holding onto the boat. Unexpected rapid acceleration or deceleration could have significant consequences for the tagger, crew and animals near the boat.

Minimising disturbance to that required to deploy a tag should be a goal of vessel approaches. Disturbing non-target animals in a group during the approach may be necessary to deploy tags on some species, but patience and caution can minimise approach-related disturbance. Care is especially important if approaching groups with calves. Criteria for when to terminate tagging attempts on an individual or group should be agreed upon before starting fieldwork, and all personnel on board should be familiar with the criteria. Example criteria include repeated display of behavioural cues that would be interpreted as strong avoidance. The total disturbance to recognisable individuals over a field season should be kept within pre-agreed limits. In field sites in which multiple research groups are approaching the same animals, whether for tagging or other research requiring close boat approaches, there should be communication between the groups to assess and minimise the total disturbance on individuals.

\subsubsection{Recommendations for boat approach for tagging free-swimming cetaceans}

- Vessel approaches should be undertaken in a way that minimises risk to the personnel on board and minimises harassment and risk of injury of cetaceans being approached/tagged. 
- Be prepared for accidents: safety and first aid equipment should be on board always, and the tagging crew should have first aid, 'man overboard' and general emergency response training.

- Clear communication and rescue protocols should be agreed before tagging efforts commence, and all personnel on the boat should be familiar with the protocols.

- Boat drivers should have as much prior experience as possible with the behaviour of the species being tagged, especially any species-specific risks of dangerous response, and need to be aware of all individual animals in a group, not just the target individual.

- Approaches should be made at the slowest feasible speed and at angles of approach that will minimise possible collisions with either target or non-target individuals.

\subsection{Capture-release and tagging of restrained animals}

\subsubsection{Rationale for capture-release}

Although capture-release techniques in general involve greater risk to animals and to people than remote tagging techniques that do not involve restraint and handling, for some cetacean species of smaller body size or whose behaviour does not allow for remote tagging, capture-release may be the more effective option. Responses to capture vary by species, and risks must be weighed carefully against the benefits of tagging. Temporarily restrained animals provide opportunities for careful and optimal placement of tags for long-term attachment and collection of information and samples not available using remote tag deployments. Sex can be determined, age can be estimated, ultrasound can be used to measure blubber stores as a proxy for body condition or for assessing reproductive status, blood, blow, swabs and other samples can be collected for health assessment and life history analyses (Townsend et al., 2018). Disinfection of the tag attachment site should occur just before surgical tag attachment. Local anesthesia should be used for small odontocetes when time permits, especially for multiple piercings, and in other cases at the discretion of the consulting veterinarian.

Because of logistical and safety considerations, capturerelease efforts typically are limited to smaller odontocetes, and a variety of species have been tagged during capturerelease operations, conducted either specifically for tagging, or as part of a broader research programme, such as population health assessments. Larger odontocetes and most mysticetes are not good candidates for this approach. Response to capture and handling differs by cetacean species but can also differ by individual within a species.

\subsubsection{Methods for capture-release}

As summarised by Loughlin et al. (2010) and Asper (1975), specific capture techniques have been developed for different species, habitats and situations. In shallow water, large-mesh seine nets have been deployed to corral or create barriers to enclose small groups of animals. Individual belugas have been caught in shallow water by driving animals into nets and by leaping from a boat and placing a hoop net around them. In intermediate water depths, fishing structures such as weirs have been used to contain porpoises. In deep water, break-away hoop nets have been used to catch individual bow-riding cetaceans of a range of sizes (Asper, 1975). Purse seines and surface gillnets have been used to capture individuals or groups of small cetaceans in deep, open waters (Loughlin et al., 2010). The duration of active pursuit should be minimised, and a limit should be determined in advance, along with a limit on the number of capture attempts made on an individual. Tagging of restrained cetaceans may occur on the deck of a boat, on a floating mat alongside a vessel, or in shallow water. One variant of tagging restrained animals occurs when stranded or rescued animals are tagged prior to release.

\subsubsection{Recommendations for capture-release}

- Capture teams must be very experienced with the capture and restraint techniques and familiar with how the gear might behave under different environmental conditions.

- An experienced marine mammal veterinarian should be included as part of the capture-release team.

- Safe capture-release sites should be scouted and selected in advance whenever possible. For shallow water encircling seine net situations, a capture site should be free of underwater obstacles, with minimal currents and mud.

- Duration of pursuit should be as short as possible.

- Disturbance to non-target animals should be minimised. When possible, the numbers of animals involved in capture attempts should be limited to those targeted for tagging.

- Weather conditions, tides and daylight should be suitable for the entire length of a capture-release event, for animal and human safety.

- Presumed mother/calf pairs should be avoided unless part of the research goals; they should not be separated during capture or handling, and they should be released together.

- The animal should be able to breathe at will, with unimpeded access to the surface; respiration rate and behaviour should be monitored carefully and capture attempts abandoned if necessary.

- Identify and assess potential stressors before proceeding with capture or handling (e.g. vulnerability from life history or physiological state such as extreme young/old age, compromised health).

- If feasible, establish contingency plans to recapture tagged animals and remove tags if health or behavioural problems associated with the tags become evident and the risks related to re-capture are outweighed by the need to remove the tag.

\subsubsection{Recommendations for restraint and handling}

- Include more personnel than the number needed to handle the expected number of captured individuals at any given time and include a dedicated veterinarian to monitor each individual cetacean throughout the procedures. 
- Restraint and handling should be at the minimum level and for the briefest time required to conduct the procedures safely and humanely, which requires an efficient handling plan with organised tool kit and data forms, and a practiced team.

- Restraint system should provide for the animal's comfort (padded, shaded, quiet) and allow rapid, safe, controlled release of the animal in the event of problems.

- Airways should not be obstructed during restraint for tagging.

- Careful monitoring should occur throughout the restraint period, including respiration interval/effectiveness (with pre-defined species-specific thresholds triggering veterinary response), heart rate (including assessing sinus arrhythmia), eye appearance, colour/response of the mucous membranes of the mouth, vocalisations and general behaviour.

- Thermal stress to the animal should be avoided by keeping it shaded, wet and cool.

- General anesthesia should not be used, but emergency medications should be readily available. The attending veterinarian should be highly familiar with indicators, drug administration and recovery protocols for the species being handled.

- A basic health assessment should be conducted when feasible without greatly increasing restraint time, including blood collection, physical exam, ultrasonic pregnancy and lung health check, morphometrics and sampling for genetics. To assess response to handling, blood can be analysed in near-real-time for parameters such as lactic acid. Determination of late term pregnancy provides guidance on duration and method of handling and procedures to be used but should not necessarily preclude tagging with currently available small tags.

\subsection{Training/qualifications of personnel}

Having qualified personnel participating in tag deployment projects (as taggers, boat drivers, photographers, data recorders) or capture-release, is paramount for the safe and successful use of these methods. Inexperience or lack of familiarity with any of the many steps involved can present real risks to the health and safety of the study animals and humans alike, as well as compromise data quality. As it may often be difficult to obtain the necessary training and supervision, people wishing to begin tagging or capturerelease operations should approach those with extensive tagging experience, and those with experience should offer opportunities to gain experience and training.

\subsubsection{Importance of training for remote tagging}

Considerable attention is often given to the qualifications of the tagger, who may bear the most obvious risks and responsibility for a successful remote deployment, particularly when powerful projectors (e.g. crossbows, pneumatic or black-powder guns) are employed. However, the success of the tagger is directly related to the skill and experience of the boat driver. A boat driver not familiar with the behaviour of the species of interest, the boat (that must have suitable characteristics for safely approaching whales) or the specific requirements of the tag deployment will greatly reduce the chances of a successful attachment and increase the chances of injury to animals and personnel (e.g. through poor tag placement or vessel/cetacean contact). Thus, adequate training is essential for all methods prior to their use.

Minimum training and competency qualifications for tagging will vary depending on the type of tag being deployed and the species being tagged. However, certain basic principles apply to all tagging scenarios, and researchers considering tagging should ensure that their protocols address these principles so that the entire team is adequately trained to safely and effectively deploy tags. The specific recommendations below apply most to taggers and boat drivers, but it is important that all personnel aboard the boat are prepared to assist and that their actions do not jeopardise the safety of the study animals, the other researchers, or themselves. The entire tagging team should consider conducting training deployments aboard the tagging vessel, targeting a simulated cetacean (e.g. a floating target).

\subsubsection{Importance of training for capture, handling, tagging and release}

Well-trained and experienced personnel can greatly expedite the process, and they can detect adverse situations and other problems early, contributing to safe release of the animals. Training should include literature review, mentoring, familiarity with the species from field observations, direct experience with the target and related species, and practicing techniques without animals present.

\subsubsection{Recommendations for training of taggers}

- Spend time observing, photographing, or engaging in other data collection techniques on the study population to become familiar with the general behavioural patterns of the species of interest.

- Become familiar with use of all equipment used in tag deployment through repetition (including use of the tag, tag attachment elements and deployment device):

- practice deployments on land with a dummy tag projected at a target placed at different distances and angles; and

- practice boat approaches and deployments aboard the tagging vessel, or one that is similar, with a dummy tag and floating target, preferably in conditions (e.g. comparable sea state and vessel speeds) that will likely be encountered during your research.

- For taggers deploying tags onto free-swimming animals using a projection device (e.g. crossbow, pneumatic rifle): - be competent with biopsy sampling of the target species or similar species; and

- complete a firearms or archery safety course or receive instruction from an individual experienced in the safe handling of firearms or crossbows and practice until proficient.

- New taggers should conduct initial deployments under the supervision of an experienced individual who can provide feedback and assess when qualified to proceed unsupervised. 


\subsubsection{Recommendations for training of boat drivers}

- Become proficient in the safe operation and handling of the vessel used for tagging before approaching cetaceans.

- Spend time observing, photographing, or engaging in other data collection on the study population to become familiar with the general behaviour of the species of interest.

- Have prior experience driving near cetaceans during biopsy sampling or other data collection methods that require specific positioning of the boat.

- For tags that require approaches closer than $5 \mathrm{~m}$ to large cetaceans, the boat driver's first approaches for deployment should be supervised by an experienced individual (which could include the tagger), who can provide feedback and assess when qualified to operate unsupervised.

\subsubsection{Recommendations for training in capture, handling and release methods}

- Spend time observing, photographing, or engaging in other data collection techniques on the study population to become familiar with the general behavioural patterns of the species of interest:

- under free-ranging conditions; and

- during handling.

- Become directly familiar with the physical characteristics and field conditions of the capture site, and/or engage local experts.

- Become familiar with all aspects of the equipment used in tag deployment through repetition (including use of the tag, tag attachment elements) to expedite process and minimise time animal is restrained.

\subsection{Selection of candidates for tagging}

\subsubsection{Conservation status}

Some basic research questions, especially physiological ones, might effectively be addressed by studying any one of many different species. In such cases, the selection of a candidate species/population should take into consideration their conservation status, population size, trends in abundance and geographic range. The use of the most invasive techniques in endangered or declining populations should be considered only if less invasive tags are not able to provide the necessary data for the project (that must have identified conservation benefits). These may include pilot or feasibility studies, which are described in more detail in Section 2.7. One option to providing safeguards and minimising risks of negative effects in a threatened species/population might be to tag only males, if they are representative of the population from the perspective of the research questions. This may not always be feasible, however, especially in species that are not sexually dimorphic, or where the sex of only a few animals is known through individual identification. Furthermore, there may be cases where males are more sensitive than females to adverse effects of tagging. Therefore, this should be evaluated on a case-by-case basis.

\subsubsection{Timing}

There are times when cetaceans may be more vulnerable to potential adverse effects of tagging and tagging operations. These include periods when animals are fasting (e.g. the breeding season) or when seasonal or cyclical temporal environmental stressors (e.g. El Niño or harmful algal blooms) can affect food availability, body condition or health status. The objectives of some studies may require tagging during these times, therefore it is important to consider the timing and location of tagging to fully appreciate the risks during periods when animals may be more sensitive to potentially negative effects of tagging.

\subsubsection{Age class}

Tagging of calves/young-of-the-year (often identified by their small size and behaviour), especially with invasive techniques, should be well justified and only conducted under special circumstances. Disturbance and the energetic effects of tagging will likely have greater impacts on calves. Tagging of females with calves, however, can be a valuable way to address certain questions. Disturbance associated with tagging approaches, tag deployment and from tag effects, however, could restrict suckling opportunities and disrupt social bonds between mother-calf pairs. If tagging of mothers is required, special care must be taken to avoid separating mothers and calves. Conservative protocols should be developed (e.g. avoid tagging of mothers with neonates [e.g. animals with fetal folds], restrict tagging attempts to a short period of time compared with animals of other sex/age classes, abort tagging attempts if behavioural indicators of disturbance are detected).

\subsubsection{Physiological status and health}

The health of the population should be considered so that potential stressors from tagging (disturbance, tag effects) do not further compromise the health of individuals in the population. Tagging studies should use available data from longitudinal studies on age, sex, reproductive condition and/or prior reproductive and health history, to select target animals (when such animals can be easily identified in the field). In such cases, taggers should collaborate with research groups conducting longitudinal studies to ensure that as much knowledge of individuals as possible is considered in the study design to minimise risks to the population. In some types of studies, a more random sample may be appropriate.

Potential effects of tagging may vary with animal age, sex, reproductive status, health and social status and level of exposure to environmental and anthropogenic stressors. When selecting individuals to tag, care should be taken to select animals in apparent good health, unless there is strong justification for using tags to monitor sick or injured animals. For typical tagging projects, individuals to avoid include those with evidence of emaciation (e.g. post-nuchal depressions, visible ribs or scapula), higher than normal external parasite load, unusual skin conditions, presence of significant pre-existing wounds (e.g. from an entanglement, predator bite, or ship strike) that have not healed or are of an unknown extent, or that are displaying unusual behavioural or respiratory patterns. For those populations for which there 
is significant longitudinal (long-term) information and individuals are easily identified in the field, candidates for tagging could be evaluated before going into the field, and/or in the field before deploying a tag. The a priori development of criteria for assessing each individual and making a tag/notag field decision is recommended.

There are occasional circumstances when the decision to tag a compromised animal may be intentionally made to monitor its movements and survival. For example, cases of individual cetaceans that have been refloated after stranding, or that have been herded or harassed to move them from out-of-habitat situations or ice entrapments, may require monitoring post intervention to evaluate the success of the methods used. Entangled animals might require tagging to facilitate location and disentanglement efforts on subsequent days. In these rare but often highly publicised events, the decision to tag, choice of tag type to use, evaluation of alternative methods to achieve goals and monitoring efforts should be evaluated on a case-by-case basis, preferably by a group of experts with pertinent expertise in the species' biology, tagging technology and veterinary medicine. Tagging a compromised animal may be justified for identifying the cause of poor health within a population, or a population decline, or the monitoring of a specific individual for its health assessment or the need to improve its welfare.

\subsubsection{Multiple tags}

Attaching more than one tag at a time, or tagging the same individual repeatedly, may be useful to address some questions. In certain cases, deploying two tags at the same time can be used to assess tag failure rate. It is important, however, to note that this inevitably increases the disturbance to the individual due to increased tagging effort, a larger number of attachment points and added drag. When considering tag deployment on an animal that was tagged in a previous field effort, if possible, first assess the health of the individual between tagging events, and for invasive tags, assess wound healing of the implant sites. In instances where individuals have been tagged multiple times, assessing the state of wound healing in these individuals should be a priority to better understand potential effects of multiple tag deployments.

\subsubsection{Recommendations for selection of candidates for} tagging

- Selection of species/populations for tagging.

- Basic (as opposed to applied or species-specific) research questions should be addressed in healthy species/populations.

- Tagging of endangered/threatened or declining species/populations should be conducted with the least invasive technique possible that will provide the necessary data over a sufficient observation period.

- To avoid impacts on females in endangered/ threatened populations, consider whether tagging males only is a feasible option that can address the questions.

- Tagging of endangered/threatened populations should generate data that are useful in guiding actions that lead to an improvement in their conservation status.
- Avoid tagging populations with known health problems and in locations and/or time periods when animals are expected to be more vulnerable, unless the project objectives require this.

- Selection of individuals for tagging.

- Consider sex, age, health and reproductive history in the selection of individuals to tag, ensuring the selection criteria do not compromise the goals of the study.

- Tag deployment should be focused on animals in apparent good body/health condition. Develop pretagging evaluations criteria for a tag/no-tag decision in the field.

- Tagging of individuals in poor health should only be considered if tagging has the potential to significantly improve welfare or if necessary for conservation goals that require such data.

- Tagging calves/young-of-the-year should be carefully justified, especially if invasive techniques are required.

- Develop conservative tagging protocols for calves and females with calves.

- If deployment of multiple tags on one individual is necessary, ensure the animal is in good health condition and use the least invasive tags possible.

- Prioritise collection of follow-up health data from individuals that are tagged multiple times.

\subsection{Assessing effects with follow-up studies}

During the planning stages of any cetacean tagging project, researchers should consider the likely effects on the tagged animals and their population. If tags or tagging cause adverse effects on physiology and health, the results of the study may be invalid due to alteration of the animal's behaviour by the procedure itself. The potential effects of tagging include behavioural and physiological changes, infection, pain and mortality; they may be short-term (minutes to days), medium-term (days to months), or long-term (months to years).

Behavioural effects include short-term responses to the boat approach and tag deployment, but might also include longer-lasting effects, such as avoidance of the area where tagging occurred, anomalously slow or fast movements, or unusual diving behaviour, such as extended surface time. The presence of the tag may increase drag or the risk of entanglement or biofouling. For invasive tags, physiological effects (Fig. 6) may include the foreign body response, local healing processes and other more serious consequences such as abscesses, granulomas, haematomas, bone fractures, systemic infections or reduced reproductive success. Noninvasive tags with attachments not intended to break the skin, can also have physiological effects due to skin chafing, haematomas resulting from strong suction cups, or excessive drag. Tagged animals may experience discomfort or pain at some point over the course of the research. In the worst-case scenario, invasive tagging could lead to the death of the tagged individual, from acute trauma at the time of attachment (due to tag hitting vital organs), inward migration of the tag through time, or systemic infection. Capture and temporary restraint of animals can also lead in exceptional circumstances to extreme behavioural/physiological 
responses and mortality. Unanticipated issues can arise, such as an increase in the vulnerability of the tagged animals (e.g. because of a previously unrecognised prey shortage), or a defect during manufacture of the equipment discovered after tag application, and therefore some of the impacts may not be recognised until after tags have been deployed (or never discovered).

Due to the range of potential impacts, whenever tagging effects are likely to be unpredictable or significant, deployments should start with a pilot study using a precautionary approach, with limits on the initial numbers of deployments and the rate at which tags are deployed to allow time for assessment of initial results and effects. To adequately assess the effects of tagging, follow-up studies using photography, health assessments and post-mortem examinations are required. A few such studies have generated valuable information on behavioural effects, the wound healing process and the fate of individuals (Andrews et al., 2015; Balmer et al., 2011; Best et al., 2015; Gendron et al., 2015; Heide-Jørgensen et al., 2017; Norman et al., 2018; Robbins et al., 2013; Wells, 2013). However, existing data with which to assess effects remain limited, even for some frequently tagged species and tag types that have a long history of use. While follow-up monitoring may not be feasible or warranted in all cases, it is especially recommended when projects use a substantially new tag design, target an individual/species/population of particular concern, or in circumstances when existing knowledge on effects may not apply.

\subsubsection{Designing an effective follow-up study}

Follow-up studies aim to assess animal behaviour, tag site tissue responses, health and condition of the tagged animal and the appearance/condition of the tag when it is still present on the animal. They can be enhanced by collaborations among population biologists, veterinarians, naturalists and whale watching operators and the group that deployed the tags. When planning a follow-up study for a new or significantly modified tag design, the best option is to choose a species/population that has been the subject of a long-term demographic study with a comprehensive catalogue of known individuals and a high individual resighting rate. This will greatly improve the ability to assess both short- and long-term tagging effects, although the need to tag such individuals must be justified. Although challenging, a tagged individual can potentially be found and observed at systematic intervals using telemetry data while the tag is still transmitting. This may only be practical in projects in which the study population is resident in an area or expected to pass by accessible sites. Opportunistic re-sightings can also be valuable, particularly regarding longterm effects after tags are no longer present or transmitting. Such data may be available from individual identification catalogues and/or facilitated by enlisting a collaborating network of knowledgeable observers in the areas used by tagged individuals. However, opportunistic data are likely to be of lower quality and to span a narrower range of data types than available from planned re-sightings. Occasionally, tagged animals may strand, so coordination amongst the tagging community and the stranding network is essential to ensure examination of stranded animals includes thorough documentation of the tag site and health status of the animal (see Section 2.8).

Researchers should attempt to obtain relevant baseline data from a 'control' sample of individuals that can be compared to the tagged animals. In species with strong social bonds, the control sample should typically be members of the same social group, because re-sighting probabilities and exposure to environmental factors that may influence wound healing and other responses can vary among social groups. These measures will help to differentiate tagging effects from other intrinsic or extrinsic causes of variation among individuals

Behavioural assessments should be based on an ethogram that is relevant to the species and, where applicable, type of habitat. Assessments should occur in real-time whenever possible, but simultaneous collection of high definition video can allow for retrospective viewing and assessments. Ideally, observations should include the immediate response to deployment, as well as extended pre- and post-tagging observations to facilitate the detection of significant tag-related effects. However, monitoring the behaviour of an individual prior to tagging can be challenging because it may not be possible to predict in advance which individual will ultimately be tagged. Focal follows that are limited to the period after tagging can still be valuable for assessing the nature and duration of some tag responses and for diagnosing tag failures related to deployment. However, researchers should consider the possible effect of the vessel on animal behaviour and either maintain adequate distance or use an alternative method (e.g. unmanned aerial vehicles) to make visual observations or video recordings to prevent unnecessary disturbance. Some tags collect frequent data on dive depth, foraging duration, speed and direction of travel, or overall activity level such that short-term responses can be studied based on changes in those parameters over time. However, many tags do not have these capabilities and tag-related responses may manifest in ways that tags cannot detect.

The best way to directly quantify physiological effects is by conducting a thorough health assessment of a well-known individual before tag attachment, monitoring the individual via observations through the duration of tag attachment and conducting a follow-up assessment after tag loss. Such health assessments can include blood analysis, ultrasound examination, hormonal status, microbial culture and in some cases histological examination of tissue. However, access to most tagged cetaceans will be limited and so reliable methods for assessing effects through remote observation need to be developed and applied when feasible. Assessment of microbiome and hormonal status can be achieved through collection of blow, faecal, or tissue samples. Hormone levels in these samples can be used to evaluate stress (corticosteroids) and reproductive status (progesterone). For a review of potential methods that could be applied, see Hunt et al. (2013).

High-resolution photographs of the tag site should be taken at the time of deployment and during each re-sighting. Images should be zoomed-in as close as possible and at several angles to the tag site. Images should also be taken of the entire animal and with a wide field of view around the 
tag site to evaluate skin and body condition. Tagging projects should also consider ways to enhance and quantify information later obtained by photographs and observation. For example, features such as etched rings on the body of consolidated tags can improve the precision of visual estimates of penetration depth and tag rejection.

A systematic scoring system can be used to standardise assessments of the tag site and animal health from photographs or video stills, with numerical scores applied to features of varying severity. An example is presented in Table 2 (see also Norman et al., 2018). Tag site features that can be scored include the presence, size and shape of raised skin areas and/or depressions at and around the tag site, extent of skin loss around the tag, tissue extrusion, changes in skin pigmentation or texture, wound margin integrity and the presence, characteristics and extent of cyamid distribution. By contrast, some tag site features, such as haemorrhage, serious discharge or inflammatory exudate, may be difficult to consistently detect in photographs as these are readily washed from the tag site during animal movement. Overall health scoring from photographs should also consider body condition, skin condition and cyamid distribution, and any known species-specific health indicators (e.g. Pettis et al., 2004). If a consistent time series of photographs is available, evaluation of whether the tag site changes are increasing or decreasing may assist in detection of tag site responses through numerical scoring of photographs. Prior to scoring, image quality should be explicitly evaluated and accounted for to minimise errors in interpretation. Similar assessment of healing of other types of injuries (e.g. shark bites) may also be useful for comparison of wound healing processes.
Once data are scored, appropriate qualitative and quantitative approaches should be used to assess the progression of changes in features over time and to predict their severity. Mark-recapture statistical models can also be used to quantify survival and reproduction relative to control groups and tag-associated covariate data. However, the effectiveness of the latter depends on sample sizes and detection probabilities that can be challenging to achieve in tagging studies.

\subsubsection{Recommendations for follow-up studies}

- Follow-up studies are desirable to assess tag effects. They are recommended in these situations:

- when using completely new or substantially modified tag attachment designs;

- when tagging species whose characteristics might limit the transferability of results from effects studies conducted on other species;

- when tags are deployed on individuals/species/ populations of particular concern; and

- when evidence emerges to suggest that tags are not performing as expected (see Section 2.2).

- Follow-up studies should be designed in advance and incorporate the elements below.

- Be based on robust statistical methods, especially given likely limitations on sample size and statistical power for determining effects. Sample design should include a cohort of control (un-tagged) animals for comparison.

- Include dedicated re-sighting attempts to evaluate the individual, preferably at pre-determined intervals.

Table 2

Example of a scoring system to characterise tag site features from photographs (from Gulland et al. unpublished).

\begin{tabular}{|c|c|c|}
\hline Feature & Description & Score \\
\hline \multirow[t]{4}{*}{ Swelling } & No visible swelling & 0 \\
\hline & Localised, focal, under $30 \mathrm{~cm}$ diameter & 1 \\
\hline & Regional, focal, over $30 \mathrm{~cm}$ diameter & 2 \\
\hline & Irregular size and shape, over $30 \mathrm{~cm}$ diameter & 3 \\
\hline \multirow[t]{4}{*}{ Skin loss } & No visible skin loss & 0 \\
\hline & Up to $1 \mathrm{~cm}$ greater than tag diameter & 1 \\
\hline & Up to 3 times tag diameter & 2 \\
\hline & Larger than 3 times tag diameter & 3 \\
\hline \multirow[t]{4}{*}{ Exudate } & No visible exudate & 0 \\
\hline & Clear & 1 \\
\hline & Blood & 2 \\
\hline & Purulent & 3 \\
\hline \multirow[t]{3}{*}{ Tissue extrusion } & No visible tissue extrusion & 0 \\
\hline & Fresh tissue & 1 \\
\hline & Necrotic tissue & 2 \\
\hline \multirow[t]{2}{*}{ Pigmentation change } & Normal pigmentation & 0 \\
\hline & Change in color of skin around tag site & 1 \\
\hline \multirow[t]{4}{*}{ Depression/divot } & No visible divot & 0 \\
\hline & Diameter of tag or less & 1 \\
\hline & Up to approx. 3 times tag diameter, shallow & 2 \\
\hline & Significantly larger than tag diameter, deep & 3 \\
\hline \multirow[t]{3}{*}{ Cyamids in tag site } & Absence of cyamids in tag site & 0 \\
\hline & Within tag site margins & 1 \\
\hline & Patch extending beyond tag site margins & 2 \\
\hline
\end{tabular}


- Promote opportunistic re-sighting by fostering collaborations with population biologists, veterinarians, naturalists, whale watching operators and stranding responders working with the same animals or in the same area.

- Include behavioural observations (preferably in realtime and video) based on an ethogram that is relevant to the species and local habitat.

- Include high-resolution photographs of the tag, tag site and as much of the entire animal as possible, from multiple angles, as well as of other body areas critical for body condition and health assessments.

- If feasible, include systemic health assessments (e.g. metabolomics, stress and reproductive hormone assessment, in blow samples, feces, biopsy tissue).

- A systematic scoring system using pre-established criteria should be used to assess tag attachment site and overall animal health.

\subsection{Reporting and data sharing}

Despite the accelerating use of tags in cetacean studies, tagging is still an evolving and experimental field, with developments in some cases occurring without broad and timely sharing of information on successful innovations, or their instructive failures. Therefore, the scientific and regulatory communities would benefit from learning the details of what did and did not work. Specifically, reports and publications that include tagging results should provide details on the tags used (maximum dimensions, volume, frontal surface area, mass), especially for implanted parts (including maximum implant depth), manufacturer, specifics of materials and configuration, the deployment method and equipment, the basic metrics of tag performance (attachment duration, data telemetry throughput or other relevant tag operation results) and information on tag effects. Those involved with tagging, including tag designers and manufacturers, should also be encouraged to share more detailed information on failures, whether electronic, mechanical, attachment or deployment related. Details and rationales for excluding data collected in the first hours or days after tagging (e.g. to reduce data bias from disturbance and/or a tagging locale effect), should be fully explained for consideration by others.

Research groups working on the same population should share information on the individuals that are tagged to facilitate follow-up, prevent unintended repeat tagging and to reduce cumulative impact on individuals and their population. Researchers should also share the identity of tagged animals, or photographs of tagged but unidentified individuals, with stranding coordinators and response groups to increase the likelihood that previously tagged animals can be recognised in advance of necropsy. In some cases, for example bottlenose dolphins and humpback whales, regionwide collaborative individual identification catalogues exist that could expedite notification to researchers about a sighted or stranded, previously tagged individual. This would facilitate the collection of additional data relevant to tagging effects, including examination of the tag attachment site. See Appendix A for recommendations regarding the necropsy and dissection of the tag implant site for a previously tagged cetacean.

A 'tagging database' that includes information on individual animals, health assessments, tag data and photoidentification would greatly improve the ability to quantify potential tagging effects; such a database would also help in determining whether new tagging studies should be contemplated or if sufficient data already exist to answer a particular question. With the broader acceptance of the need to make government-funded data publicly available, more data repositories are becoming available. However, many of these repositories do not have the capability to host the essential data and photographs that should be included in a comprehensive cetacean tagging database, so until the cetacean tagging community or an academic society establishes an appropriate repository site, individual researchers could host the information on their own websites and make its existence known to interested parties. Wherever possible, this information should be provided in a machinesearchable form using standard data formats. An example of the data fields that could be included in such a form is provided in Table 3. If real-time posting of movement data is contemplated, researchers should consider the potential for unintended use of telemetry data (Hammerschlag et al., 2014), but in most cases the ability to follow animals in realtime will engage the public and outweigh disadvantages. As with most decisions regarding tagging of cetaceans, the pros and cons must be weighed, but with use of best practices, researchers should be able to ensure that benefits dominate.

Table 3

Examples of some of the data fields that should be collected by tag users. Most fields could also be included in a standard data form for sharing with other researchers.

FIELD FIELD DESCRIPTION

Device information

Tag (device) type

Tag (device) manufacturer

Tag model name/number

Tag serial number

PTT ID number

Transmitter frequency

Anchor type

Anchor manufacturer

Tag firmware
Type of device used (e.g., archival tags, satellite tags, satellite archival tags, acoustic tags).

Name of the manufacturer or, in the case of instruments from multiple manufacturers, list all manufacturers.

The name or number of the tag model.

The unique serial number of the device.

The Argos ID number of the Platform Transmitting Terminal (PTT) (if applicable, i.e., for tags equipped with Argos transmitters).

The frequency in $\mathrm{Hz}$ of any transmitter not on the standard Argos frequency (e.g., a VHF beacon or ultrasonic transmitter). A description of the anchoring system used to attach the tag to the animal (if applicable).

If the anchor manufacturer is different from the tag manufacturer, provide the name here.

Version number of the firmware encoded in the tag. 
Table 3 (continued)

FIELD

FIELD DESCRIPTION

Deployment device

Deployment device

Type of applicator

Deployment force parameters

Deployment information

Field number

Deployment date/time

Deployment location

Deployment coordinates

Height of the tagging platform

Horizontal distance to the whale

Tag Placement, Animal Reaction and Follow-up

Tag placement

Reaction to tagging

Behavior post tagging

Reapproach

Time lapse for reapproach

Closest distance on reapproach

Reaction to reapproach

Animal information

Species

Sex

Size

Age or age class

Animal ID

Group composition

Role in the group

Other documentation

Biopsy sample

Photographs

Video

Tagging Platform Information

Vessel name

Vessel crew

Position of tagger within vesse

Environmental Conditions

Weather

Visibility

Sea state (Beaufort)

Other Observations

Notes startle). preserved. names.
Description of the device used for deployment (e.g., pole, crossbow, pneumatic rifle) and manufacturer.

Description of the applicator or tag carrier used with the deployment device (e.g., $30 \mathrm{~cm}$ "rocket" or carrier, $45 \mathrm{~cm}$ crossbow bolt, $81 \mathrm{~cm}$ arrow for air rifle, etc.) and manufacturer/vendor, if applicable.

For pneumatic deployment devices, the pressure used to deploy the tag (in psi, bars, or Pascals) and the diameter of the barrel. For crossbows, the draw strength and the power stroke length.

Number assigned in the field for the tag deployment (e.g., a unique deployment or animal identification code).

Date and time the instrument was deployed.

Locality, State/Province, Country or water mass (such as the Large Marine Ecosystem) where the deployment occurred.

Latitude and longitude of the deployment.

For tags that are remotely deployed, specify the height of the platform where the tagger was located relative to the surface of the water for each deployment.

Estimated horizontal distance between the tagger and the animal upon tag deployment. Include a description of the method used to estimate horizontal distance (e.g. visual approximation, laser range finder)

The location on the body where the tag was placed (e.g., left or right side, dorsum or flank, on the dorsal fin). Whenever possible provide horizontal and vertical references, for example, $1 \mathrm{~m}$ ahead (cranial) of the dorsal fin and $50 \mathrm{~cm}$ circumferentially from the dorsal midline of the body. Specify whether full tag penetration was achieved and, if possible, provide information on the penetration angle relative to the plane of the local skin surface.

Description or numerical classification (e.g., Weinrich et al., 1991) of the behavioral reaction (if any) to the tagging process (e.g., boat approach, tag deployment) that was observed. If possible, separately record responses to the approach (e.g., evasive behavior, changes in displacement speed or direction) and to the deployment of the tag (e.g., tails flicks,

The behavior of the tagged individual shortly after tag deployment (if observed)

Specify whether the animal was reapproached after tagging on the same day.

The time lapse between tagging and reapproach.

The closest distance to the tagged animal on reapproach.

Description of the behavioral reaction to the reapproach.

Species of the cetacean that was tagged.

The sex of the tagged individual, and how it was determined (e.g., morphological features, molecular methods from a biopsy sample).

Approximate size of the tagged individual.

The age (in years) or maturity/age class (juvenile, sub-adult) of the tagged animal and how this was determined.

If a catalogued individual is recognized in the field, or later from photographs, note the catalog ID number.

The group composition (e.g., mother-calf pair, competitive group), if the animal was tagged while in a group.

The role of the animal in the group (e.g., a mother in a mother-calf pair, an escort in a competitive group).

If a biopsy sample was collected from the tagged animal, specify the biopsy sample identification number and how

Indicate whether photographs were obtained for photo-identification and of the deployment and the tag placement at the time of tagging, immediately after deployment and during follow-up. Specify photo frames and file names.

Indicate whether video images were made of the deployment, the tag placement and during follow-up. Specify video file

Name of the vessel used for deployment of the tag, if applicable.

Names of the boat crew, including their roles (e.g., driver, tagger, photographer)

Specify where the tag was deployed from (e.g. bow of the boat, a tagging platform such as a bow pulpit, other)

Weather conditions (e.g., rain, fog) at the time of deployment.

The distance at which an object ( $\geq$ human size) can be visibly identified against the background (e.g., Very poor $(<1 \mathrm{~km})$, Poor $(1-4 \mathrm{~km})$, Moderate $(4-9 \mathrm{~km})$, Good $(>9 \mathrm{~km})$

Sea state condition based on the modern Beaufort wind force scale. 


\subsubsection{Recommendations for reporting and data sharing}

- All tagging reports/publications should include:

- details on tag manufacturer, size, shape, materials and configuration, especially of implanted sections (including the maximum implant depth);

- photographs of the tags from multiple angles;

- information on deployment method, including devices used (note power of projectile devices, or velocity);

- information on tag performance, including at least mean/median and range of attachment duration; include numbers of tags that failed and when and how they failed;

- information on whether a follow-up study was conducted and, if so, provision of numbers of resights and details of any unexpected issues that occurred, including photographs; and

- information on data exclusion and inclusion criteria.

- Researchers should deposit metadata describing tag data holdings and any information from which to assess effects (e.g. including key photographs for individual ID and of tag and tag site) into publicly accessible data portals.

\section{ACKNOWLEDGEMENTS}

We are grateful to the participants in the following workshops for their contributions to the development of these guidelines: Cetacean Tag Design Workshop sponsored by ONR, March 2009; Workshop on Living Whales in the Southern Ocean, March 2012; Long Term Health Impacts of Cetacean Tagging: A Review of Follow Up Studies and Approaches at the 20th Biennial Conference on the Biology of Marine Mammals, December 2013; and the Workshop on Cetacean Tag Development, Tag Follow-up and Tagging Best Practices sponsored by IWC, NMFS/NOAA and ONR (grant N000141712275), September 2017. We are especially grateful to the participants of the latter workshop for their reviews of an earlier version of this manuscript. Thanks to Wildlife Computers, Inc., for their assistance with producing Fig. 2. Ann Pabst provided invaluable input, especially on cetacean anatomy. Ted Cranford provided information and imagery of mysticete anatomy. ONR Marine Mammal and Biology Program (programme manager: Michael Weise) funded part of the development of this manuscript through grant N000141010601.

\section{REFERENCES}

Andrews, R.D., Baird, R.W., Schorr, G.S., Mittal, R., Howle, L.E. and Hanson, M.B. 2015. Improving attachments of remotely-deployed dorsal fin-mounted tags: tissue structure, hydrodynamics, in situ performance, and tagged-animal follow-up. Report to the Office of Naval Research, Grant No. N000141010686. 6pp. [Available at: http://www.marecotel.org/ reports.html].

Asper, E.D. 1975. Techniques of live capture of smaller Cetacea. J. Fish. Res. Bd Can. 32(7): 1191-96.

Baker, C.S., Galletti, B., Childerhouse, S., Brownell, R.L., Jr., Friedlaender, A., Gales, N., Hall, A.J., Jackson, J., Leaper, R., Perryman, W., Steel, D., Valenzuela, L.O. and Zerbini, A.N. 2012. Report of the Symposium and Workshop on Living Whales in the Southern Ocean: Puerto Varas, Chile, 27-29 March 2012. Paper SC/64/O14 presented to the IWC Scientific Committee, June 2012, Panama City (unpublished). 40pp. [Paper available from the Office of this Journal]

Balmer, B., Wells, R.S., Schwacke, L.H., Rowles, T.K., Hunter, C., Zolman, E.S., Townsend, F.I., Danielson, B., Westgate, A.J., McLellan, W.A. and Pabst, D.A. 2011. Short note: Evaluation of a single-pin, satellite-linked transmitter deployed on bottlenose dolphins (Tursiops truncatus) along the coast of Georgia, USA. Aquat. Mamm. 37(2): 187-92.

Best, P.B., Mate, B.R. and Lagerquist, B. 2015. Tag retention, wound healing, and subsequent reproductive history of southern right whales following staellite-tagging. Mar. Mamm. Sci. 31(2): 520-39.

Casper, R.M. 2009. Guidelines for the instrumentation of wild birds and mammals. Anim. Behav. 78(6): 1477-83.

Dalstrom, D.J., Venkatarayappa, I., Manternach, A.L., Palcic, M.S., Heyse, B.A. and Prayson, M.J. 2008. Time-dependent contamination of opened sterile operating-room trays. J. Bone Joint Surg. Am. 90(5): 1022-5.

FDA. 2015. US FDA-Cleared Sterilants and High Level Disinfectants with General Claims for Processing Reusable Medical and Dental Devices March 2015. 9pp. [Available at: www.fda.gov/MedicalDevices/Device RegulationandGuidance/ReprocessingofReusableMedicalDevices/ucm 437347.htm].

Gales, N.J., Bowen, W.D., Johnston, D.W., Kovacs, K.M., Littnan, C.L., Perrin, W.F., Reynolds III, J.E. and Thompson, P.M. 2009. Guidelines for the treatment of marine mammals in field research. Mar. Mamm. Sci. 25(3): 725-36.

Gendron, D., Martinez Serrano, I., Ugalde de la Cruz, A., Calambokidis, J. and Mate, B. 2015. Long-term individual sighting history database: an effective tool to monitor satellite tag effects on cetaceans. Endang. Species Res. 26: 235-41.

Govindaraj, S. and Muthuraman, M.S. 2015. Systematic Review on Sterilization Methods of Implants and Medical Devices. Int. J. ChemTech Res. 8(2): 897-911.

Hammerschlag, N., Cooke, S.J., Gallagher, A.J. and Godley, B.J. 2014. Considering the fate of electronic tags: interactions with stakeholders and user responsibility when encountering tagged aquatic animals. Methods Ecol. Evol. 5(11): 1147-53.

Hays, G.C., Bradshaw, C.J.A., James, M.C., Lovell, P. and Sims, D.W. 2007. Why do Argos satellite tags deployed on marine animals stop transmitting? J. Exp. Mar. Biol. Ecol. 349(1): 52-60.

Heide-Jørgensen, M.P., Nielsen, N.H., Teilmann, J. and Leifsson, P.S. 2017. Long-term tag retention on two species of small cetaceans. Mar. Mamm. Sci. 33(3): 713-25.

Horning, M., Haulena, M., Tuomi, P.A., Mellish, J.-A.E., Goertz, C.E., Woodie, K., Berngartt, R.K., Johnson, S., Shuert, C.R., Walker, K.A., Skinner, J.P. and Boveng, P.L. 2017. Best practice recommendations for the use of fully implanted telemetry devices in pinnipeds. Animal Biotelemetry 5: 13.

Horning, M., Andrews, R.D., Bishop, A.M., Boveng, P.L., Costa, D.P., Crocker, D.E., Haulena, M., Hindell, M., Hindle, A.G., Holser, R.R., Hooker, S.K., Hückstädt, L.A., Johnson, S., Lea, M.-A., McDonald, B.I., McMahon, C.R., Robinson, P.W., Sattler, R.L., Shuert, C.R., Steingass, S.M., Thompson, D., Tuomi, P.A., Williams, C.L. and Womble, J.N. 2019. Best practice recommendations for the use of external telemetry devices on pinnipeds. Anim. Biotelemetry 7:20.

Hunt, K.E., Moore, M.J., Rolland, R.M., Kellar, N.M., Hall, A., Kershaw, J., Raverty, S., Davis, C.E., Yeates, L.C., Fauquier, D.A., Rowles, T. and Kraus, S. 2013. Overcoming the challenges of studying conservation physiology in large whales: a review of available methods. Cons. Physiol. 1(1): $24 \mathrm{pp}$.

International Whaling Commission. In press. Report of the Joint US Office of Naval Research, International Whaling Commission and US National Oceanic and Atmospheric Administration Workshop on Cetacean Tag Development, Tag Follow-up and Tagging Best Practices, 6-8 September 2017, Silver Spring, Maryland, USA (and 19 and 20 June 2018, Seattle, WA, USA). J. Cetacean Res. Manage. (Suppl.) 21 [2020].

Lander, M.E., Westgate, A.J., Balmer, B.C., Reid, J.P., Murray, M.J. and Laidre, K.L. 2018. Tagging and tracking pp.767-98. In: F.M.D. Gulland, L.A. Dierauf and K.L.Whitman (eds). CRC Handbook of Marine Mammal Medicine. 3rd Edn. CRC Press, Boca Raton, Florida. xxi+1124pp.

Loughlin, T., Cunningham, L., Gales, N., Wells, R.S. and Boyd, I. 2010. Marking and capturing. pp.16-41. In: Boyd, I., Bowen, D. and Iverson, S. (eds). Marine Mammal Ecology and Conservation: A Handbook of Techniques. Oxford University Press, Oxford, UK.

Mate, B., Mesecar, R. and Lagerquist, B. 2007. The evolution of satellitemonitored radio tags for large whales: one laboratory's experience. Deep Sea Res. II 54 (Special Issue: Bio-logging science: logging and relaying physical and biological data using animal-attached tags. Proceedings of the 2005 International Symposium on Bio-logging Science): 224-47.

McConnell, B., Fedak, M., Hooker, S. and Patterson, T. 2010. Telemetry. pp.222-41. In: Boyd, I.L., Bowen, W.D. and Iverson, S.J. (eds). Marine Mammal Ecology and Conservation. Oxford University Press, Oxford. xxvi+450pp.

McMahon, C.R., Harcourt, R., Bateson, P. and Hindell, M.A. 2012. Animal welfare and decision making in wildlife research. Biol. Cons. 153: 25456. 
Morton, D.B., Hawkins, P., Bevan, R., Heath, K., Kirkwood, J., Pearce, P., Scott, L., Whelan, G. and Webb, A. 2003. Refinements in telemetry procedures: Seventh report of BVAAWF/FRAME/RSPCA/UFAW Joint Working Group on Refinement, Part A. Lab. Anim. 37(4): 261-99.

Mulcahy, D.M. 2011. Antibiotic use during the intracoelomic implantation of electronic tags into fish. Rev. Fish. Biol. Fisher. 21(1): 83-96.

Mulcahy, D.M. 2013. Legal, ethical, and procedural bases for the use of aseptic techniques to implant electronic devices. J. Fish. Wildl. Manag. 4(1): 211-19.

Norman, S.A., Flynn, K.R., Zerbini, A.N., Gulland, F.M.D., Moore, M.J., Raverty, S., Rotstein, D.S., Mate, B.R., Hayslip, C., Gendron, D., Sears, R., Douglas, A.B. and Calambokidis, J. 2018. Assessment of wound healing of tagged gray (Eschrichtius robustus) and blue (Balaenoptera musculus) whales in the eastern North Pacific using long-term series of photographs. Mar. Mamm. Sci. 34(1): 27-53.

ONR. 2009. Final Workshop Proceedings for Cetacean Tag Design Workshop 16-17 March 2009 Arlington, Virginia. 18pp. [Available at: https://www.onr.navy.mil/-/media/Files/32/Tag-Final-Report-Oct2009.ashx? la $=$ en\&hash=69E088C5BD20F71ABDEBBBD703B816F47FA1676E].

Pettis, H.M., Rolland, R.M., Hamilton, P.K., Brault, S., Knowlton, A.R. and Kraus, S.D. 2004. Visual health assessment of North Atlantic right whales (Eubalaena glacialis) using photographs. Can. J. Zool. - Revue Canadienne de Zoologie 82: 8-19.

Ratner, B., Hoffman, A., Schoen, S. and Lemons, J. 2013. Biomaterials Science: An Introduction to Materials in Medicine. 3rd Edn. Elsevier, Amsterdam. 1573pp

Robbins, J., Zerbini, A.N., Gales, N., Gulland, F.M.D., Double, M., Clapham, P.J., Andrews-Goff, V., Kennedy, A.S., Landry, S., Mattila, D.K. and Tackaberry, J. 2013. Satellite tag effectiveness and impacts on large whales: preliminary results of a case study with Gulf of Maine humpback whales. Paper SC/65a/SH05 presented to the IWC Scientific Committee, June 2013, Jeju Island, Republic of Korea (unpublished) 10pp. [Paper available from the Office of this Journal].
Russell, W.M.S. and Burch, R.L. 1959. The Principles of Humane Experimental Technique. Methuen, London. xvi+238pp.

Rutala, W.A., Weber, D.W., Weinstein, R.A., Siegel, J.D., Pearson, M.L. Chinn, R.Y.W., DeMaria Jr, A., Lee, J.T., Scheckler, W.E., Stover, B.H. and Underwood, M.A. 2008. Guideline for Disinfection and Sterilization in Healthcare Facilities (2008). Updated 15 February 2017. 161pp. [Available at: https://www.cdc.gov/infectioncontrol/guidelines/ disinfection/].

Scholander, P.F. 1940. Experimental investigations on the respiratory function in diving mammals and birds. Hvalrådets Skrifter 22: 1-131.

Scott, M.D., Wells, R.S., Irvine, A.B. and Mate, B.R. 1990. Tagging and marking studies on small cetaceans. pp.489-514. In: Leatherwood, S. and Reeves, R.R. (eds). The Bottlenose Dolphin. Academic Press, San Diego, California. 653pp

Shorter, K.A., Murray, M.M., Johnson, M., Moore, M. and Howle, L.E. 2014. Drag of suction cup tags on swimming animals: Modeling and measurement. Mar. Mamm. Sci. 30(2): 726-46.

Townsend, F.I., Smith, C.R. and Rowles, T.K. 2018. Health assessment of bottlenose dolphins in capture-release studies. pp.823-33. In: Gulland, F.M.D., Dierauf, L.A. and Whitman, K.L. (eds). CRC Handbook of Marine Mammal Medicine. 3rd Edn. CRC Press, Boca Raton, Florida. xxi+1124pp

Weller, D.W. 2008. Report of the Large Whale Tagging Workshop convened by the US Marine Mammal Commission and US National Marine Fisheries Service, 10 December 2005, San Diego, California, USA Contract Report to the US Marine Mammal Commission. 32pp. [Available at:http://www.mmc.gov/pdf/final_tagging_82608.pdf].

Wells, R.S. 2005. Report to the Marine Mammal Commission on the small cetacean electronic tag workshop, June 11-12, 2003, Mote Marine Laboratory, Sarasota, Florida. 73pp. [Available from the author]

Wells, R.S. 2013. Evaluation of Tag Attachments on Small Cetaceans. Final report to the Office of Naval Research Award Number N000141210391. 5pp. [Available at: https://www.onr.navy.mil/reports/FY13/mbwells2.pdf].

\section{APPENDIX A}

\section{RECOMMENDATIONS FOR NECROPSY AND DISSECTION OF THE TAG IMPLANT SITE FOR A PREVIOUSLY TAGGED CETACEAN}

This protocol will help taggers, stranding responders and necropsy teams investigate the effects of tagging and integrate ante mortem history of the stranded individual with postmortem findings. Information obtained from using this protocol will also be valuable to all others involved with cetacean tagging, including researchers, veterinarians and marine mammal managers, especially as we strive to understand implant-tissue interactions and healing processes, and to improve tag design and deployment methodology. The authors of these guidelines may be contacted for additional advice, collaborative proposals and recommendations of other resources. For those unfamiliar with some of the methods recommended below, we strongly recommend working with stranding coordinators, other marine mammal research scientists with tagging expertise and regional veterinary diagnostic pathologists, prior to dissection of a tag implant site. If local resources are not available to accomplish the post-necropsy examinations of the implant site tissue block as detailed in steps 11-15 below, shipment of an entire tissue block to a marine mammal pathologist is recommended; please contact the authors of these guidelines to discuss collaborative opportunities.

When a previously-tagged cetacean is confirmed dead or a tag is observed on initial examination of a stranded animal and a postmortem examination is scheduled, the principal investigator (PI) or other representative of the study that deployed the tag should provide stranding and necropsy responders with annotated photographs of the animal, highlighting the anatomic site of attachment. They should also provide images and specifications of the model of tag deployed, especially the shape and dimensions of the implanted parts. The tagging project PI should collaborate closely with responders and provide shipping supplies (containers and labels) and courier account numbers to facilitate shipping of tissues to diagnostic laboratories or marine mammal pathologists. Responders should review the photographs to confirm the tag implant site, if possible, prior to commencing the necropsy (although this may not be logistically feasible in some situations). In addition to following conventional necropsy protocols, include a scale marker with the Field ID\# and date in each photograph, and avoid obscuring the areas of interest in the field of view. Document gross findings in a necropsy report and include photos and sketches. If the tag implant site is partly or completely healed, then steps 5-15 may not all be necessary or possible. However, whenever the tag implant site can be identified, we recommend that all steps be followed, even for carcasses that are not fresh.

(1) Photo-document the animal and the tag site. Photograph the tag site from three different perspectives: (a) wide angle images of the carcass to place the tag location in anatomic context; (b) intermediate scale images to illustrate adjoining tissues and potential changes; and (c) external macroscopic images of the implant site to detail host response. Rulers or other objects that may lend scale to each image are imperative. 
- These photographs will be used to help assess overall impact of the tag and to make more precise measurements of the exact tag placement than could be made from photographs of the live animal and will be invaluable to the taggers and others.

(2) Compile as complete a set of morphometric data as possible from the animal.

- See, for example, Chapter 10 in Geraci and Lounsbury (2005) and Appendix F in Pugliares et al. (2007).

(3) Collect a $1.0 \times 0.5 \mathrm{~cm} \times$ full depth skin sample including the dermis, away from the implant site and freeze it in a sterile container for genetic analysis.

(4) If possible, measure the straight-line and curvilinear distance between the tag implant site and the tip of the rostrum.

(5) Swab the implant wound aperture. If no parts of the tag are visible, and if the implant site is open (patent), or in the early stages of resolution, five sterile (Teflon or cotton tip) swabs should be obtained prior to excision of the implant site tissue block. Collect two of these swabs from the external aperture and three swabs from deeper in along the penetration tract. The swabs should be collected as gently as possible to avoid tissue damage. Place one of the external swabs and two of the deeper swabs in transport media for routine microbiology (bacteriology and fungal culture). If the microbiology samples will be submitted to a diagnostic lab within 24-48 hours, they may be chilled and shipped on ice; otherwise they may be frozen, although this will reduce the viability of the bacteria. One external and one deeper swab for microbiome studies should be placed in sterile containers and either chilled for immediate transport or frozen (preferably in liquid nitrogen) for later submission to a laboratory. If RNAlater or other tissue stabilisation or culture media are available, these may be suitable alternatives and the swabs should be maintained chilled. If swabs are not available in the field, tissue and swabs may be collected later at the lab from the excised implant site tissue block (step 6).

(6) Excise the implant site and surrounding tissue, to include unaltered tissue at the edges of the block, for diagnostic imaging and subsequent lab analyses (steps 11-15). If no parts of the tag are externally evident, outline a $20 \times 20 \mathrm{~cm}$ square around the original implant site and excise the skin and blubber around the site down to and including underlying muscle. If the tag (or parts of the tag) are present, they should be retained in situ within the surrounding soft tissues excised as a block; include at least $10 \mathrm{~cm}$ of tissue beyond all margins of the implant. Depending upon the body curvature or potential swelling at the tag site, additional tissue may need to be incorporated into the excised sample to ensure all altered tissue is within the block. Photograph the cut surfaces and examine them for any discoloration or other abnormality.
(7) After excising the implant site tissue block, if abnormal tissues are observed beneath or in the vicinity of the implant site, collect specimen swabs or tissue samples (using a sterile blade) from those areas for subsequent laboratory analyses. Samples of regional or local lymph nodes and any associated gross lesions in the underlying or adjoining soft tissues may be collected and chilled or frozen for microbiology, with subsamples preserved in formalin for microscopic evaluation. Document gross lesions with photographs and include a scale marker with field number.

(8) If feasible, retain the excised block on ice, and arrange for subsequent examinations within 48 hours (steps 11-15).

(9) If conditions during necropsy do not permit the full execution of steps 5-8, collection of a single sample, measuring at least $2 \times 2 \mathrm{~cm}$ on the surface, cut down to the full thickness of skin and blubber, including a margin of the implant site, would be valuable. If the tissue sample can be submitted to a diagnostic lab within 24-48 hours after collection, the sample may be secured in a sterile plastic bag, chilled on wet ice or gel ice packs and submitted for evaluation; on receipt, the tissues may be subsampled for molecular studies and microbiology as well as representative subsamples preserved in formalin. If the carcass is condition code 2 or 3 and only a single portion of tissue is available, this sample may be subdivided (dissected in half) on site, with a portion chilled (if laboratory analysis is likely with $48 \mathrm{~h}$, otherwise frozen) and retained for microbiology and molecular studies and a formalin fixed sample for histopathology. If late code 3 or 4 , the tissue may be preserved in formalin for diagnostic evaluation.

(10) The necropsy of the whole animal should be completed by conventional protocols and systemic pathology recorded with appropriate tissue samples archived for additional studies.

(11) Back at the lab, and before further sectioning of the excised tag implant site tissue block, obtain precise measurements, photographs, radiographs (x-rays), CT and, if possible, MR scans, to document the degree of tissue penetration by the tag, possible implant structural failures (if any parts were retained), and any associated inflammatory exudate or tissue necrosis.

(12) Serial slices (every 5-10 mm; bread-loafing) through the tissue block should be made parallel to the long axis of the tag implant tract, examining each cut surface for any abnormalities or retained tag elements. These slices should be placed on a cutting board in sequence for photography (with scale) and further analyses. Preservation of multiple representative samples in $10 \%$ formalin and separately at $-80^{\circ} \mathrm{C}$ (no formalin) is required for additional histopathologic and microbiologic analysis. If a significant portion or an entire Type $\mathrm{C}$ tag or anchor from a Type $\mathrm{A}$ tag (e.g., a LIMPET dart), or rod, pin or bolt from a Type B tag remained implanted, instead of starting serial slices from one margin of the tissue block, start by cutting 
along opposing margins of the percutaneous tag body or dart from the surface of the skin down to the bottom of the tissue block, separating the tissue block in two. The approach should expose the tag tract from the skin through the blubber (and possibly muscle) and facilitate removal of half of the excised tissue block, gently separating tissue from implant protrusions, such as retention petals. The two halves can then be sectioned serially as above.

(13) Swab the penetration site and any parts of the tag or implanted pieces that are encountered during serial sectioning of the tissue block with bacteriology and dry swabs, and place swabs and tag parts in separate sterile containers for microbiology, microbiome studies and potential mechanical or metallurgic analyses.

(14) Label each tissue slice with a laundry tag or other identifier, then fix abnormal tissue and surrounding normal tissue. Ensure that the laundry tag clip is placed as far away from the site of interest, so that it does not damage visibly abnormal tissues.
(15) Have an experienced veterinary pathologist examine the sections and if the tissues are sufficiently well preserved, follow-up transmission electron microscopy may be considered.

(16) Ensure a full report is collated with gross, histological and ancillary (imaging, microbiology) diagnostic findings.

REFERENCES (and additional resources for necropsy and sample collection methodology)

Geraci, J.R. and Lounsbury, V.J. 2005. Marine Mammals Ashore: A Field Guide for Strandings, 2nd edn. National Aquarium in Baltimore, Baltimore, MD. i-xi+371pp. [Available from: https://apps.dtic.mil/dtic/ tr/fulltext/u2/a456126.pdf]

Pugliares, K.R., Bogomolni, A.L., Touhey, K.M., Herzig, S.M., Harry, C.T. and Moore, M.J. 2007. Marine Mammal Necropsy: An Introductory Guide for Stranding Responders and Field Biologists. Woods Hole Oceanog. Inst. Tech. Rep., WHOI-2007-06., Woods Hole, MA. [Available from https://darchive.mblwhoilibrary.org/handle/1912/1823]

Raverty, S., Duignan, P., Jepson, P.D. and Morell, M. 2018. Marine Mammal Gross Necropsy. pp. 249-65. In: F.M.D. Gulland, L.A. Dierauf and K.L. Whitman (eds.). CRC Handbook of Marine Mammal Medicine, 3rd edn. CRC Press: Taylor and Francis Group. Boca Raton. i-xix+ 1124 pp.

\section{APPENDIX B}

\section{SUPPLEMENTARY BIBLIOGRAPHY}

Abecassis, M., Polovina, J., Baird, R.W., Copeland, A., Drazen, J.C., Domokos, R., Oleson, E., Jia, Y., Schorr, G.S., Webster, D.L. and Andrews, R.D. 2015. Characterizing a Foraging Hotspot for Short-Finned Pilot Whales and Blainville's Beaked Whales Located off the West Side of Hawai'i Island by Using Tagging and Oceanographic Data. PLoS One 10(11): e0142628.

Abrahms, B., Hazen, E.L., Aikens, E.O., Savoca, M.S., Goldbogen, J.A., Bograd, S.J., Jacox, M.G., Irvine, L.M., Palacios, D.M. and Mate, B.R. 2019a. Memory and resource tracking drive blue whale migrations. Proc. Natl Acad. Sci. 116(12): 5582-87.

Abrahms, B., Welch, H., Brodie, S., Jacox, M.G., Becker, E.A., Bograd, S.J., Irvine, L.M., Palacios, D.M., Mate, B.R. and Hazen, E.L. 2019 b. Dynamic ensemble models to predict distributions and anthropogenic risk exposure for highly mobile species. Divers. Distrib. [Available at: https://doi.org/10.1111/ddi.12940].

Acevedo-Gutierrez, A., Croll, D.A. and Tershy, B.R. 2002. High feeding costs limit dive time in the largest whales. J. Exp. Biol. 205(12): 1747-53.

Aguilar de Soto, N., Johnson, M., Madsen, P.T., Tyack, P.L., Bocconcelli, A. and Fabrizio Borsani, J. 2006. Does intense ship noise disrupt foraging in deep-diving Cuvier's beaked whales (Ziphius cavirostris)? Mar. Mamm. Sci. 22(3): 690-99.

Aguilar de Soto, N., Johnson, M.P., Madsen, P.T., Díaz, F., Domínguez, I., Brito, A. and Tyack, P. 2008. Cheetahs of the deep sea: deep foraging sprints in short-finned pilot whales off Tenerife (Canary Islands). J. Anim. Ecol. 77(5): 936-47.

Aguilar de Soto, N., Madsen, P.T., Tyack, P., Arranz, P., Marrero, J., Fais, A., Revelli, E. and Johnson, M. 2012. No shallow talk: Cryptic strategy in the vocal communication of Blainville's beaked whales. Mar. Mamm. Sci. 28(2): E75-E92.

Akamatsu, T., Hatakeyama, Y., Kojima, T. and Soeda, H. 1994. Echolation rates of two harbor porpoises (Phocoena phocoena). Mar. Mamm. Sci. 10(4): 401-11.

Akamatsu, T., Matsuda, A., Suzuki, S., Wang, D., Wang, K., Suzuki, M., Muramoto, H., Sugiyama, N. and Oota, K. 2005a. New stereo acoustic data logger for free-ranging dolphins and porpoises. Mar. Technol. Soc. J. 39(2): 3-9.

Akamatsu, T., Rasmussen, M.H. and Iversen, M. 2014. Acoustically invisible feeding blue whales in Northern Icelandic waters. J. Acoust. Soc. Am. 136(2): 939-44.

Akamatsu, T., Teilmann, J., Miller, L.A., Tougaard, J., Dietz, R., Wang, D., Wang, K., Siebert, U. and Naito, Y. 2007. Comparison of echolocation behaviour between coastal and riverine porpoises. DSR 54(3-4): 290-97.

Akamatsu, T., Wang, D., Wang, K., Li, S. and Dong, S. 2010. Scanning sonar of rolling porpoises during prey capture dives. J. Exp. Biol. 213(1): $146-52$.
Akamatsu, T., Wang, D., Wang, K. and Naito, K. 2005b. Biosonar behaviour of free-ranging porpoises. P. Roy. Soc. B-Biol. Sci. 272(1565): 979-801.

Akamatsu, T., Wang, D., Wang, K. and Naito, Y. 2000. A method for individual identification of echolocation signals in free-ranging finless porpoises carrying data loggers. J. Acoust. Soc. Am. 108(3): 1353-56.

Akamatsu, T., Wang, D., Wang, K., Wei, Z., Zhao, Q. and Naito, Y. 2002. Diving behaviour of freshwater finless porpoises (Neophocaena phocaenoides) in an oxbow of the Yangtze River, China. ICES J. Mar Sci. 59(2): 438-43.

Akiyama, Y., Akamatsu, T., Rasmussen, M.H., Iversen, M.R., Iwata, T., Goto, Y., Aoki, K. and Sato, K. 2019. Leave or stay? Video-logger revealed foraging efficiency of humpback whales under temporal change in prey density. PLoS One 14(2): e0211138.

Allen, A.N., Goldbogen, J.A., Friedlaender, A.S. and Calambokidis, J. 2016. Development of an automated method of detecting stereotyped feeding events in multisensor data from tagged rorqual whales. Ecol. Evol. 6(20): 7522-35.

Allen, A.N., Schanze, J.J., Solow, A.R. and Tyack, P.L. 2014. Analysis of a Blainville's beaked whale's movement response to playback of killer whale vocalizations. Mar. Mamm. Sci. 30(1): 154-68.

Alves, A., Antunes, R., Bird, A., Tyack, P.L., Miller, P.J.O., Lam, F.A. and Kvadsheim, P.H. 2014. Vocal matching of naval sonar signals by longfinned pilot whales (Globicephala melas). Mar. Mamm. Sci. 30(3) 1248-57.

Alves, F., Dinis, A., Cascao, I. and Frietas, L. 2010a. Bryde's whale (Balaenoptera brydei) stable associations and dive profiles: New insights into foraging behavior. Mar. Mamm. Sci. 26(1): 202-12.

Alves, F., Dinis, A., Ribeiro, C., Nicolau, C., Kaufmann, M., Fortuna, C.M. and Frietas, L. 2013. Daytime dive characteristics from six short-finned pilot whales Globicephala macrorhynchus off Madeira Island. Arquipel. Life Mar. Sci. 31: 1-8.

Alves, L.C.P.S., Moreira, S., Simões-Lopes, P.C. and Andriolo, A. 2010 b. Behavioral responses of humpback whales, Megaptera novaeangliae (Cetacea: Balaenopteridae), to satellite transmitter deployment procedures. Zoologia (Curitiba) 27(1): 01-06.

Amano, M. and Yoshioka, M. 2003. Sperm whale diving behavior monitored using a suction-cup-attached TDR tag. Mar. Ecol. Prog. Ser. 258: 29195.

Amano, M., Yoshioka, M. and Mori, K. 2003. Study on diving behavior of sperm whales using suction cup attached TDR tag: an overview. Otsuchi Mar. Sci. 28: 1-5.

Andrews-Goff, V., Bestley, S., Gales, N.J., Laverick, S.M., Paton, D., Polanowski, A.M., Schmitt, N.T. and Double, M.C. 2018. Humpback whale migrations to Antarctic summer foraging grounds through the southwest Pacific Ocean. Sci. Rep. 8(1): 12333. 
Andrews-Goff, V., Olson, P.A., Gales, N.J. and Double, M.C. 2013. Satellite telemetry derived summer movements of Antarctic blue whales. Paper $\mathrm{SC} / 65 \mathrm{a} / \mathrm{SH} 03$ presented to the IWC Scientific Committee, June 2013 Jeju Island, Republic of Korea (unpublished). 10pp. [Paper available from the Office of this Journal]

Andrews, R.D., Baird, R.W., Schorr, G.S., Mittal, R., Howle, L.E. and Hanson, M.B. 2015. Improving attachments of remotely-deployed dorsal fin-mounted tags: tissue structure, hydrodynamics, in situ performance, and tagged-animal follow-up. Final Report to the Office of Naval Research - Grant Number N000141010686. 37pp.

Andrews, R.D. and Enstipp, M.R. 2016. Diving physiology of seabirds and marine mammals: Relevance, challenges and some solutions for field studies. Comp. Biochem. Physiol. A Mol. Integr. Physiol. 202: 38-52.

Andrews, R.D., Mazzuca, L. and Matkin, C.O. 2005. Satellite tracking of killer whales. pp.238-48. In: Loughlin, T.R., Atkinson, S. and Calkins, D.G. (eds). Synopsis of Research on Steller Sea Lions: 2001-2005. Alaska SeaLife Center, Seward, AK.

Andrews, R.D., Pitman, R.L. and Ballance, L.T. 2008. Satellite tracking reveals distinct movement patterns for Type B and Type $\mathrm{C}$ killer whales in the southern Ross Sea, Antarctica. Polar Biol. 31(12): 1461-68.

Andriolo, A., Zerbini, A.N., Moreira, S., Pizzorno, J.L., Danilewicz, D., Maia, Y.G., Mamede, N., de Castro, F.R. and Clapham, P. 2014. What do humpback whales Megaptera novaeangliae (Cetartiodactyla: Balaenopteridae) pairs do after tagging? Zoologia (Curitiba) 31(2): 10513.

Anonymous. 2009. Final workshop proceedings for Cetacean Tag Design Workshop, 16-17 March 2009, Arlington, Virginia. Office of Naval Research, Marine Mammal and Biological Oceanography Program, Arlington, Virginia. 18pp. [Available from: https://www.onr.navy/mil].

Aoki, K., Amano, M., Kubodera, T., Mori, K., Okamoto, R. and Sato, K. 2015. Visual and behavioral evidence indicates active hunting by sperm whales. Mar. Ecol. Prog. Ser. 523: 233-41.

Aoki, K., Amano, M., Mori, K., Kourogi, A., Kubodera, T. and Miyazaki, N. 2012. Active hunting by deep-diving sperm whales: 3D dive profiles and maneuvers during bursts of speed. Mar. Ecol. Prog. Ser. 444: 289-301.

Aoki, K., Amano, M., Sugiyama, N., Muramoto, H., Suzuki, M., Yoshioka, M., Mori, K., Tokuda, D. and Miyazaki, N. 2007a. Measurement of swimming speed in sperm whales. [Available at: https://doi.org/10.1109/ UT.2007.370754]

Aoki, K., Amano, M., Yoshioka, M., Mori, K., Tokuda, D. and Miyazaki, N. 2007b. Diel diving behavior of sperm whales off Japan. Mar. Ecol. Prog. Ser. 349: 277-87.

Aoki, K., Sakai, M., Miller, P.J.O., Visser, F. and Sato, K. 2013. Body contact and synchronous diving in long-finned pilot whales. Behav Process. 99: 12-20.

Aoki, K., Sato, K., Isojunno, S., Narazaki, T. and Miller, P.J.O. 2017. High diving metabolic rate indicated by high-speed transit to depth in negatively buoyant long-finned pilot whales. J. Exp. Biol. 220: 3802-11.

Argüelles, M.B., Fazio, A., Fiorito, C., Pérez-Martínez, D., Coscarella, M. and Bertellotti, M. 2016. Diving behavior of southern right whales (Eubalaena australis) in a maritime traffic area in Patagonia, Argentina. Aquat. Mamm. 42(1): 104-08.

Arranz, P., Benoit-Bird, K.J., Friedlaender, A.S., Hazen, E.L., Goldbogen, J.A., Stimpert, A.K., DeRuiter, S.L., Calambokidis, J., Southall, B.L., Fahlman, A. and Tyack, P.L. 2019. Diving behavior and fine-scale kinematics of free-ranging Risso's dolphins foraging in shallow and deepwater habitats. Front. Ecol. Evol. 7: 53.

Arranz, P., Benoit-Bird, K.J., Southall, B.L., Calambokidis, J., Friedlaender, A.S. and Tyack, P.L. 2018. Risso's dolphins plan foraging dives. J. Exp. Biol. 221(4): jeb165209.

Arranz, P., de Soto, N.A., Madsen, P.T., Brito, A., Bordes, F. and Johnson, M.P. 2011. Following a foraging fish-finder: diel habitat use of Blainville's beaked whales revealed by echolocation. PLoS One 6(12): e28353.

Arranz, P., DeRuiter, S.L., Stimpert, A.K., Neves, S., Friedlaender, A.S. Goldbogen, J.A., Visser, F., Calambokidis, J., Southall, B.L. and Tyack, P.L. 2016. Discrimination of fast click series produced by tagged Risso's dolphins (Grampus griseus) for echolocation or communication. J. Exp. Biol. 219(18): 2898-907.

Asper, E.D. 1975. Techniques of live capture of smaller cetacea. J. Fish. Res. Board Can. 32(7): 1191-96.

Au, W., Finneran, J.J. and Branstetter, B.K. 2016. What do acoustic tags placed on the back of echolocating dolphins really measure? J. Acoust. Soc. Am. 139: 2060

Bailey, H., Mate, B., Palacios, D., Irvine, L., Bograd, S. and Costa, D. 2009. Behavioural estimation of blue whale movements in the Northeast Pacific from state-space model analysis of satellite tracks. Endanger. Spec. Res. 10: 93-106.

Bailleul, F., Lesage, V., Power, M., Doidge, D. and Hammill, M.O. 2012a. Differences in diving and movement patterns of two groups of beluga whales in a changing Arctic environment reveal discrete populations. Endanger. Spec. Res. 17(1): 27-41.

Bailleul, F., Lesage, V., Power, M., Doidge, D.W. and Hammill, M.O. 2012 b. Migration phenology of beluga whales in a changing Arctic. Clim. Res. 53(3): 169-78.

Baird, R. 1998. Studying diving behavior of whales and dolphins using suction-cup attached tags. Whalewatcher 31(3): 3-7.

Baird, R.W., Borsani, J.F., Hanson, M.B., Tyack, P.L. and others. 2002. Diving and night-time behavior of long-finned pilot whales in the Ligurian Sea. Mar. Ecol. Prog. Ser. 237: 301-05.

Baird, R.W., Hanson, M.B., Ashe, E.A., Heithaus, M.R. and Marshall, G.J. 2003. Studies of foraging in southern resident killer whales during July 2002: Dive depths, bursts in speed, and the use of a Crittercam system for examining sub-surface behavior. Report prepared under Order Number AB133F-02-SE-1744 for the National Marine Mammal Laboratory, Seattle, WA.

Baird, R.W., Hanson, M.B. and Dill, L.M. 2005. Factors influencing the diving behaviour of fish-eating killer whales: sex differences and diel and interannual variation in diving rates. Can. J. Zool. 83(2): 257-67.

Baird, R.W., Hanson, M.B., Schorr, G.S., Webster, D.I., McSweeney, D.J., Gorgone, A.M., Mahaffy, S.D., Holzer, D.M., Oleson, E.M. and Andrews, R.D. 2012. Range and primary habitats of Hawaiian insular false killer whales: informing determination of critical habitat. Endanger. Spec. Res. 18(1): 47-61.

Baird, R.W., Ligon, A.D., Hooker, S.K. and Gorgone, A.M. 2001. Subsurface and night time behaviour of pantropical spotted dolphins in Hawai'i. Can. J. Zool. 79(6): 988-96.

Baird, R.W., Oleson, E.M., Barlow, J., Ligon, A.D., Gorgone, A.M. and Mahaffy, S.D. 2013. Evidence of an island-associated population of false killer whales (Pseudorca crassidens) in the Northwestern Hawaiian Islands. Pac. Sci. 67(4): 513-21.

Baird, R.W., Schorr, G.S., Webster, D.I., McSweeney, D.J., Hanson, M.B. and Andrews, R.D. 2010. Movements and habitat use of satellite-tagged false killer whales around the main Hawaiian Islands. Endanger. Spec. Res. 10: 107-21.

Baird, R.W., Schorr, G.S., Webster, D.L., Mahaffy, S.D., McSweeney, D.J., Hanson, M.B. and Andrews, R.D. 2011a. Open-ocean movements of a satellite-tagged Blainville's beaked whale (Mesoplodon densirostris): evidence for an offshore population in Hawai'i? Aquat. Mamm. 37(4): 506-11.

Baird, R.W., Schorr, G.S., Webster, D.L., McSweeney, D.J., Hanson, M.B. and Andrews, R.D. 2008a. Multi-species cetacean satellite tagging to examine movements in relation to the 2008 Rim-of-the-Pacific (RIMPAC) naval exercise.

Baird, R.W., Schorr, G.S., Webster, D.L., McSweeney, D.J., Hanson, M.B. and Andrews, R.D. 2011b. Movements of two satellite-tagged pygmy killer whales (Feresa attenuata) off the island of Hawai'i. Mar. Mamm. Sci. 27(4): E332-E37.

Baird, R.W., Webster, D.L., McSweeney, D.J., Ligon, A.D., Schorr, G.S. and Barlow, J. 2006. Diving behaviour of Cuvier's (Ziphius cavirostris) and Blainville's (Mesoplodon densirostris) beaked whales in Hawai'i. Can. J. Zool. 84(8): 1120-28.

Baird, R.W., Webster, D.L., Schorr, G.S., McSweeney, D.J. and Barlow, J. 2008b. Diel variation in beaked whale diving behavior. Mar. Mamm. Sci. 24(3): 630-42.

Baker, C.S., Galletti, B., Childerhouse, S., Brownell, R.L., Jr, Friedlaender, A., Gales, N.J., Hall, A., Jackson, J., Leaper, R., Perryman, W., Steel, D., Valenzuela, L. and Zerbini, A. 2012. Report of the Symposium and Workshop on Living Whales in the Southern Ocean. Paper SC/64/O14rev presented to the IWC Scientific Committee, Panama City, Panama, June 2012 (unpublished). 40pp. [Paper available from the Office of this Journal].

Baldwin, H.A. 1965. Marine biotelemetry. BioSci. 15(2): 95-97.

Balmer, B., Wells, R.S., Schwacke, L.H., Rowles, T.K., Hunter, C., Zolman, E.S., Townsend, F.I., Danielson, B., Westgate, A.J., McLellan, W.A. and Pabst, D.A. 2011. Evaluation of a single-pin, satellite-linked transmitter deployed on bottlenose dolphins (Tursiops truncatus) along the coast of Georgia, USA. Aquat. Mamm. 37(2): 187-92.

Balmer, B., Zolman, E., Rowles, T., Smith, C., Townsend, F., Fauquier, D., George, C., Goldstein, T., Hansen, L., Quigley, B., McFee, W., Morey, J., Rosel, P., Saliki, J., Speakman, T. and Schwacke, L. 2018. Ranging patterns, spatial overlap, and association with dolphin morbillivirus exposure in common bottlenose dolphins (Tursiops truncatus) along the Georgia, USA coast. Ecol. Evol. 8(24): 12890-904.

Balmer, B.C., Schwacke, L.H. and Wells, R.S. 2010. Linking dive behavior to satellite-linked tag condition for a bottlenose dolphin (Tursiops truncatus) along Florida's northern Gulf of Mexico coast. Aquat. Mamm. 36(1): 1-8.

Balmer, B.C., Wells, R.S., Howle, L.E., Barleycorn, A.A., McLellan, W.A., Ann Pabst, D., Rowles, T.K., Schwacke, L.H., Townsend, F.I., Westgate, A.J. and Zolman, E.S. 2014. Advances in cetacean telemetry: A review of single-pin transmitter attachment techniques on small cetaceans and 
development of a new satellite-linked transmitter design. Mar. Mamm. Sci. 30(2): 656-73.

Balmer, B.C., Wells, R.S., Nowacek, S.M., Schwacke, L.H., McLellan, W.A., Scharf, S.F., Rowles, T.K., Hansen, L.J., Spradlin, T.R. and Pabst, D.A. 2008. Seasonal abundance and distribution patterns of common bottlenose dolphins (Tursiops truncatus) near St. Joseph Bay, Florida, USA. J. Cetacean Res. Manage. 10(2): 157-67.

Barber, D.G., Saczuk, E. and Richard, P.R. 2001. Examination of belugahabitat relationships through the use of telemetry and a geographic information system. Arctic 54(3): 305-16.

Baumann-Pickering, S., Simonis, A.E., Oleson, E.M., Baird, R.W., Roch, M.A. and Wiggins, S.M. 2015. False killer whale and short-finned pilot whale acoustic identification. Endanger. Spec. Res. 28(2): 97-108.

Baumgartner, M.F., Hammar, T. and Robbins, J. 2015. Development and assessment of a new dermal attachment for short-term tagging studies of baleen whales. Methods Ecol. Evol. 6(3): 289-97.

Baumgartner, M.F., Lysiak, N.S.J., Carter Esch, H., Zerbini, A.N., Berchok, C.I. and Clapham, P.J. 2013. Associations between North Pacific right whales and their zooplanktonic prey in the southeastern Bering Sea. Mar Ecol. Prog. Ser. 490: 267-84

Baumgartner, M.F. and Mate, B.R. 2003. Summertime foraging ecology of North Atlantic right whales. Mar. Ecol. Prog. Ser. 264: 123-35.

Baumgartner, M.F. and Mate, B.R. 2005. Summer and fall habitat of North Atlantic right whales (Eubalaena glacialis) inferred from satellite telemetry. Can. J. Fish. Aquat. Sci. 62(3): 527-43.

Baumgartner, M.F., Wenzel, F.W., Lysiak, N.S.J. and Patrician, M.R. 2017. North Atlantic right whale foraging ecology and its role in human-caused mortality. Mar. Ecol. Prog. Ser. 581: 165-81.

Bejder, L., Videsen, S., Hermannsen, L., Simon, M., Hanf, D. and Madsen, P.T. 2019. Low energy expenditure and resting behaviour of humpback whale mother-calf pairs highlights conservation importance of sheltered breeding areas. Sci. Rep. 9(1): 771

Bentaleb, I., Martin, C., Vrac, M., Mate, B., Mayzaud, P., Siret, D., de Stephanis, R. and Guinet, C. 2011. Foraging ecology of Mediterranean fin whales in a changing environment elucidated by satellite tracking and baleen plate stable isotopes. Mar. Ecol. Prog. Ser. 438: 285-302.

Best, P.B. and Mate, B. 2007. Sighting history and observations of southern right whales following satellite tagging off South Africa. J. Cetacean Res. Manage. 9(2): 111-14.

Best, P.B., Mate, B. and Lagerquist, B. 2015. Tag retention, wound healing, and subsequent reproductive history of southern right whales following satellite-tagging. Mar. Mamm. Sci. 31(2): 520-39.

Blackwell, S.B., Tervo, O.M., Conrad, A.S., Sinding, M.H.S., Hansen, R.G., Ditlevsen, S. and Heide-Jørgensen, M.P. 2018. Spatial and temporal patterns of sound production in East Greenland narwhals. PLoS One 13(6): e0198295

Blair, H.B. 2015. Impacts of ship noise on the nighttime foraging behaviors of the North Atlantic humpback whale (Megaptera novaeangliae) Syracuse University, New York, USA. 53pp

Blair, H.B., Merchant, N.D., Friedlaender, A.S., Wiley, D.N. and Parks, S.E 2016. Evidence for ship noise impacts on humpback whale foraging behaviour. Biol. Lett. 12: 20160005.

Blix, A.S. and Folkow, A.P. 1995. Daily energy expenditure in free living minke whales. Acta Physiol. Scand. 153(1): 61-66.

Bloch, D., Heide-Jorgensen, M.P., Stefansson, E., Mikkelsen, B., Ofstad, L.H., Dietz, R. and Andersen, L.W. 2003. Short-term movements of longfinned pilot whales Globicephala melas around the Faroe Islands. Wildl. Biol. 9(1): 47-58.

Block, B.A., Costa, D.P., Boehlert, G.W. and Kochevar, R.E. 2003 Revealing pelagic habitat use: the tagging of Pacific pelagics program. AcOC 25: 255-66.

Blomqvist, C. 2004. Directional aggressive pulse sounds in the bottlenose dolphin (Tursiops truncatus): technical aspects and social implications. $\mathrm{PhD}$ thesis, Linköping University. 28pp

Blomqvist, C. and Amundin, M. 2004. An acoustic tag for recording directional pulsed ultrasounds aimed at free-swimming bottlenose dolphins (Tursiops truncatus) by conspecifics. Aquat. Mamm. 30(3): 34556.

Bograd, S.J., Block, B.A., Costa, D.P. and Godley, B.J. 2010. Biologging technologies: new tools for conservation. Introduction. Endanger. Spec. Res. 10: 1-7.

Bowers, M.T., Friedlaender, A.S., Janik, V.M., Nowacek, D.P., Quick, N.J., Southall, B.L. and Read, A.J. 2018. Selective reactions to different killer whale call categories in two delphinid species. J. Exp. Biol. 221(11): jeb162479.

Boyd, I.L. 2012. Technology requirements to investigate the effects of sound on marine wildlife. Underwat. Technol. 30(3): 123-33.

Breed, G.A., Matthews, C.J.D., Marcoux, M., Higdon, J.W., LeBlanc, B., Petersen, S.D., Orr, J., Reinhart, N.R and Ferguson, S.H. 2017. Sustained disruption of narwhal habitat use and behavior in the presence of Arctic killer whales. Proc. Natl Acad. Sci. 114(10): 2628-33.
Buffrénil, V.D., Dziedzic, A. and Robineau, D. 1989. Répartition et déplacements des Dauphins de Commerson (Cephalorhynchus commersonii (Lacépède, 1804)) dans un golfe des îles Kerguelen; données du marquage individuel. Can. J. Zool. 67(2): 516-21. [In French].

Burgess, W.C. 2010. Development of a wideband acoustic recording tag to assess the acoustic behaviour of marine wildlife. Final Report prepared for the Office of Naval Research, GS011A-1001. 33pp.

Burrows, J.A., Johnston, D.W., Straley, J.M., Chenoweth, E.M., Ware, C., Curtice, C., DeRuiter, S.L. and Friedlaender, A.S. 2016. Prey density and depth affect the fine-scale foraging behavior of humpback whales Megaptera novaeangliae in Sitka Sound, Alaska, USA. Mar. Ecol. Prog. Ser. 561: 245-60.

Cade, D.E., Barr, K.R., Calambokidis, J., Friedlaender, A.S. and Goldbogen, J.A. 2018. Determining forward speed from accelerometer jiggle in aquatic environments. J. Exp. Biol. 221(2): jeb170449.

Cade, D.E., Friedlaender, A.S., Calambokidis, J. and Goldbogen, J.A. 2016 Kinematic diversity in rorqual whale feeding mechanisms. Curr. Biol. 26(19): 2617-24

Calambokidis, J. 2011. Examination of health effects and long-term impacts of deployments of multiple tag types on blue, humpback, and gray whales in the Eastern North Pacific. Report to the Office of Naval Research, N000141010902. 12pp.

Calambokidis, J., Schorr, G.S., Steiger, G.H., Francis, J., Bakhtiari, M., Marshall, G., Oleson, E.M., Gendron, D. and Robertson, K. 2007. Insights into the Underwater Diving, Feeding, and Calling Behavior of Blue Whales from a Suction-Cup-Attached Video-Imaging Tag (Crittercam). Mar. Technol. Soc. J. 41(4): 19-29.

Canning, C., Crain, D., Eaton Jr., T.S., Nuessly, K., Friedlaender, A., Hurst, T., Parks, S., Ware, C. and Weinrich, M. 2011. Population-level lateralized feeding behavior in North Atlantic humpback whales (Megaptera novaeangliae). Anim. Behav. 82: 901-09.

Casper, R.M. 2009. Guidelines for the instrumentation of wild birds and mammals. Anim. Behav. 78(6): 1477-83.

Cerchio, S., Trudelle, L., Zerbini, A.N., Charrassin, J., Geyer, Y., Mayer, F.X., Andrianarivelo, N., Jung, J., Adam, O. and Rosenbaum, H.C. 2016. Satellite telemetry of humpback whales off Madagascar reveals insights on breeding behavior and long-range movements within the southwest Indian Ocean. Mar. Ecol. Prog. Ser. 562: 193-209.

Chambault, P., Albertsen, C.M., Patterson, T.A., Hansen, R.G., Tervo, O., Laidre, K.L. and Heide-Jørgensen, M.P. 2018. Sea surface temperature predicts the movements of an Arctic cetacean: the bowhead whale. Sci Rep. 8(1): 9658.

Chen, J., Pack, A.A., Au, W.W.L. and Stimpert, A.K. 2016. Measurements of humpback whale song sound levels received by a calf in association with a singer. J. Acoust. Soc. Am. 140(5): 4010-15.

Childerhouse, S., Double, M.C. and Gales, N. 2010. Satellite tracking of southern right whales (Eubalaena australis) at the Auckland Islands, New Zealand. Paper SC/62/BRG19 presented to the IWC Scientific Committee, Agadir, Morocco (unpublished). 5pp. [Paper available from the Office of this Journal].

Chilvers, B.L., Corkeron, P.J., Blanshard, W.H., Long, T.R. and Martin, A.R. 2001. A new VHF tag and attachment technique for small cetaceans. Aquat. Mamm. 27: 11-15.

Chivers, S.J. and Scott, M.D. 2002. Tagging and tracking of Stenella spp during the 2001 chase encirclement stress studies cruise. Rep. No. LJ02-033, SWFSC, NOAA, La Jolla, CA, USA, 23pp.

Christman, C.L., Citta, J.J., Quakenbush, L.T., Clarke, J.T., Rone, B.K., Shea, R.A., Ferguson, M.C. and Heide-Jørgensen, M.P. 2013. Presence and behavior of bowhead whales (Balaena mysticetus) in the Alaskan Beaufort Sea in July 2011. Polar Biol. 36(12): 1851-56.

Citta, J.J., Burns, J.J., Quakenbush, L.T., Vanek, V., George, J.C., Small, R.J., Heide-Jørgensen, M.P. and Brower, H. 2014. Potential for bowhead whale entanglement in cod and crab pot gear in the Bering Sea. Mar Mamm. Sci. 30(2): 445-59.

Citta, J.J., Lowry, L.F., Quakenbush, L.T., Kelly, B.P., Fischbach, A.S., London, J.M., Jay, C.V., Frost, K.J., Crowe, G.O.C., Crawford, J.A., Boveng, P.L., Cameron, M., Von Duyke, A.L., Nelson, M., Harwood, L.A., Richard, P., Suydam, R., Heide-Jørgensen, M.P., Hobbs, R.C., Litovka, D.I., Marcoux, M., Whiting, A., Kennedy, A.S., George, J.C., Orr, J. and Gray, T. 2018a. A multi-species synthesis of satellite telemetry data in the Pacific Arctic (1987-2015): Overlap of marine mammal distributions and core use areas. DSR 152: 132-53.

Citta, J.J., O'Corry-Crowe, G., Quakenbush, L.T., Bryan, A.L., Ferrer, T., Olson, M.J., Hobbs, R.C. and Potgieter, B. 2018b. Assessing the abundance of Bristol Bay belugas with genetic mark-recapture methods. Mar. Mamm. Sci. 34(3): 666-86.

Citta, J.J., Okkonen, S.R., Quakenbush, L.T., Maslowski, W., Osinski, R., George, J.C., Small, R.J., Brower, H., Heide-Jørgensen, M.P. and Harwood, L.A. 2018c. Oceanographic characteristics associated with autumn movements of bowhead whales in the Chukchi Sea. DSR 152 121-31. 
Citta, J.J., Quakenbush, L.T., George, J.C., Small, R.J., Heide-Jørgensen, M.P., Brower, H., Adams, B. and Brower, L. 2012. Winter movements of bowhead whales (Balaena mysticetus) in the Bering Sea. Arctic 65(1): $13-34$

Citta, J.J., Quakenbush, L.T., Okkonen, S.R., Druckenmiller, M.L., Maslowski, W., Clement-Kinney, J., George, J.C., Brower, H., Small, R.J., Ashjian, C.J., Harwood, L.A. and Heide-Jørgensen, M.P. 2015. Ecological characteristics of core-use areas used by Bering-ChukchiBeaufort (BCB) bowhead whales, 2006-2012. Prog. Oceanogr. 136: 201-22.

Citta, J.J., Richard, P., Lowry, L.F., O’Corry-Crowe, G., Marcoux, M., Suydam, R., Quakenbush, L.T., Hobbs, R.C., Litovka, D.I., Frost, K.J., Gray, T., Orr, J., Tinker, B., Aderman, H. and Druckenmiller, M.L. 2017. Satellite telemetry reveals population specific winter ranges of beluga whales in the Bering Sea. Mar. Mamm. Sci. 33(1): 236-50.

Citta, J.J., Suydam, R.S., Quakenbush, L.T., Frost, K.J. and O'Corry-Crowe, G.M. 2013. Dive behavior of eastern Chukchi beluga whales (Delphinapterus leucas), 1998-2008. Arctic 66(4): 389-406.

Clausen, K.T., Wahlberg, M., Beedholm, K., DeRuiter, S. and Madsen, R.T. 2011. Click communication in harbour porpoises Phocoena phocoena. Bioacoustics 20(1): 1-28.

Constantine, R., Iwata, T., Nieukirk, S.L. and Penry, G.S. 2018. Future directions in research on Bryde's whales. Front. Mar. Sci. 5: 333.

Constantine, R., Johnson, M., Riekkola, L., Jervis, S., Kozmian-Ledward, L., Dennis, T., Torres, L.G. and de Soto, N.A. 2015. Mitigation of vesselstrike mortality of endangered Bryde's whales in the Hauraki Gulf, New Zealand. Biol. Conserv. 186: 149-57.

Corkeron, P.J. and Martin, A.R. 2004. Ranging and diving behaviour of two 'offshore' bottlenose dolphins, Tursiops sp., off eastern Australia. J. Mar Biol. Assoc. U.K. 84(02): 465-68.

Cotte, C., d'Ovidio, F., Chaigneau, A., Lèvy, M., Taupier-Letage, I., Mate, B. and Guinet, C. 2011. Scale-dependent interactions of Mediterranean whales with marine dynamics. Limnol. Oceanogr. 56(1): 219-32.

Cotté, C., Guinet, C., Taupier-Letage, I., Mate, B. and Petiau, E. 2009. Scale-dependent habitat use by a large free-ranging predator, the Mediterranean fin whale. Deep Sea Res. Pt I Oceanogr. Res. Pap. 56(5): 801-11.

Crain, D.D., Friedlaender, A.S., Johnston, D.W., Nowacek, D.P., Roberts, B.L., Urain, K.W., Waples, D.M. and Read, A.J. 2014. A quantitative analysis of the response of short-finned pilot whales, Globicephald macrorhynchus, to biopsy sampling. Mar. Mamm. Sci. 30(2): 819-26.

Croll, D.A., Acevedo-Gutiérrez, A., Tershy, B.R. and Urbán-Ramírez, J. 2001a. The diving behavior of blue and fin whales: is dive duration shorter than expected based on oxygen stores? Comp. Biochem. Phys. A. Mol. Integr. Physiol. 129(4): 797-809.

Croll, D.A., Clark, C.W., Calambokidis, J., Ellison, W.T. and Tershy, B.R. 2001b. Effect of anthropogenic low-frequency noise on the foraging ecology of Balaenoptera whales. Anim. Conserv. 4(01): 13-27.

Croll, D.A., Marinovic, B., Benson, S., Chavez, F.P., Black, N., Ternullo, R. and Tershy, B.R. 2005. From wind to whales: trophic links in a coastal upwelling system. Mar. Ecol. Prog. Ser. 289: 117-30.

Croll, D.A., Tershy, B.R., Hewitt, R.P., Demer, D.A., Fiedler, P.C., Smith S.E., Armstrong, W., Popp, J.M., Kiekhefer, T., Lopez, V.R., Urban, J. and Gendron, D. 1998. An integrated approach to the foraging ecology of marine birds and mammals. DSR 45(7): 1353-71.

Curé, C., Antunes, R., Alves, A.C., Visser, F., Kvadsheim, P.H. and Miller, P.J.O. 2013. Responses of male sperm whales (Physeter macrocephalus) to killer whale sounds: implications for anti-predator strategies. Sci. Rep. 3(1579): 1-7.

Curé, C., Antunes, R., Samarra, F., Catarina Alves, A., Visser, F., Kvadsheim, P.H. and Miller, P.J.O. 2012. Pilot whales attracted to killer whale sounds: acoustically-mediated interspecific interactions in cetaceans. PLoS One 7(12): e52201.

Curé, C., Doksæter Sivle, L., Visser, F., Wensveen, P.J., Isojunno, S., Harris, C., Kvadsheim, P.H., Lam, F.P.A. and Miller, P.J.O. 2015. Predator sound playbacks reveal strong avoidance responses in a fight strategist baleen whale. Mar. Ecol. Prog. Ser. 526: 267-82.

Cure, C., Isojunno, S., Visser, F., Wensveen, P.J., Sivle, L.D., Kvadsheim, P.H., Lam, F.A. and Miller, P.J.O. 2016. Biological significance of sperm whale responses to sonar: comparison with anti-predator responses. Endanger. Spec. Res. 31: 89-102.

Curtice, C., Johnson, D.W., Ducklow, H., Gales, N., Halpin, P.N. and Friedlaender, A.S. 2015. Modeling the spatial and temporal dynamics of foraging movements of humpback whales (Megaptera novaeangliae) in the Western Antarctic Peninsula. Mov. Ecol. 3(1): 13.

Dalla Rosa, L., Secchi, E.R., Maia, Y.G., Zerbini, A.N. and Heide-Jørgensen, M.P. 2008. Movements of satellite-monitored humpback whales on their feeding ground along the Antarctic Peninsula. Polar Biol. 31(7): $771-81$

Dalstrom, D.J., Venkatarayappa, I., Manternach, A.L., Palcic, M.S., Heyse, B.A. and Prayson, M.J. 2008. Time-dependent contamination of opened sterile operating-room trays. J. Bone Jt. Surg.-American Volume 90(5): 1022-25.

Davis, R.W., David, J.H.M., Meÿer, M.A., Sekiguchi, K., Best, P.B., Dassis, M. and Rodríguez, D.H. 2014. Home range and diving behaviour of Heaviside's dolphins monitored by satellite off the west coast of South Africa. Afr. J. Mar. Sci. 36(4): 455-66.

Davis, R.W., Jaquet, N., Gendron, D., Markaida, U., Bazzino, G. and Gilly, W. 2007. Diving behavior of sperm whales in relation to behavior of a major prey species, the jumbo squid, in the Gulf of California, Mexico. Mar. Ecol. Prog. Ser. 333: 291-302.

Davis, R.W. and Williams, T.M. 2012. The marine mammal dive response is exercise modulated to maximize aerobic dive duration. J. Comp. Physiol. A 198: 583-91.

Davis, R.W., Worthy, G.A.J., Wursig, B., Lynn, S.K. and Townsend, F.I. 1996. Diving behavior and at-sea movements of an Atlantic spotted dolphin in the Gulf of Mexico. Mar. Mamm. Sci. 12(4): 569-81.

de Castro, F.R., Mamede, N., Danilewicz, D., Geyer, Y., Pizzorno, J.L.A., Zerbini, A.N. and Andriolo, A. 2014. Are marine protected areas and priority areas for conservation representative of humpback whale breeding habitats in the western South Atlantic? Biol. Conserv. 179: 10614.

DeRuiter, S.L., Bahr, A., Blanchet, M.A., Hansen, S.F., Kristensen, J.H., Madsen, P.T., Tyack, P.L. and Wahlberg, M. 2009. Acoustic behaviour of echolocating porpoises during prey capture. J. Exp. Biol. 212(19): 3100 07.

DeRuiter, S.L., Boyd, I.L., Claridge, D.E., Clark, C.W., Gagnon, C., Southall, B.L. and Tyack, P.L. 2013a. Delphinid whistle production and call matching during playback of simulated military sonar. Mar. Mamm. Sci. 29(2): E46-E59.

DeRuiter, S.L. and Harris, C.M. 2014. Measuring whale and dolphin call rates as a function of behavioral, social, and environmental context. $J$. Acoust. Soc. Am. 136: 2247

DeRuiter, S.L., Langrock, R., Skirbutas, T., Goldbogen, J.A., Calambokidis, J., Friedlaender, A.S. and Southall, B.L. 2017. A multivariate mixed hidden Markov model for blue whale behaviour and responses to sound exposure. Ann. Appl. Stat. 11(1): 362-92.

DeRuiter, S.L., Southall, B.L., Calambokidis, J., Zimmer, W.M.X., Sadykova, D., Falcone, E.A., Friedlaender, A.S., Joseph, J.E., Moretti, D., Schorr, G.S., Thomas, L. and Tyack, P.L. 2013b. First direct measurements of behavioural responses by Cuvier's beaked whales to mid-frequency active sonar. Biol. Lett. 9(4): 20130223.

DeRuiter, S.L., Tyack, P.L., Lin, Y., Newhall, A.E., Lynch, J.F. and Miller, P.J.O. 2006. Modeling acoustic propagation of airgun array pulses recorded on tagged sperm whales (Physeter macrocephalus). J. Acoust. Soc. Am. 120(6): 4100-14.

Derville, S., Torres, L.G., Iovan, C. and Garrigue, C. 2018. Finding the right fit: Comparative cetacean distribution models using multiple data sources and statistical approaches. Divers. Distrib. 24(11): 1657-73.

Dietz, R. and Heide-Jørgensen, M.P. 1995. Movements and swimming speed of narwhals, Monodon monoceros, equipped with satellite transmitters in Melville Bay, northwest Greenland. Can. J. Zool. 73(11): 2106-19.

Dietz, R., Heide-Jørgensen, M.P., Richard, P., Orr, J., Laidre, K. and Schmidt, H.C. 2008. Movements of narwhals (Monodon monoceros) from Admiralty Inlet monitored by satellite telemetry. Polar Biol. 31(11): 1295-306.

Dietz, R., Heide-Jørgensen, M.P., Richard, P.R. and Acquarone, M. 2001. Summer and fall movements of narwhals (Monodon monoceros) from northeastern Baffin Island towards northern Davis Strait. Arctic 54(3): 244-61.

Dietz, R., Shapiro, A.D., Bakhtiari, M., Orr, J., Tyack, P.L., Richard, P., Eskesen, I. and Marshall, G. 2007. Upside-down swimming behaviour of free-ranging narwhals. BMC Ecol. 7(1): 14.

DiMarzio, N., Moretti, D., Ward, J., Morrissey, R., Jarvis, S., Izzi, A.M., Johnson, M., Tyack, P. and Hansen, A. 2008. Passive acoustic measurement of dive vocal behavior and group size of Blainville's beaked whale (Mesoplodon densirostris) in the tongue of the ocean (TOTO). Can. Acoustics 36(1): 166-72.

Doniol-Valcroze, T., Lesage, V., Giard, J. and Michaud, R. 2011. Optimal foraging theory predicts diving and feeding strategies of the largest marine predator. Behav. Ecol. 22(4): 880-88.

Doniol-Valcroze, T., Lesage, V., Giard, J. and Michaud, R. 2012. Challenges in marine mammal habitat modelling: evidence of multiple foraging habitats from the identification of feeding events in blue whales. Endanger. Spec. Res. 17(3): 255-68.

Double, M.C., Andrews-Goff, V., Jenner, K.C.S., Jenner, M., Laverick, S.M., Branch, T.A. and Gales, N.J. 2014. Migratory movements of pygmy blue whales (Balaenoptera musculus brevicauda) between Australia and Indonesia as revealed by satellite telemetry. PLoS One 9(4): e93578.

Druckenmiller, M.L., Citta, J.J., Ferguson, M.C., Clarke, J.T., George, J.C. and Quakenbush, L. 2018. Trends in sea-ice cover within bowhead whale habitats in the Pacific Arctic. DSR 152: 95-107. 
Dulau, V., Pinet, P., Geyer, Y., Fayan, J., Mongin, P., Cottarel, G., Zerbini, A. and Cerchio, S. 2016. Continuous movement behavior of humpback whales during the breeding season in the southwest Indian Ocean: on the road again! Mov. Ecol. 5: 11.

Dunlop, R.A., Noad, M.J., Cato, D.H., Kniest, E., Miller, P.J.O., Smith, J.N and Stokes, M.D. 2013. Multivariate analysis of behavioural response experiments in humpback whales (Megaptera novaeangliae). J. Exp. Biol. 216(5): 759-70.

Dunn, C., Hickmott, L., Talbot, D., Boyd, I. and Rendell, L. 2013. Midfrequency broadband sounds of Blainville's beaked whales. Bioacoustics 22(2): 153-63

Dunn, C.A., Tyack, P., Miller, P. and Rendell, L. 2017. Short first click intervals in echolocation trains of three species of deep diving odontocetes. J. Acoust. Soc. Am. 141: 900

Durban, J.W. and Pitman, R.L. 2012. Antarctic killer whales make rapid, round-trip movements to subtropical waters: evidence for physiological maintenance migrations? Biol. Lett. 8(2): 274-77.

Durden, W.N., O'Corry-Crowe, G., Shippee, S., Jablonski, T., Rodgers, S., Mazzoil, M., Howells, E., Hartel, E., Potgieter, B., Londono, C., Moreland, L., Townsend, F., McCulloch, S. and Bossart, G. 2019. SmallScale Movement Patterns, Activity Budgets, and Association Patterns of Radio-Tagged Indian River Lagoon Bottlenose Dolphins (Tursiops truncatus). Aquat. Mamm. 45(1): 66-87.

Edrén, S.M.C., Wisz, M.S., Teilmann, J., Dietz, R. and Söderkvist, J. 2010 Modelling spatial patterns in harbour porpoise satellite telemetry data using maximum entropy. Ecography 33(4): 698-708.

Elmegaard, S.L., Johnson, M., Madsen, P.T. and McDonald, B.I. 2016. Cognitive control of heart rate in diving harbor porpoises. Curr. Biol. 26(22): R1175-R76.

Elwen, S., Meÿer, M.A., Best, P.B., Kotze, P.G.H., Thornton, M. and Swanson, S. 2006. Range and movements of female Heaviside's dolphins (Cephalorhynchus heavisidii), as determined by satellite-linked telemetry. J. Mammal. 87(5): 866-77.

Eskesen, I.G., Teilmann, J., Geertsen, B.M., Desportes, G., Riget, F., Dietz, R., Larsen, F. and Siebert, U. 2009. Stress level in wild harbour porpoises (Phocoena phocoena) during satellite tagging measured by respiration, heart rate and cortisol. J. Mar. Biol. Assoc. U.K. 89(05): 885.

Etnoyer, P., Canny, D., Mate, B.R., Morgan, L.E., Ortega-Ortiz, J.G. and Nichols, W.J. 2006. Sea-surface temperature gradients across blue whale and sea turtle foraging trajectories off the Baja California Peninsula, Mexico. DSR 53(3-4): 340-58.

Evans, W.E. 1971. Orientation behavior of delphinids: radio telemetric studies. Ann. N. Y. Acad. Sci. 188: 142-60.

Evans, W.E. 1974. Telemetering of temperature and depth data from a free ranging yearling California gray whale, Eschrichtius robustus. Mar. Fish Rev. 36(4): 52-58.

Evans, W.E., Hall, J.D., Irvine, A.B. and Leatherwood, J.S. 1972. Methods for tagging small cetaceans. Fish. Bull. 70(1): 61-65.

Ezer, T., Ashford, J.R., Jones, C.M., Mahoney, B.A. and Hobbs, R.C. 2013 Physical-biological interactions in a subarctic estuary: How do environmental and physical factors impact the movement and survival of beluga whales in Cook Inlet, Alaska? JMS 111-112: 120-29.

Ezer, T., Hobbs, R. and Oey, L. 2008. On the movement of beluga whales in Cook Inlet, Alaska. Oceanography 21(4): 186.

Fagan, W.F. 2019. Migrating whales depend on memory to exploit reliable resources. Proc. Natl Acad. Sci. 116(12): 5217-19.

Fais, A., Aguilar Soto, N., Johnson, M., Pérez-González, C., Miller, P.J.O and Madsen, P.T. 2015. Sperm whale echolocation behaviour reveals a directed, prior-based search strategy informed by prey distribution. Behav. Ecol. Sociobiol. 69(4): 663-374.

Fais, A., Johnson, M., Wilson, M., Aguilar Soto, N. and Madsen, P.T. 2016a Sperm whale predator-prey interactions involve chasing and buzzing, but no acoustic stunning. Sci. Rep. 6: 28562.

Fais, A., Lewis, T.P., Zitterbart, D.P., Álvarez, O., Tejedor, A. and Aguilar Soto, N. 2016b. Abundance and distribution of sperm whales in the canary islands: Can sperm whales in the archipelago sustain the current level of ship-strike mortalities? PLoS One 11(3): e0150660.

Falcone, E.A., Schorr, G.S., Watwood, S.L., DeRuiter, S.L., Zerbini, A.N., Andrews, R.D., Morrissey, R.P. and Moretti, D.J. 2017. Diving behaviour of Cuvier's beaked whales exposed to two types of military sonar. R. Soc. Open Sci. 4(8): 170629.

FDA. 2015. FDA-cleared sterilants and high level disinfectants with general claims for processing reusable medical and dental devices - March 2015. [Available at: www.fda.gov/MedicalDevices/DeviceRegulationand Guidance/ReprocessingofReusableMedicalDevices/ucm437347.htm].

Félix, F. and Guzmán, H.M. 2014. Satellite tracking and sighting data analyses of southeast Pacific humpback whales (Megaptera novaeangliae): is the migratory route coastal or oceanic? Aquat. Mamm. 40(4): 329-40.

Ferguson, S.H., Dueck, L., Loseto, L.1. and Luque, S.P. 2010. Bowhead whale Balaena mysticetus seasonal selection of sea ice. Mar. Ecol. Prog. Ser. 411: 285-97.
Fiore, G., Anderson, E., Garborg, C.S., Murray, M., Johnson, M., Moore, M.J., Howle, L. and Shorter, K.A. 2017. From the track to the ocean Using flow control to improve marine bio-logging tags for cetaceans. PLoS One 12(2): e0170962.

Ford, J.K.B., Durban, J.W., Ellis, G.M., Towers, J.R., Pilkington, J.F., Barrett-Lennard, L.G. and Andrews, R.D. 2013. New insights into the northward migration route of gray whales between Vancouver Island, British Columbia, and southeastern Alaska. Mar. Mamm. Sci. 29(2): 325 37.

Fossette, S., Heide-Jørgensen, M.P., Jensen, M.V., Kiszka, J., Bérubé, M., Bertrand, N. and Vély, M. 2014. Humpback whale (Megaptera novaeangliae) post breeding dispersal and southward migration in the western Indian Ocean. J. Exp. Mar. Biol. Ecol. 450: 6-14.

Franklin, W., Franklin, T., Andrews-Goff, V., Paton, D.A. and Double, M. 2017. Movement of two humpback whales (Megaptera novaeangliae) satellite-radio tagged off Eden, NSW and matched by photo-identification with the Hervey Bay catalogue. J. Cetacean Res. Manage. 17: 29-33.

Friedlaender, A.S., Goldbogen, J.A., Hazen, E.L., Calambokidis, J. and Southall, B.L. 2015. Feeding performance by sympatric blue and fin whales exploiting a common prey resource. Mar. Mamm. Sci. 31(1): 345 54.

Friedlaender, A.S., Goldbogen, J.A., Nowacek, D.P., Read, A.J., Johnson, D. and Gales, N. 2014. Feeding rates and under-ice foraging strategies of the smallest lunge filter feeder, the Antarctic minke whale (Balaenoptera bonaerensis). J. Exp. Biol. 217(16): 2851-54.

Friedlaender, A.S., Hazen, E.L., Goldbogen, J.A., Stimpert, A.K., Calambokidis, J. and Southall, B.L. 2016a. Prey-mediated behavioral responses of feeding blue whales in controlled sound exposure experiments. Ecol. Appl. 26(4): 1075-85.

Friedlaender, A.S., Hazen, E.L., Nowacek, D.P., Halpin, P.N., Ware, C., Weinrich, M.T., Hurst, T. and Wiley, D. 2009. Diel changes in humpback whale Megaptera novaeangliae feeding behavior in response to sand lance Ammodytes spp. behavior and distribution. Mar. Ecol. Prog. Ser. 395: $91-100$

Friedlaender, A.S., Herbert-Read, J., Hazen, E.L., Cade, D.E., Calambokidis, J., Southall, B.L., Stimpert, A.K. and Goldbogen, J.A. 2017. Context-dependent lateralized feeding strategies in blue whales. Curr. Biol. 27: R1193-R213.

Friedlaender, A.S., Johnston, D.W., Tyson, R.B., Kaltenberg, A., Goldbogen, J.A., Stimpert, A.K., Curtice, C., Hazen, E.L., Halpin, P.N., Read, A.J. and Nowacek, D.P. 2016b. Multiple-stage decisions in a marine centralplace forager. R. Soc. Open Sci. 3(5): 160043

Friedlaender, A.S., Tyson, R.B., Stimpert, A.K., Read, A.J. and Nowacek, D.P. 2013. Extreme diel variation in the feeding behavior of humpback whales along the western Antarctic Peninsula during autumn. Mar. Ecol. Prog. Ser. 494: 281-89.

Frost, K.J., Lowry, L.F. and Nelson, R.R. 1985. Radiotagging studies of belukha whales (Delphinapterus leucas) in Bristol Bay, Alaska. Mar Mamm. Sci. 1(3): 191-202.

Gales, N., Bowers, M., Durban, J.W., Friedlaender, A.S., Nowacek, D.P. Pitman, R.L., Read, A.J. and Tyson, R.B. 2013. Advances in non-lethal research on Antarctic minke whales: biotelemetry, photo-identification and biopsy sampling. Paper SC/65a/IA12 presented to the IWC Scientific Committee, June 2013, Jeju Island, Republic of Korea (unpublished) $15 \mathrm{pp}$. [Paper available from the Office of this Journal].

Gales, N., Double, M.C., Robinson, S., Jenner, C., Jenner, M., King, E., Gedamke, J., Childerhouse, S. and Paton, D. 2010. Satellite tracking of Australian humpback (Megaptera novaeangliae) and pygmy blue whales (Balaenoptera musculus brevicauda). Paper SC/62/SH21 presented to the IWC Scientific Committee, June 2010, Agadir, Morocco (unpublished). 9pp. [Paper available from the Office of this Journal].

Gales, N., Double, M.C., Robinson, S., Jenner, C., Jenner, M., King, E., Gedamke, J., Paton, D. and Raymond, B. 2009. Satellite tracking of southbound East Australian humpback whales (Megaptera novaeangliae) challenging the feast or famine model for migrating whales. Paper SC/61/SH17 presented to the IWC Scientific Committee, June 2009 , Madeira, Portugal (unpublished). 11pp. [Paper available from the Office of this Journal].

Gales, N.J., Bowen, W.D., Johnston, D.W., Kovacs, K.M., Littnan, C.L., Perrin, W.F., Reynolds, J.E. and Thompson, P.M. 2009b. Guidelines for the treatment of marine mammals in field research. Mar. Mamm. Sci. 25(3): $725-36$

Gales, R., Alderman, R., Thalmann, S. and Carlyon, K. 2012. Satellite tracking of long-finned pilot whales (Globicephala melas) following stranding and release in Tasmania, Australia. Wildl. Res. 39(6): 520-31.

Garcia-Rojas, M.I., Jenner, K.C.S., Gill, P.C., Jenner, M.-N.M., Sutton, A.L. and McCauley, R.D. 2018. Environmental evidence for a pygmy blue whale aggregation area in the Subtropical Convergence Zone south of Australia. Mar. Mamm. Sci. 34(4): 901-23.

Garrigue, C., Clapham, P.J., Geyer, Y., Kennedy, A.S. and Zerbini, A.N. 2015. Satellite tracking reveals novel migratory patterns and the 
importance of seamounts for endangered South Pacific humpback whales. R. Soc. Open Sci. 2: 150489.

Garrigue, C., Zerbini, A.N., Geyer, Y., Heide-Jørgensen, M.P., Hanaoka, W. and Clapham, P. 2010. Movements of satellite-monitored humpback whales from New Caledonia. J. Mammal. 91(1): 109-15.

Gaskin, D.E., Smith, G.J.D. and Watson, A.P. 1975. Preliminary study of movements of harbor porpoises (Phocoena phocoena) in the Bay of Fundy using radiotelemetry. Can. J. Zool. 53(10): 1466-71.

Geertsen, B.M., Tielmann, J., Kastelein, R.A., Vlemmix, H.N.J. and Miller, L.A. 2004. Behaviour and physiological effects of transmitter attachments on a captive harbour porpoise (Phocoena phocoena). J. Cetacean Res. Manage. 6(2): 139-46.

Gendron, D., Serrano, I.M., Cruz, A.U., Calambokidis, J. and Mate, B. 2015. Long-term individual sighting history database: an effective tool to monitor satellite tag effects on cetaceans. Endanger. Spec. Res. 26(3): 235-41.

Geraci, J.R. and Smith, G.J.D. 1990. Cutaneous response to implants, tags, and marks in beluga whales, Delphinapterus leucas, and bottlenose dolphins, Tursiops truncatus. Can. Bull. Fish. Aquat. Sci. 224: 81-95.

Geraci, J.R., St Aubin, D.J., Smith, G.J.D. and Hicks, B.D. 1985. Cutaneous response to plastic and metallic implants of potential use for marking cetaceans, Washington, DC. Final Report Part II. Report to the US Dept. Interior, MMS, Washington, DC. 120pp.

Godwin, E.M., Noad, M.J., Kniest, E. and Dunlop, R.A. 2016. Comparing multiple sampling platforms for measuring the behavior of humpback whales (Megaptera novaeangliae). Mar. Mamm. Sci. 32(1): 268-86.

Goldbogen, J.A., Cade, D., Calambokidis, J., Stimpert, A. and Friedlaender, A.S. 2016. Insights into the underwater behavior, species interactions, and biomechanics of baleen whales using suction-cup attached video and inertial sensors. FASEB Journal 30(1): Supplement - 90.3.

Goldbogen, J.A., Cade, D.E., Boersma, A.T., Calambokidis, J., KahaneRapport, S.r., Segre, P.S., Stimpert, A.K. and Friedlaender, A.S. 2017a. Using digital tags with integrated video and inertial sensors to study moving morphology and associated function in large aquatic vertebrates. Anat. Rec. 300(11): 1935-41.

Goldbogen, J.A., Cade, D.E., Calambokidis, J., Friedlaender, A.S., Potvin, J., Segre, P.S. and Werth, A.J. 2017b. How baleen whales feed: the biomechanics of engulfment and filtration. Ann. Rev. Mar. Sci. 9(1): 36786.

Goldbogen, J.A., Calambokidis, J., Croll, D.A., Harvey, J.T., Newton, K.M., Oleson, E.M., Schorr, G. and Shadwick, R.E. 2008. Foraging behavior of humpback whales: kinematic and respiratory patterns suggest a high cost for a lunge. J. Exp. Biol. 211(23): 3712-19.

Goldbogen, J.A., Calambokidis, J., Friedlaender, A.S., Francis, J., DeRuiter, S.L., Stimpert, A.K., Falcone, E. and Southall, B.L. 2012. Underwater acrobatics by the world's largest predator: 360 rolling manoeuvres by lunge-feeding blue whales. Biol. Lett. 9(1): 20120986.

Goldbogen, J.A., Calambokidis, J., Oleson, E., Potvin, J., Pyenson, N.D. Schorr, G. and Shadwick, R.E. 2011. Mechanics, hydrodynamics and energetics of blue whale lunge feeding: efficiency dependence on krill density. J. Exp. Biol. 214(4): 698-99.

Goldbogen, J.A., Calambokidis, J., Shadwick, R.E., Oleson, E.M., McDonald, M.A. and Hildebrand, J.A. 2006. Kinematics of foraging dives and lunge-feeding in fin whales. J. Exp. Biol. 209(7): 1231-44.

Goldbogen, J.A., Friedlaender, A.S., Calambokidis, J., McKenna, M.F., Simon, M. and Nowacek, D.P. 2013a. Integrative approaches to the study of baleen whale diving behavior, feeding performance, and foraging ecology. BioScience. 63(2): 90-100.

Goldbogen, J.A., Hazen, E.L., Friedlaender, A.S., Calambokidis, J. DeRuiter, S.L., Stimpert, A.K. and Southall, B.L. 2015. Prey density and distribution drive the three-dimensional foraging strategies of the largest filter feeder. Funct. Ecol. 29: 951-61.

Goldbogen, J.A., Pyenson, N.D. and Shadwick, R.E. 2007. Big gulps require high drag for fin whale lunge feeding. Mar. Ecol. Prog. Ser. 349: 289-301.

Goldbogen, J.A., Southall, B.L., DeRuiter, S.L., Calambokidis, J., Friedlaender, A.S., Hazen, E.L., Falcone, E.A., Schorr, G.S., Douglas, A., Moretti, D.J., Kyburg, C., McKenna, M.F. and Tyack, P.L. 2013 b. Blue whales respond to simulated mid-frequency military sonar. Proc. $R$. Soc. B Biol. Sci. 280(1765): 20130657.

Goldbogen, J.A., Stimpert, A.K., DeRuiter, S.L., Calambokidis, J., Friedlaender, A.S., Schorr, G.S., Moretti, D.J., Tyack, P.L. and Southall, B.L. 2014. Using accelerometers to determine the calling behavior of tagged baleen whales. J. Exp. Biol. 217(14): 2449-55.

Goodyear, J.D. 1989. Night behavior and ecology of humpback whales (Megaptera novaeangliae) in the western North Atlantic. MSc thesis, San Jose State University. 70pp.

Goodyear, J.D. 1993. A sonic/radio tag for monitoring dive depths and underwater movements of whales. J. Wildl. Manag. 57(3): 503-13.

Govindaraj, S. and Muthuraman, M. 2015. Systematic review on sterilization methods of implants and medical devices. J. Chemtech Res. 8(2): 897-911.
Grist, J.P., Josey, S.A., Boehme, L., Meredith, M.P., Davidson, F.J.M., Stenson, G.B. and Hammill, M.O. 2011. Temperature signature of high latitude Atlantic boundary currents revealed by marine mammal-borne sensor and Argo data. GeoRL 38(15): L15601.

Guerra, M., Hickmott, L., van der Hoop, J., Rayment, W., Leunissen, E., Slooten, E. and Moore, M. 2017. Diverse foraging strategies by a marine top predator: Sperm whales exploit pelagic and demersal habitats in the Kaikōura submarine canyon. Deep Sea Res. Pt. I Oceanogr. Res. Pap. 128(Supplement C): 98-108.

Gurarie, E., Fleming, C.H., Fagan, W.F., Laidre, K.L., Hernández-Pliego, J. and Ovaskainen, O. 2017. Correlated velocity models as a fundamental unit of animal movement: synthesis and applications. Mov. Ecol. 5(1): 13.

Guzman, H.M. and Capella, J.J. 2017. Short-term recovery of humpback whales after percutaneous satellite tagging. J. Wildl. Manag. 81(4): 72833.

Guzman, H.M. and Félix, F. 2017. Movements and habitat use by Southeast Pacific humpback whales (Megaptera novaeangliae) satellite tracked at two breeding sites. Aquat. Mamm. 43(2): 139-55.

Guzman, H.M., Gomez, C.G., Guevara, C.A. and Kleivane, L. 2013. Potential vessel collisions with Southern Hemisphere humpback whales wintering off Pacific Panama. Mar. Mamm. Sci. 29(4): 629-42.

Hamilton, P.K., Stone, G.S. and Martin, S.M. 1997. Note on a deep humpback whale Megaptera novaeangliae dive near Bermuda. Bull. Mar. Sci. 61(2): 491-94.

Hammerschlag, N., Cooke, S.J., Gallagher, A.J. and Godley, B.J. 2014. Considering the fate of electronic tags: interactions with stakeholders and user responsibility when encountering tagged aquatic animals. Methods Ecol. Evol. 5(11): 1147-53.

Hanson, M.B. 2001. An evaluation of the relationship between small cetacean tag design and attachment durations: A bioengineering approach. $\mathrm{PhD}$ thesis, University of Washington. 208pp.

Hanson, M.B. and Baird, R.W. 1998. Dall's porpoise reactions to tagging attempts using a remotely-deployed suction-cup tag. Mar. Technol. Soc. J. 32(2): 18-23

Harcourt, R., van der Hoop, J., Kraus, S. and Carroll, E.L. 2019. Future directions in Eubalaena spp.: comparative research to inform conservation. Front. Mar. Sci. 5: 530.

Harrison, A.-L., Costa, D.P., Winship, A.J., Benson, S.R., Bograd, S.J., Antolos, M., Carlisle, A.B., Dewar, H., Dutton, P.H., Jorgensen, S.J., Kohin, S., Mate, B.R., Robinson, P.W., Schaefer, K.M., Shaffer, S.A., Shillinger, G.L., Simmons, S.E., Weng, K.C., Gjerde, K.M. and Block, B.A. 2018. The political biogeography of migratory marine predators. Nat. Ecol. Evol. 2(10): 1571-78.

Harwood, L.A., Quakenbush, L.T., Small, R.J., George, J.C., Pokiak, J., Heide-Jørgensen, M.P., Lea, E.V. and Brower, H. 2017. Movements and inferred foraging by bowhead whales in the Canadian Beaufort Sea during August and September, 2006-12. Arctic 70(2): 161-76.

Hauser, D.D.W., Laidre, K.L., Parker-Stetter, S.L., Horne, J.K., Suydam, R.S. and Richard, P.R. 2015. Regional diving behavior of Pacific Arctic beluga whales Delphinapterus leucas and possible associations with prey. Mar. Ecol. Prog. Ser. 541: 245-64.

Hauser, D.D.W., Laidre, K.L., Stern, H.L., Moore, S.E., Suydam, R.S. and Richard, P.R. 2017a. Habitat selection by two beluga whale populations in the Chukchi and Beaufort seas. PLoS One 12(2): e0172755.

Hauser, D.D.W., Laidre, K.L., Stern, H.L., Suydam, R.S. and Richard, P.R. 2018. Indirect effects of sea ice loss on summer-fall habitat and behaviour for sympatric populations of an Arctic marine predator. Divers. Distrib. 24(6): 791-99.

Hauser, D.D.W., Laidre, K.L., Suydam, R.S. and Richard, P.R. 2014. Population-specific home ranges and migration timing of Pacific Arctic beluga whales (Delphinapterus leucas). Polar Biol. 37(8): 1171-83.

Hauser, D.W., Laidre, K.L., Stafford, K.M., Stern, H.L., Suydam, R.S. and Richard, P.R. 2017b. Decadal shifts in autumn migration timing by Pacific Arctic beluga whales are related to delayed annual sea ice formation. Global Change Biol. 23: 2206-17.

Hauser, N., Zerbini, A.N., Geyer, Y., Heide-Jørgensen, M.P. and Clapham, P. 2009. Movements of satellite-monitored humpback whales, Megaptera novaeangliae, from the Cook Islands. Mar. Mamm. Sci. 26(3): 679-385.

Hays, G.C., Bradshaw, C.J.A., James, M.C., Lovell, P. and Sims, D.W. 2007. Why do Argos satellite tags deployed on marine animals stop transmitting? J. Exp. Mar. Biol. Ecol. 349(1): 52-60.

Hazen, E.L., Friedlaender, A.S. and Goldbogen, J.A. 2015. Blue whales (Balaenoptera musculus) optimize foraging efficiency by balancing oxygen use and energy gain as a function of prey density. Sci. Adv. 1(9): e1500469.

Hazen, E.L., Friedlaender, A.S., Thompson, M.A., Ware, C.R., Weinrich, M.T., Halpin, P.N. and Wiley, D.N. 2009. Fine-scale prey aggregations and foraging ecology of humpback whales (Megaptera novaeangliae). Mar. Ecol. Prog. Ser. 395: 75-89. 
Hazen, E.L., Maxwell, S.M., Bailey, H., Bograd, S.J., Hamann, M., Gaspar, P., Godley, B.J. and Shillinger, G.I. 2012. Ontogeny in marine tagging and tracking science: technologies and data gaps. Mar. Ecol. Prog. Ser 457: 221-40

Hazen, E.L., Palacios, D.M., Forney, K.A., Howell, E.A., Becker, E., Hoover, A.L., Irvine, L., DeAngelis, M., Bograd, S.J., Mate, B.R. and Bailey, H. 2017. WhaleWatch: a dynamic management tool for predicting blue whale density in the California Current. J. Appl. Ecol. 54(5): 141528

Heide-Jørgensen, M., Dietz, R., Laidre, K. and Richard, P. 2002a. Autumn movements, home ranges, and winter density of narwhals (Monodon monoceros) tagged in Tremblay Sound, Baffin Island. Polar Biol. 25(5) $331-41$.

Heide-Jørgensen, M.P., Bloch, D., Stefansson, E., Mikkelsen, B., Ofstad, L.H. and Dietz, R. 2002b. Diving behaviour of long-finned pilot whales Globicephala melas around the Faroe Islands. Wildl. Biol. 8(4): 307-13.

Heide-Jørgensen, M.P. and Dietz, R. 1995. Some characteristics of narwhal, Monodon monoceros, diving behaviour in Baffin Bay. Can. J. Zool. 73(11): 2120-32.

Heide-Jørgensen, M.P., Dietz, R., Laidre, K.L., Nicklen, P., Garde, E., Richard, P. and Orr, J. 2008. Resighting of a narwhal (Monodon monoceros) instrumented with a satellite transmitter. Arctic 61(4): 395 98.

Heide-Jørgensen, M.P., Dietz, R., Laidre, K.L., Richard, P., Orr, J. and Schmidt, H.C. 2003a. The migratory behaviour of narwhals (Monodon monoceros). Can. J. Zool. 81(8): 1298-305.

Heide-Jørgensen, M.P., Hammeken, N., Dietz, R., Orr, J. and Richard, P.R 2001a. Surfacing times and dive rates for narwhals (Monodon monoceros) and belugas (Delphinapterus leucas). Arctic 54(3): 284-98.

Heide-Jørgensen, M.P., Kleivane, L., ØIen, N., Laidre, K.L. and Villum Jensen, M. 2001b. A new technique for deploying satellite transmitters on baleen whales: Tracking a blue whale (Balaenoptera musculus) in the North Atlantic. Mar. Mamm. Sci. 17(4): 949-54.

Heide-Jørgensen, M.P., Laidre, K., Borchers, D., Samarra, F. and Stern, H. 2007. Increasing abundance of bowhead whales in West Greenland. Biol. Lett. 3(5): 577-80.

Heide-Jørgensen, M.P., Laidre, K.L., Jensen, M.V., Dueck, L. and Postma, L.D. 2006. Dissolving stock discreteness with satellite tracking: bowhead whales in Baffin Bay. Mar. Mamm. Sci. 22(1): 34-45.

Heide-Jørgensen, M.P., Laidre, K.L., Litovka, D., Villum Jensen, M., Grebmeier, J.M. and Sirenko, B.I. 2012. Identifying gray whale (Eschrichtius robustus) foraging grounds along the Chukotka Peninsula, Russia, using satellite telemetry. Polar Biol. 35(7): 1035-45.

Heide-Jørgensen, M.P., Laidre, K.L., Nielsen, N.H., Hansen, R.G. and Røstad, A. 2013a. Winter and spring diving behavior of bowhead whales relative to prey. Animal Biotelemetry 1(1): 1-14.

Heide-Jorgensen, M.P., Laidre, K.L., Quakenbush, L.T. and Citta, J.J. 2012. The Northwest Passage opens for bowhead whales. Biol. Lett. 8(2): 27073

Heide-Jørgensen, M.P., Laidre, K.L., Wiig, Ø., Jensen, M.V., Dueck, L., Maiers, L.D., Schmidt, H.C. and Hobbs, R.C. 2003b. From Greenland to Canada in ten days: tracks of bowhead whales, Balaena mysticetus, across Baffin Bay. Arctic 56(1): 21-31.

Heide-Jørgensen, M.P., Nielsen, N.H., Hansen, R.G. and Blackwell, S.B. 2014. Stomach temperature of narwhals (Monodon monoceros) during feeding events. Animal Biotelemetry 2(1): 1-10.

Heide-Jørgensen, M.P., Nielsen, N.H., Hansen, R.G. and Schmidt, H.C. 2015. The predictable narwhal: satellite tracking shows behavioura similarities between isolated subpopulations. J. Zool. 297(1): 54-65.

Heide-Jørgensen, M.P., Nielsen, N.H., Teilmann, J. and Leifsson, P.S. 2017. Long-term tag retention on two species of small cetaceans. Mar. Mamm. Sci. 33(3): 713-25

Heide-Jørgensen, M.P., Nordøy, E.S., Øien, N., Folkow, L.P., Kleivane, L., Blix, A.S., Jensen, M.V. and Laidre, K.L. 2001c. Satellite tracking of minke whales (Balaenoptera acutorostrata) off the coast of northern Norway. J. Cetacean Res. Manage. 3(2): 175-78.

Heide-Jørgensen, M.P., Richard, P., Dietz, R., Laidre, K.L., Orr, J. and Schmidt, H.C. 2003c. An estimate of the fraction of belugas (Delphinapterus leucas) in the Canadian High Arctic that winter in West Greenland. Polar Biol. 26(5): 318-26.

Heide-Jørgensen, M.P., Richard, P.R., Dietz, R. and Laidre, K.L. 2013b. A metapopulation model for Canadian and West Greenland narwhals. Anim. Conserv. 16(3): 331-43.

Heide-Jørgensen, M.P., Richard, P.R. and Rosing-Asvid, A. 1998. Dive patterns of belugas (Delphinapterus lencas) in waters near Eastern Devon Island. Arctic 51(1): 17-26.

Herman, E.Y.K., Herman, L.M., Pack, A.A., Marshall, G., Shepard, M.C. and Bakhtiari, M. 2007. When whales collide: Crittercam offers insight into the competitive behavior of humpback whales on their Hawaiian wintering grounds. Mar. Technol. Soc. J. 41(4): 35-43.
Hobbs, R.C., Laidre, K.L., Vos, D.J., Mahoney, B.A. and Eagleton, M. 2005 Movements and area use of belugas, Delphinapterus lencas, in a subarctic Alaskan estuary. Arctic 58(4): 331-40.

Holt, M.M., Hanson, M.B., Giles, D.A., Emmons, C.K. and Hogan, J.T. 2017. Noise levels received by endangered killer whales Orcinus orca before and after implementation of vessel regulations. Endanger. Spec. Res. 34: 15-26.

Hooker, S.K. and Baird, R.W. 1999. Deep-diving behaviour of the northern bottlenose whale, Hyperoodon ampullatus (Cetacea: Ziphiidae). Proc. $R$ Soc. Lond. B. Biol. Sci. 266(1420): 671-76.

Hooker, S.K. and Baird, R.W. 2001. Diving and ranging behaviour of odontocetes: a methodological review and critique. Mamm. Rev. 31(1) 81-105.

Hooker, S.K., Baird, R.W., Al-Omari, S., Gowans, S. and Whitehead, H. 2001. Behavioral reactions of northern bottlenose whales (Hyperoodon ampullatus) to biopsy darting and tag attachment procedures. Fish. Bull. 99(2): 303-08

Hooker, S.K., Whitehead, H., Gowans, S. and Baird, R.W. 2002. Fluctuations in distribution and patterns of individual range use of northern bottlenose whales. Mar. Ecol. Prog. Ser. 225: 287-97.

Hornsby, F.E., McDonald, T.L., Balmer, B.C., Speakman, T.R., Mullin, K.D., Rosel, P.E., Wells, R.S., Telander, A.C., Marcy, P.W., Klaphake, K.C. and Schwacke, L.H. 2017. Using salinity to identify common bottlenose dolphin habitat in Barataria Bay, Louisiana, USA. Endanger Spec. Res. 33: 181-92

Horton, T.W., Hauser, N., Zerbini, A.N., Francis, M.P., Domeier, M.L., Andriolo, A., Costa, D.P., Robinson, P.W., Duffy, C.A.J., Nasby-Lucas, N., Holdaway, R.N. and Clapham, P.J. 2017. Route fidelity during marine megafauna migration. Front. Mar. Sci. 4: 422

Horton, T.W., Holdaway, R.N., Zerbini, A.N., Hauser, N., Garrigue, C., Andriolo, A. and Clapham, P.J. 2011. Straight as an arrow: humpback whales swim constant course tracks during long-distance migration. Biol. Lett. 7(5): 674-79

Houghton, J., Holt, M.M., Giles, D.A., Hanson, M.B., Emmons, C.K., Hogan, J.T., Branch, T.A. and VanBlaricom, G.R. 2015. The Relationship between Vessel Traffic and Noise Levels Received by Killer Whales (Orcinus orca). PLoS One 10(12): e0140119.

Hucke-Gaete, R., Bedrinana-Romano, L., Viddi, F.A., Ruiz, J.E., TorresFlorez, J.P. and Zerbini, A.N. 2018. From Chilean Patagonia to Galapagos, Ecuador: novel insights on blue whale migratory pathways along the Eastern South Pacific. Peerj 6: e4695.

Hunt, K.E., Moore, M.J., Rolland, R.M., Kellar, N.M., Hall, A.J., Kershaw, J., Raverty, S.A., Davis, C.E., Yeates, L.C., Fauquier, D.A., Rowles, T.K and Kraus, S.D. 2013. Overcoming the challenges of studying conservation physiology in large whales: a review of available methods Conserv. Physiol. 1(1). [Available at: https://dx.doi.org/10.1093/conphys/ cot006].

Irvine, A.B., Scott, M.D., Wells, R.S. and Kaufmann, J.H. 1981. Movements and activities of the Atlantic bottlenose dolphin, Tursiops truncatus, near Sarasota, Florida. Fish. Bull. 79(4): 671-88.

Irvine, A.B., Wells, R.S. and Scott, M.D. 1982. An evaluation of the techniques for tagging small odontocete cetaceans. Fish. Bull. 80(1): 13543.

Irvine, L., Palacios, D.M., Urbán, J. and Mate, B. 2017. Sperm whale dive behavior characteristics derived from intermediate-duration archival tag data. Ecol. Evol. 7(19): 7822-37.

Irvine, L.M., Mate, B.R., Winsor, M.H., Palacios, D.M., Bograd, S.J., Costa, D.P. and Bailey, H. 2014. Spatial and temporal occurrence of blue whales off the U.S. west coast, with implications for management. PLoS One 9(7): e102959.

Ishii, M., Murase, H., Fukuda, Y., Sawada, K., Sasakura, T., Tamura, T., Bando, T., Matsuoka, K., Shinohara, A., Nakatsuka, S., Katsumata, N., Okazaki, M., Miyashita, K. and Mitani, Y. 2017. Diving behavior of se whales Balaenoptera borealis relative to the vertical distribution of their potential prey. Mamm. Study 42(4): 191-99.

Isojunno, S. 2015. Influence of natural factors and anthropogenic stressors on sperm whale foraging effort and success at high latitudes. $\mathrm{PhD}$ thesis, University of St Andrews, UK. 256pp.

Isojunno, S., Cure, C., Kvadsheim, P.H., Lam, F.A., Tyack, P.L., Wensveen, P.J. and Miller, P.J.O. 2016. Sperm whales reduce foraging effort during exposure to 1-2 kHz sonar and killer whale sounds. Ecol. Appl. 26(1): $77-93$

Isojunno, S. and Miller, P.J.O. 2015. Sperm whale response to tag boat presence: biologically informed hidden state models quantify lost feeding opportunities. Ecosphere 6(1): 1-46.

Isojunno, S. and Miller, P.J.O. 2016. Hidden Markov models capture behavioral responses to suction-cup tag deployment: A functional state approach to behavioral context. pp.489-96. The Effects of Noise on Aquatic Life II, Advances in Experimental Medicine and Biology 875. Springer, New York, USA. 
Isojunno, S. and Miller, P.J.O. 2018. Movement and biosonar behavior during prey encounters indicate that male sperm whales switch foraging strategy with depth. Front. Ecol. Evol. 6: 200.

Isojunno, S., Sadykova, D., DeRuiter, S., Curé, C., Visser, F., Thomas, L., Miller, P.J.O. and Harris, C.M. 2017. Individual, ecological, and anthropogenic influences on activity budgets of long-finned pilot whales. Ecosphere 8(12): e02044.

Izadi, S., Johnson, M., Soto, N.A.d. and Constantine, R. 2018. Night-life of Bryde's whales: ecological implications of resting in a baleen whale. Behav. Ecol. Sociobiol. 72(5): 78.

Jeanniard-du-Dot, T., Holland, K., Schorr, G.S. and Vo, D. 2017. Motes enhance data recovery from satellite-relayed biologgers and can facilitate collaborative research into marine habitat utilization. Animal Biotelemetry 5(1): 17

Jensen, F.H., Bejder, L., Wahlberg, M., Soto, N.A., Johnson, M. and Madsen, P.T. 2009. Vessel noise effects on delphinid communication. Mar. Ecol. Prog. Ser. 395: 161-75.

Jensen, F.H., Perez, J.M., Johnson, M., Soto, N.A. and Madsen, P.T. 2011. Calling under pressure: short-finned pilot whales make social calls during deep foraging dives. Proc. R. Soc. B Biol. Sci. 278(1721): 3017 25.

Johnson, M., Aguilar de Soto, N. and Madsen, P.T. 2009. Studying the behaviour and sensory ecology of marine mammals using acoustic recording tags: a review. Mar. Ecol. Prog. Ser. 395: 55-73.

Johnson, M., Hickmott, L.S., de Soto, N.A. and Madsen, P.T. 2008. Echolocation behaviour adapted to prey in foraging Blainville's beaked whale (Mesoplodon densirostris). Proc. R. Soc. B Biol. Sci. 275(1631): 133-39.

Johnson, M., Madsen, P.T., Zimmer, W.M.X., de Soto, N.A. and Tyack, P.L. 2004. Beaked whales echolocate on prey. Proc. R. Soc. B Biol. Sci. 271(Suppl 6): S383-S86.

Johnson, M., Madsen, P.T., Zimmer, W.M.X., de Soto, N.A. and Tyack, P.L. 2006. Foraging Blainville's beaked whales (Mesoplodon densirostris) produce distinct click types matched to different phases of echolocation. J. Exp. Biol. 209(24): 5038-50.

Johnson, M.P. and Tyack, P.L. 2003. A digital acoustic recording tag for measuring the response of wild marine mammals to sound. IJOE 28(1): $3-12$.

Johnston, D.W., Westgate, A.J. and Read, A.J. 2005. Effects of fine-scale oceanographic features on the distribution and movements of harbour porpoises Phocoena phocoena in the Bay of Fundy. Mar. Ecol. Prog. Ser. 295: 279-93.

Jones, B.A., Stanton, T.K., Lavery, A.C., Johnson, M.P., Madsen, P.T. and Tyack, P.L. 2008. Classification of broadband echoes from prey of a foraging Blainville's beaked whale. J. Acoust. Soc. Am. 123(3): 1753.

Joyce, G.G., Sigurjónsson, J. and Vikingsson, G. 1990. Radio tracking a minke whale (Balaenoptera acutorostrata) in Icelandic waters for the examination of dive-time patterns, 1990. Paper SC/41/NHMi13 presented to the IWC Scientific Committee, San Diego, CA, USA (unpublished). $5 \mathrm{pp}$. [Paper available from the Office of this Journal].

Joyce, T.W., Durban, J.W., Claridge, D.E., Dunn, C.A., Fearnbach, H., Parsons, K.M., Andrews, R.D. and Ballance, L.T. 2017. Physiological, morphological, and ecological tradeoffs influence vertical habitat use of deep-diving toothed-whales in the Bahamas. PLoS One 12(10): e0185113.

Joyce, T.W., Durban, J.W., Fearnbach, H., Claridge, D. and Ballance, L.T 2016. Use of time-at-temperature data to describe dive behavior in five species of sympatric deep-diving toothed whales. Mar. Mamm. Sci. 32(3): 1044-71.

Kaplan, M.B., Mooney, T.A., Sayigh, L.S. and Baird, R.W. 2014. Repeated call types in Hawaiian melon-headed whales (Peponocephala electra). J. Acoust. Soc. Am. 136(3): 1394-401.

Keen, E.M., Falcone, E.A., Andrews, R.D. and Schorr, G.S. 2019. Diel Dive Behavior of Fin Whales (Balaenoptera physalus) in the Southern California Bight. Aquat. Mamm. 45(2): 233-43.

Kennedy, A.S. 2013. Satellite telemetry and humpback whales: A tool for determining the habitat use, distribution and behaviour of an endangered large whale species, Université Paris-Sud.

Kennedy, A.S., Zerbini, A.N., Rone, B.K. and Clapham, P.J. 2014a. Individual variation in movements of satellite-tracked humpback whales Megaptera novaeangliae in the eastern Aleutian Islands and Bering Sea. Endanger. Spec. Res. 23(2): 187-95.

Kennedy, A.S., Zerbini, A.N., Vásquez, O.V., Gandilhon, N., Clapham, P.J. and Adam, O. 2014b. Local and migratory movements of humpback whales (Megaptera novaeangliae) satellite-tracked in the North Atlantic Ocean. Can. J. Zool. 92(1): 9-18.

Kenyon, K.A., Yurkowski, D.J., Orr, J., Barber, D. and Ferguson, S.H. 2018. Baffin Bay narwhal (Monodon monoceros) select bathymetry over sea ice during winter. Polar Biol. 41(10): 2053-63.

Kingsley, M.C.S., Gosselin, S. and Sleno, G.A. 2001. Movements and dive behaviour of belugas in Northern Quebec. Arctic 54(3): 262-75.
Kirchner, T., Wiley, D.N., Hazen, E.L., Parks, S.E., Torres, L.G. and Friedlaender, A.S. 2018. Hierarchical foraging movement of humpback whales relative to the structure of their prey. Mar. Ecol. Prog. Ser. 607: 237-50.

Klatsky, L.J., Wells, R.S. and Sweeney, J.C. 2007. Offshore bottlenose dolphins (Tursiops truncatus): Movement and dive behavior near the Bermuda Pedestal. J. Mammal. 88(1): 59-66.

Konishi, K., Isoda, T., Bando, T., Minamikawa, S. and Kleivane, L. 2018. Results of satellite monitored tagging experiments on North Pacific sei whales conducted during the 2017 NEWREP-NP offshore survey, April 2018. Paper SC/67b/SCSP03 presented to the IWC Scientific Committee, April-May 2018, Bled, Slovenia (unpublished). 8pp. [Paper available from the Office of this Journal].

Krutzikowsky, G.K. and Mate, B.R. 2000. Dive and surfacing characteristics of bowhead whales (Balaena mysticetus) in the Beaufort and Chukchi seas. Can. J. Zool. 78(7): 1182-98.

Kuznetsova, D.M., Glazov, D.M., Shpak, O.V. and Roshnov, V.V. 2016. Winter distribution and migrations of beluga whales (Delphinapterus leucas) in the White Sea based on satellite tracking data. Biol. Bull. 43(8): 914-17.

Kvadsheim, P.H., DeRuiter, S., Sivle, L.D., Goldbogen, J., Ronald-Hanson, R., Miller, P.J.O., Lam, F.A., Calambokidis, J., Friedlaender, A.S., Visser, F., Tyack, P.L., Kleivane and Southall, B. 2017. Avoidance responses of minke whales to $1-4 \mathrm{kHz}$ naval sonar. Mar. Pollut. Bull. 121(1-2): 60-68.

Ladegaard, M., Mulsow, J., Houser, D.S., Jensen, F.H., Johnson, M., Madsen, P.T. and Finneran, J.J. 2019. Dolphin echolocation behaviour during active long-range target approaches. J. Exp. Biol. 222(2): jeb189217.

Lagerquist, B.A., Mate, B.R., Ortega-Ortiz, J.G., Winsor, M. and UrbánRamirez, J. 2008. Migratory movements and surfacing rates of humpback whales (Megaptera novaeangliae) satellite tagged at Socorro Island, Mexico. Mar. Mamm. Sci. 24(2): 815-30.

Lagerquist, B.A., Stafford, K.M. and Mate, B.R. 2000. Dive characteristics of satellite monitored blue whales (Balaenoptera musculus) off the central California coast. Mar. Mamm. Sci. 16(2): 375-91.

Laidre, K.L. 2003. Space use patterns of narwhals (Monodon monoceros) in the high Arctic. University of Washington.

Laidre, K.L. and Heide-Jørgensen, M.P. 2005. Arctic sea ice trends and narwhal vulnerability. Biol. Conserv. 121(4): 509-17.

Laidre, K.L. and Heide-Jørgensen, M.P. 2007. Using narwhals as oceanobserving platforms. Oceanography 20(4): 30

Laidre, K.L. and Heide-Jørgensen, M.P. 2012. Spring partitioning of Disko Bay, West Greenland, by Arctic and Subarctic baleen whales. ICES J. Mar. Sci. 69(7): 1226-33.

Laidre, K.L., Heide-Jørgensen, M.P. and Dietz, R. 2002. Diving behaviour of narwhals (Monodon monoceros) at two coastal localities in the Canadian High Arctic. Can. J. Zool. 80(4): 624-35.

Laidre, K.L., Heide-Jørgensen, M.P., Dietz, R., Hobbs, R.C. and Jørgensen, O.A. 2003. Deep-diving by narwhals Monodon monoceros: differences in foraging behavior between wintering areas? Mar. Ecol. Prog. Ser. 261: 269-81.

Laidre, K.L., Heide-Jørgensen, M.P., Ermold, W. and Steele, M. 2010a. Narwhals document continued warming of southern Baffin Bay. JGR Oceans 115(C10): 1-11.

Laidre, K.L., Heide-Jørgensen, M.P., Logdson, M.L., Dietz, R., Jørgensen, O.A., Treble, M.A., Heagerty, P. and Hobbs, R.C. 2004a. Seasonal narwhal habitat associations in the high Arctic. Mar. Biol. 145: 821-31.

Laidre, K.L., Heide-Jørgensen, M.P., Logsdon, M.L., Delwiche, L. and Nielsen, T.G. 2010b. A whale of an opportunity: Examining the vertical structure of chlorophyll a in high Arctic waters using instrumented marine predators. Mar. Biol. Res. 6(6): 519-29.

Laidre, K.L., Heide-Jørgensen, M.P., Logsdon, M.L., Hobbs, R.C., Dietz, R. and VanBlaricom, G.R. 2004b. Fractal analysis of narwhal space use patterns. Zoology 107(1): 3-11.

Laidre, K.L., Heide-Jørgensen, M.P. and Nielsen, T.G. 2007. Role of the bowhead whale as a predator in West Greenland. Mar. Ecol. Prog. Ser. 346: 285-97.

Laidre, K.L., Heide-Jørgensen, M.P. and Orr, J.R. 2006. Reactions of narwhals, Monodon monoceros, to killer whale, Orcinus orca, attacks in the eastern Canadian Arctic. Can. Field-Nat. 120(4): 457-65.

Laidre, K.L., Moon, T., Hauser, D.D.W., McGovern, R., Heide-Jørgensen, M.P., Dietz, R. and Hudson, B. 2016. Use of glacial fronts by narwhals (Monodon monoceros) in West Greenland. Biol. Lett. 12(10).

Lander, M.E., Westgate, A.J., Balmer, B.C., Reid, J.P., Murray, M.J. and Laidre, K.L. 2018. Tagging and tracking. pp.767-98. In: Gulland, F.M.D., Dierauf, L.A. and Whitman, K.L. (eds). CRC Handbook of Marine Mammal Medicine, 3rd edition. CRC Press: Taylor and Francis Group. $1,124 \mathrm{pp}$.

Laplanche, C., Marques, T.A. and Thomas, L. 2015. Tracking marine mammals in 3D using electronic tag data. Methods Ecol. Evol. 6(9): 98796. 
Lee, J.F., Friedlaender, A.S., Oliver, M.J. and DeLiberty, T.L. 2017. Behavior of satellite-tracked Antarctic minke whales (Balaenoptera bonaerensis) in relation to environmental factors around the western Antarctic Peninsula. Animal Biotelemetry 5: 23

Lemieux Lefebvre, S., Lesage, V., Michaud, R. and Humphries, M.M. 2018. Classifying and combining herd surface activities and individual dive profiles to identify summer behaviours of beluga (Delphinapterus leucas) from the St. Lawrence Estuary, Canada. Can. J. Zool. 96(5): 393-410.

Lemieux Lefebvre, S., Michaud, R., Lesage, V. and Berteaux, D. 2012. Identifying high residency areas of the threatened St. Lawrence beluga whale from fine-scale movements of individuals and coarse-scale movements of herds. Mar. Ecol. Prog. Ser. 450: 243-57.

Lennox, R.J., Engler-Palma, C., Kowarski, K., Filous, A., Whitlock, R., Cooke, S.J. and Auger-Méthé, M. 2018. Optimizing marine spatial plans with animal tracking data. Can. J. Fish. Aquat. Sci. 76(3): 497-509.

Lerczak, J.A., Shelden, K.E.W. and Hobbs, R.C. 2000. Application of suction-cup-attached VHF transmitters to the study of beluga, Delphinapterus leucas, surfacing behavior in Cook Inlet, Alaska. Mar. Fish. Rev. 62(3): 99-111.

Lesage, V., Gavrilchuk, K., Andrews, R.D. and Sears, R. 2017. Foraging areas, migratory movements and winter destinations of blue whales from the western North Atlantic. Endanger. Spec. Res. 34: 27-43.

Lewis, A.E., Hammill, M.O., Power, M., Doidge, D.W. and Lesage, V. 2009. Movement and aggregation of eastern Hudson Bay beluga whales (Delphinapterus leucas): A comparison of patterns found through satellite telemetry and Nunavik traditional ecological knowledge. Arctic 62(1): $13-24$

Lewis, L.A., Calambokidis, J., Stimpert, A.K., Fahlbusch, J., Friedlaender, A.S., McKenna, M.F., Mesnick, S.L., Oleson, E.M., Southall, B.L., Szesciorka, A.R. and Šrović, A. 2018. Context-dependent variability in blue whale acoustic behaviour. R. Soc. Open Sci. 5(8): 180241.

Linnenschmidt, M., Teilmann, J., Akamatsu, T., Dietz, R. and Miller, L.A. 2013. Biosonar, dive, and foraging activity of satellite tracked harbor porpoises (Phocoena phocoena). Mar. Mamm. Sci. 29(2): E77-E97.

López-Urbán, A., Thode, A., Durán, C.B., Urbán-R, J. and Swartz, S. 2018. Two new grey whale call types detected on bioacoustic tags. J. Mar. Biol. Assoc. UK. 98(5): 1169-75.

López, L.M.M., de Soto, N.A., Miller, P. and Johnson, M. 2016. Tracking the kinematics of caudal-oscillatory swimming: a comparison of two onanimal sensing methods. J. Exp. Biol. 219: 2103-09.

López, L.M.M., Miller, P.J.O., de Soto, N.A. and Johnson, M. 2015. Gait switches in deep-diving beaked whales: biomechanical strategies for long-duration dives. J. Exp. Biol. 218: 1325-38.

López, M.E.J., Palacios, D.M., Legorreta, A.J., R, J.U. and Mate, B.R. 2019 Fin whale movements in the Gulf of California, Mexico, from satellite telemetry. PLoS One 14(1): e0209324.

Loseto, L.L., Richard, P., Stern, G.A., Orr, J. and Ferguson, S.H. 2006 Segregation of Beaufort Sea beluga whales during the open-water season. Can. J. Zool. 84(12): 1743-51.

Loughlin, T., Cunningham, L., Gales, N.J., Wells, R. and Boyd, I.L. 2010. Marking and capturing. pp.16-41. In: Boyd, I.L., Bowen, W.D. and Iverson, S.J. (eds). Marine Mammal Ecology and Conservation: A Handbook of Techniques. Oxford University Press, Oxford. 476pp.

Lydersen, C., Freitas, C., Wiig, Ø., Bachmann, L., Heige-Jorgensen, M.P., Swift, R. and K., K.M. 2012. Lost highway not forgotten: satellite tracking of a bowhead whale (Balaena mysticetus) from the critically endangered Spitsbergen stock. Arctic 65(1): 76-86.

Lydersen, C., Martin, A.R., Gjertz, I. and Kovacs, K.M. 2007. Satellite tracking and diving behaviour of sub-adult narwhals (Monodon monoceros) in Svalbard, Norway. Polar Biol. 30(4): 437-42.

Lydersen, C., Martin, A.R., Kovacs, K.M. and Gjertz, I. 2001. Summer and autumn movements of white whales Delphinapterus leucas in Svalbard, Norway. Mar. Ecol. Prog. Ser. 219: 265-74.

Lydersen, C., Nøst, O.A., Lovell, P., McConnell, B.J., Gammelsrød, T., Hunter, C., Fedak, M.A. and Kovacs, K.M. 2002. Salinity and temperature structure of a freezing Arctic fjord-monitored by white whales (Delphinapterus leucas). Geophys. Res. Lett. 29(23): 34-1-34-4.

Macfarlane, N.B.W. 2015. Tagging wild cetaceans: investigating the balance between more and less invasive techniques. MSc thesis, Massachusetts Institute of Technology. xxpp.

Mackay, R.S. 1964a. Deep body temperature of untethered dolphin recorded by ingested radio transmitter. Science 144(3620): 864-66.

Mackay, R.S. 1964b. Dolphin telemetry. Science 145(3629): 296

Madsen, P.T., de Soto, N.A., Arranz, P. and Johnson, M. 2013. Echolocation in Blainville's beaked whales (Mesoplodon densirostris). J. Comp. Physiol. A 199(6): 451-69.

Madsen, P.T., de Soto, N.A., Tyack, P.L. and Johnson, M. 2014. Beaked whales. Curr. Biol. 24(16): R728-R30.

Madsen, P.T., Johnson, M., de Soto, N.A., Zimmer, W.M.X. and Tyack, P. 2005. Biosonar performance of foraging beaked whales (Mesoplodon densirostris). J. Exp. Biol. 208(2): 181-94.
Madsen, P.T., Johnson, M., Miller, P.J.O., de Soto, N.A., Lynch, J. and Tyack, P. 2006. Quantitative measures of air-gun pulses recorded on sperm whales (Physeter macrocephalus) using acoustic tags during controlled exposure experiments. J. Acoust. Soc. Am. 120(4): 2366-79.

Madsen, P.T., Payne, R., Kristiansen, N.U., Wahlberg, M., Kerr, I. and Møhl, B. 2002. Sperm whale sound production studied with ultrasound time/depth-recording tags. J. Exp. Biol. 205(13): 1899-906.

Marshall, G.J. 1998. CRITTERCAM: an animal-borne imaging and data logging system. Mar. Technol. Soc. J. 32(1): 11-17.

Martin, A.R. and Da Silva, V.M.F. 1998. Tracking aquatic vertebrates in dense tropical forest using VHF telemetry. Mar. Technol. Soc. J. 32(1): 82-88

Martin, A.R., Da Silva, V.M.F. and Rothery, P.R. 2006. Does radio tagging affect the survival or reproduction of small cetaceans? A test. Mar Mamm. Sci. 22(1): 17-24.

Martin, A.R., Hall, P. and Richard, P.R. 2001. Dive behaviour of belugas (Delphinapterus leucas) in the shallow waters of western Hudson Bay. Arctic 54(3): 276-83.

Martin, A.R., Kingsley, M.C.S. and Ramsay, M.A. 1994. Diving behaviour of narwhals (Monodon monoceros) on their summer grounds. Can. J. Zool. 72(1): 118-25.

Martin, A.R. and Smith, T.G. 1992. Deep diving in wild, free-ranging beluga whales, Delphinapterus leucas. Can. J. Fish. Aquat. Sci. 49(3): 462-66.

Martin, A.R. and Smith, T.G. 1999. Strategy and capability of wild belugas, Delphinapterus leucas, during deep, benthic diving. Can. J. Zool. 77(11) 1783-93.

Martin, A.R., Smith, T.G. and Cox, O.P. 1998. Dive form and function in belugas Delphinapterus leucas of the eastern Canadian High Arctic. Polar Biol. 20(3): 218-28.

Mate, B. 1994. Movements and dive behavior of a satellite-monitored Atlantic white-sided dolphin (Lagenorhynchus acutus) in the Gulf of Maine. Mar. Mamm. Sci. 10(1): 116-21.

Mate, B., Bradford, A., Tsidulko, G., Vertyankin, V. and Ilyashenko, V. 2011a. Late feeding season movements of a western North Pacific gray whale off Sakhalin Island, Russia and subsequent migration into the eastern North Pacific.

Mate, B., Mesecar, R. and Lagerquist, B. 2007. The evolution of satellitemonitored radio tags for large whales: One laboratory's experience. DSR 54(3-4): 224-47.

Mate, B.R. 1989a. Satellite-monitored radio tracking as a method for studying cetacean movements and behaviour. Rep Int. Whal. Comm 39 389-91.

Mate, B.R. 1989b. Watching habits and habitats from Earth satellites. Oceanus 32: 14-18.

Mate, B.R. 2008. Technical instrumentation issues related to the design and execution of a controlled-exposure experiment for large cetaceans to assess possible behavioural responses and potential impacts. Bioacoustics 17(1-3): 334-36.

Mate, B.R. 2009. GPS/TDR satellite tracking of sperm whales with 3-axis accelerometers-background. Final Report from Oregon University for JIP sponsored research. 17pp. [Available from: https://gisserver.intertek.com/ JIP/DMS/ProjectReports/Cat5/JIP-Proj5.2.2 BMate 2011 TDRSatellite TrackingSpermWhales_2012.pdf].

Mate, B.R. 2012. Implementation of acoustic dosimeters with recoverable month-long GPS/TDR tags to interpret controlled-exposure experiments for large whales. pp.203-05. In: Popper, A.N. and Hawkins, A. (eds). The Effects of Noise on Aquatic Life. Springer (ebook).

Mate, B.R., Best, P.B., Lagerquist, B.A. and Winsor, M.H. 2011b. Coastal, offshore, and migratory movements of South African right whales revealed by satellite telemetry. Mar. Mamm. Sci. 27(3): 455-76.

Mate, B.R., Gisiner, R. and Mobley, J. 1998. Local and migratory movements of Hawaiian humpback whales tracked by satellite telemetry Can. J. Zool. 76(5): 863-68.

Mate, B.R. and Harvey, J.T. 1983. A new attachment device for radiotagging large whales. J. Wildl. Manage. 47(3): 868-72.

Mate, B.R., Ilyashenko, V.Y., Bradford, A.L., Vertyankin, V.V., Tsidulko, G.A., Rozhnov, V.V. and Irvine, L.M. 2015. Critically endangered western gray whales migrate to the eastern North Pacific. Biol. Lett. 11(4) 20150071

Mate, B.R., Irvine, L.M. and Palacios, D.M. 2017. The development of an intermediate-duration tag to characterize the diving behavior of large whales. Ecol. Evol. 7(2): 585-95.

Mate, B.R., Krutzikowsky, G.K. and Winsor, M.H. 2000. Satellitemonitored movements of radio-tagged bowhead whales in the Beaufort and Chukchi seas during the late-summer feeding season and fall migration. Can. J. Zool. 78(7): 1168-81.

Mate, B.R., Lagerquist, B.A. and Calambokidis, J. 1999. Movements of north Pacific blue whales during the feeding season off southern California and their southern fall migration. Mar. Mamm. Sci. 15(4): 1246-57.

Mate, B.R., Lagerquist, B.A. and Urban-Ramirez, J. 2003. A note on using satellite telemetry to document the use of San Ignacio Lagoon by gray 
whales (Eschrichtius robustus) during their reproductive season. J. Cetacean Res. Manage. 5(2): 149-54.

Mate, B.R., Lagerquist, B.A., Winsor, M., Geraci, J. and Prescott, J.H. 2005. Movements and dive habits of a satellite-monitored long-finned pilot whale (Globicephala melas) in the Northwest Atlantic. Mar. Mamm. Sci. 21(1): 136-44

Mate, B.R., Nieukirk, S.L. and Kraus, S.D. 1997. Satellite-monitored movements of the northern right whale. J. Wildl. Manage. 61(4): 1393-405.

Mate, B.R., Rossbach, K.A., Nieukirk, S.L., Wells, R.S., Irvine, A.B., Scott, M.D. and Read, A.J. 1995. Satellite-monitored movements and dive behavior of a bottlenose dolphin (Tursiops truncatus) in Tampa Bay, Florida. Mar. Mamm. Sci. 11(4): 452-63.

Mate, B.R. and Urban-Ramirez, J. 2003. A note on the route and speed of a gray whale on its northern migration from Mexico to central California, tracked by satellite-monitored radio tag. J. Cetacean Res. Manage. 5: 155-57.

Mathias, D., Thode, A.M., Straley, J. and Andrews, R.D. 2013. Acoustic tracking of sperm whales in the Gulf of Alaska using a two-element vertical array and tags. J. Acoust. Soc. Am. 134(3): 2446-61.

Mathias, D., Thode, A.M., Straley, J., Calambokidis, J., Schorr, G.S. and Folkert, K. 2012. Acoustic and diving behavior of sperm whales (Physeter macrocephalus) during natural and depredation foraging in the Gulf of Alaska. J. Acoust. Soc. Am. 132(1): 518-32.

Matkin, C.O., Durban, J.W., Saulitis, E.L., Andrews, R.D., Straley, J.M., Matkin, D.R. and Ellis, G.M. 2012. Contrasting abundance and residency patterns of two sympatric populations of transient killer whales (Orcinus orca) in the northern Gulf of Alaska. Fish. Bull. 110: 143-55.

Matthews, C.J.D., Luque, S.P., Petersen, S.D., Andrews, R.D. and Ferguson, S.H. 2011. Satellite tracking of a killer whale (Orcinus orca) in the eastern Canadian Arctic documents ice avoidance and rapid, long-distance movement into the North Atlantic. Polar Biol. 34(7): 1091-96.

Mazzoil, M.S., McCulloch, S.D., Youngbluth, M.J., Kilpatrick, D.S., Murdoch, M.E., Mase-Guthrie, B., Odell, D.K. and Bossart, G.D. 2008 Radio-tracking and survivorship of two rehabilitated bottlenose dolphins (Tursiops truncatus) in the Indian River Lagoon, Florida. Aquat. Mamm. 34(1): 54-64.

McConnell, B., Fedak, M., Hooker, S. and Patterson, T. 2010. Telemetry. pp.222-41. In: Boyd, I.L., Bowen, W.D. and Iverson, S.J. (eds). Marine Mammal Ecology and Conservation: A Handbook of Techniques. Oxford University Press, Oxford. 476pp.

McDonald, B.I., Johnson, M. and Madsen, P.T. 2018. Dive heart rate in harbour porpoises is influenced by exercise and expectations. J. Exp. Biol. 221(1): jeb168740

McIntyre, T. 2014. Trends in tagging of marine mammals: a review of marine mammal biologging studies. Afr. J. Mar. Sci. 36(4): 409-22.

McKenna, M.F., Calambokidis, J., Oleson, E.M., Laist, D.W. and Goldbogen, J.A. 2015. Simultaneous tracking of blue whales and large ships demonstrates limited behavioral responses for avoiding collision. Endanger. Spec. Res. 27: 219-32.

McMahon, C.R., Harcourt, R., Bateson, P. and Hindell, M.A. 2012. Animal welfare and decision making in wildlife research. Biol. Conserv. 153: 254-56.

McSweeney, D.J., Baird, R.W. and Mahaffy, S.D. 2007. Site fidelity, associations, and movements of Cuvier's (Ziphius cavirostris) and Blainville's (Mesoplodon densirostris) beaked whales off the islands of Hawaii. Mar. Mamm. Sci. 23(3): 666-87.

Mikkelsen, L., Rigét, F.F., Kyhn, L.A., Sveegaard, S., Dietz, R., Tougaard, J., Carlström, J.A.K., Carlén, I., Koblitz, J.C. and Teilmann, J. 2016. Comparing distribution of harbour porpoises (Phocoena phocoena) derived from satellite telemetry and passive acoustic monitoring. PLoS One 11(7): e0158788.

Miksis, J.L., Grund, M.D., Nowacek, D.P., Solow, A.R., Connor, R.C. and Tyack, P.L. 2001. Cardiac responses to acoustic playback experiments in the captive bottlenose dolphin (Tursiops truncatus). J. Comp. Psychol. 115(3): 227-32.

Miller, P., Narazaki, T., Isojunno, S., Aoki, K., Smout, S. and Sato, K. 2016. Body density and diving gas volume of the northern bottlenose whale (Hyperoodon ampullatus). J. Exp. Biol. 219: 2458-68.

Miller, P.J.O., Antunes, R.N., Wensveen, P.J., Samarra, F.I.P., Alves, A.C. and Tyack, P.L. 2014. Dose-response relationships for the onset of avoidance of sonar by free-ranging killer whales. J. Acoust. Soc. Am. 135(2): 975-93

Miller, P.J.O., Aoki, K., Rendell, L.E. and Amano, M. 2008. Stereotypical resting behavior of the sperm whale. Curr. Biol. 18(1): R21-R23.

Miller, P.J.O., Johnson, M.P., Madsen, P.T., Biassoni, N., Quero, M. and Tyack, P.L. 2009. Using at-sea experiments to study the effects of airguns on the foraging behavior of sperm whales in the Gulf of Mexico. Deep Sea Res. Pt. I Oceanogr. Res. Pap. 56(7): 1168-81.

Miller, P.J.O., Johnson, M.P. and Tyack, P.L. 2004a. Sperm whale behaviour indicates the use of echolocation click buzzes 'creaks' in prey capture. Proc. R. Soc. B Biol. Sci. 271(1554): 2239-47.
Miller, P.J.O., Johnson, M.P., Tyack, P.L. and Terray, E.A. 2004b. Swimming gaits, passive drag and buoyancy of diving sperm whales Physeter macrocephalus. J. Exp. Biol. 207(11): 1953-67.

Miller, P.J.O., Kvadsheim, P.H., Lam, F.A., Wensveen, P.J., Antunes, R., Alves, A.C., Visser, F., Kleivane, L., Tyack, P.L. and Sivle, L.D. 2012. The severity of behavioral changes observed during experimental exposures of killer (Orcinus orca), long-finned pilot (Globicephala melas), and sperm (Physeter macrocephalus) whales to naval sonar. Aquat. Mamm. 38(4): 362-401.

Miller, P.J.O., Kvadsheim, P.H., Lam, F.P.A., Tyack, P.L., Cure, C., DeRuiter, S.L., Kleivane, L., Sivle, L.D., van Ijsselmuide, S.P., Visser, F., Wensveen, P.J., von Benda-Beckmann, A.M., López, L.M.M., Narazaki, T. and Hooker, S.K. 2015. First indications that northern bottlenose whales are sensitive to behavioural disturbance from anthropogenic noise. R. Soc. Open Sci. 2: 140484.

Miller, P.J.O., Shapiro, A.D. and Deecke, V.B. 2010. The diving behaviour of mammal-eating killer whales (Orcinus orca): variations with ecological not physiological factors. Can. J. Zool. 88(11): 1103-12.

Minamikawa, S., Iwasaki, T. and Kishiro, T. 2007. Diving behaviour of a Baird's beaked whale, Berardius bairdii, in the slope water region of the western North Pacific: first dive records using a data logger. Fish. Oceanogr. 16(6): 573-77.

Minamikawa, S., Watanabe, H. and Iwasaki, T. 2013. Diving behavior of a false killer whale, Pseudorca crassidens, in the Kuroshio-Oyashio transition region and the Kuroshio front region of the western North Pacific. Mar. Mamm. Sci. 29(1): 177-85.

Mizroch, S.A., Tillman, M.F., Jurasz, S., Straley, J.M., Von Ziegesar, O., Herman, L.M., Pack, A.A., Baker, S., Darling, J., Glockner-Ferrari, D., Ferrari, M., Salden, D.R. and Clapham, P.J. 2011. Long-term survival of humpback whales radio-tagged in Alaska from 1976 through 1978. Mar. Mamm. Sci. 27(1): 217-29.

Moore, M., Andrews, R., Austin, T., Bailey, J., Costidis, A., George, C., Jackson, K., Pitchford, T., Landry, S., Ligon, A., McLellan, W., Morin, D., Smith, J., Rotstein, D., Rowles, T., Slay, C. and Walsh, M. 2013. Rope trauma, sedation, disentanglement, and monitoring-tag associated lesions in a terminally entangled North Atlantic right whale (Eubalaena glacialis). Mar. Mamm. Sci. 29(2): E98-E113.

Morton, D.B., Hawkins, P., Bevan, R., Heath, K., Kirkwood, J., Pearce, P., Scott, L., Whelan, G. and Webb, A. 2003. Refinements in telemetry procedures: Seventh report of BVAAWF/FRAME/RSPCA/UFAW Joint Working Group on Refinement, Part A. Lab. Anim. 37(4): 261-99.

Mouillot, D. and Viale, D. 2001. Satellite tracking of a fin whale (Balaenoptera physalus) in the north-western Mediterranean Sea and fractal analysis of its trajectory. Hydrobiologia 452(1-3): 163-71.

Mulcahy, D.M. 2011. Antibiotic use during the intracoelomic implantation of electronic tags into fish. Rev. Fish Biol. Fish. 21(1): 83-96.

Mulcahy, D.M. 2013. Legal, ethical, and procedural bases for the use of aseptic techniques to implant electronic devices. J. Fish Wildl. Manag. 4(1): 211-19.

Murase, H., Tamura, T., Otani, S. and Nishiwaki, S. 2016. Satellite tracking of Bryde's whales Balaenoptera edeni in the offshore western North Pacific in summer 2006 and 2008. Fish. Sci. 82(1): 35-45.

Nachtigall, P.E., Mooney, T.A., Taylor, K.A., Miller, L.A., Rasmussen, M.H., Akamatsu, T., Teilmann, J., Linnenschmidt, M. and Vikingsson, G.A. 2008. Shipboard measurements of the hearing of the white-beaked dolphin Lagenorhynchus albirostris. J. Exp. Biol. 211: 642-47.

Narazaki, T., Isojunno, S., Nowacek, D.P., Swift, R., Friedlaender, A.S., Ramp, C., Smout, S., Aoki, K., Deecke, V.B., Sato, K. and Miller, P.J.O. 2018. Body density of humpback whales (Megaptera novaengliae) in feeding aggregations estimated from hydrodynamic gliding performance. PLoS One 13(7): e0200287.

Nielsen, N.H., Laidre, K., Larsen, R.S. and Heide-Jørgensen, M.P. 2015. Identification of potential foraging areas for bowhead whales in Baffin Bay and adjacent waters. Arctic 88(2): 169-79.

Nielsen, N.H., Teilmann, J., Sveegaard, S., Hansen, R.G., Sinding, M.-H.S., Dietz, R. and Heide-Jørgensen, M.P. 2018. Oceanic movements, site fidelity and deep diving in harbour porpoises from Greenland show limited similarities to animals from the North Sea. Mar. Ecol. Prog. Ser. 597: 259-72.

Nishiwaki, S., Otani, S. and Tamura, T. 2009. Movements of Bryde's whales in the western North Pacific as revealed by satellite tracking experiments conducted under JARPN II. Paper SC/61/O7 presented to the IWC Scientific Committee, June 2009, Madeira, Portugal (unpublished). 7pp. [Paper available from the Office of this Journal].

Noren, S.R., Cuccurullo, V. and Williams, T.M. 2004. The development of diving bradycardia in bottlenose dolphins (Tursiops truncatus). J. Comp. Physiol. B 174: 139-47.

Noren, S.R., Kendall, T., Cuccurullo, V. and Williams, T.M. 2012. The dive response redefined: underwater behavior influences cardiac variability in freely diving dolphins. J. Exp. Biol. 215: 2735-41.

Norman, S.A., Flynn, K.R., Zerbini, A.N., Gulland, F.M.D., Moore, M.J., Raverty, S., Rotstein, D.S., Mate, B.R., Hayslip, C., Gendron, D., Sears, 
R., Douglas, A.B. and Calambokidis, J. 2018. Assessment of wound healing of tagged gray (Eschrichtius robustus) and blue (Balaenoptera musculus) whales in the eastern North Pacific using long-term series of photographs. Mar. Mamm. Sci. 34(1): 27-53.

Norman, S.A., Hobbs, R.C., Foster, J., Schroeder, J.P. and Townsend, F.I 2004. A review of animal and human health concerns during capturerelease, handling and tagging of odontocetes. J. Cetacean Res. Manage. 6(1): 53-62.

Norris, K.S. and Gentry, R.L. 1974. Capture and harnessing of young California gray whales, Eschrichtius robustus. Mar. Fish. Rev. 36(4): 58-

Norris, K.S., Goodman, R.M., Villa-Ramirez, B. and Hobbs, L. 1977. Behaviour of California gray whale, Eschrichtius robustus, in Southern Baja California, Mexico. Fish. Bull. 75(1): 159-72.

Nousek-McGregor, A.E., Miller, C.A., Moore, M.J. and Nowacek, D.P 2014. Effects of body condition on buoyancy in endangered North Atlantic right whales. Physiol. Biochem. Zool. 87(1): 160-71.

Nowacek, D.P., Christiansen, F., Bejder, L., Goldbogen, J.A. and Friedlaender, A.S. 2016. Studying cetacean behaviour: new technological approaches and conservation applications. Anim. Behav. 120: 235-44.

Nowacek, D.P., Johnson, M.P. and Tyack, P.L. 2004. North Atlantic right whales (Eubalaena glacialis) ignore ships but respond to alerting stimuli. Proc. R. Soc. Lond. B. Biol. Sci. 271(1536): 227-31.

Nowacek, D.P., Johnson, M.P., Tyack, P.L., Shorter, K.A., McLellan, W.A and Pabst, D.A. 2001. Buoyant balaenids: the ups and downs of buoyancy in right whales. Proc. $R$. Soc. B Biol. Sci. 268(1478): 1811-16.

O’Corry-Crowe, G., Suydam, R., Quakenbush, L., Potgieter, B., Harwood, L., Litovka, D., Ferrer, T., Citta, J., Burkanov, V., Frost, K. and Mahoney, B. 2018. Migratory culture, population structure and stock identity in North Pacific beluga whales (Delphinapterus leucas). PLoS One 13(3): e0194201.

Øien, N., Bøthun, G. and Kleivane, L. 2008. VHF and satellite tagging of minke whales at Svalbard in 2007 - update on minke whale surfacing rates. Paper SC/60/PFI8 presented to the IWC Scientific Committee, June 2008, Santiago, Chile (unpublished). 6pp. [Paper available from the Office of this Journal].

Oleson, E.M., Calambokidis, J., Burgess, W.C., McDonald, M.A., LeDuc, C.A. and Hildebrand, J.A. 2007. Behavioral context of call production by eastern North Pacific blue whales. Mar. Ecol. Prog. Ser. 330: 26984.

Oliveira, C., Wahlberg, M., Johnson, M., Miller, P.J.O. and Madsen, P.T. 2013. The function of male sperm whale slow clicks in a high latitude habitat: Communication, echolocation, or prey debilitation? J. Acoust. Soc. Am. 133(5): 3135-44.

Oliveira, C., Wahlberg, M., Silva, M.A., Johnson, M., Antunes, R., Wisniewska, D.M., Fais, A., Goncalves, J. and Madsen, P.T. 2016. Sperm whale codas may encode individuality as well as clan identity. J. Acoust. Soc. Am. 139(5): 2860-69.

Olsen, D.W., Matkin, C.O., Andrews, R.D. and Atkinson, S. 2018. Seasonal and pod-specific differences in core use areas by resident killer whales in the Northern Gulf of Alaska. DSR 147: 196-202.

Olsen, E., Budgell, W.P., Head, E., Kleivane, L., Nøttestad, L., Prieto, R., Silva, M.A., Skov, H., Víkingsson, G.A., Waring, G. and Øien, N. 2009. First satellite-tracked long-distance movement of a sei whale (Balaenoptera borealis) in the North Atlantic. Aquat. Mamm. 35(3): 31318.

ONR. 2009. Final Workshop Proceedings for Cetacean Tag Design Workshop. Report (unpublished) on workshop held 16 - 17 March 2009 , Arlington, VA. [Available at: https://www.onr.navy.mil/-/media/Files/ 32/Tag-Final-Report-Oct2009.ashx]. 18pp.

Orr, J.R., Aubin, D.J., Richard, P.R. and Heide-Jørgensen, M.P. 1998 Recapture of belugas, Delphinapterus leucas, tagged in the Canadian Arctic. Mar. Mamm. Sci. 14(4): 829-34.

Orr, J.R., Joe, R. and Evic, D. 2001. Capturing and handling of white whales (Delphinapterus lencas) in the Canadian Arctic for instrumentation and release. Arctic 54(3): 299-304.

Ortega-Ortiz, J.G., Engelhaupt, D., Winsor, M., Mate, B.R. and Hoelzel, A.R. 2011. Kinship of long-term associates in the highly social sperm whale. Mol. Ecol. 21: 732-44.

Otani, S., Naito, Y., Kato, A. and Kawamura, A. 2000. Diving behavior and swimming speed of a free-ranging harbor porpoise, Phocoena phocoena. Mar. Mamm. Sci. 16(4): 811-14.

Otani, S., Naito, Y., Kato, A. and Kawamura, A. 2001. Oxygen consumption and swim speed of the harbor porpoise Phocoena phocoena. Fish. Sci. 67(5): 894-98.

Otani, S., Naito, Y., Kawamura, A., Kawasaki, M., Nishiwaki, S. and Kato, A. 1998. Diving behavior and performance of harbor porpoises, Phocoena phocoena, in Funka Bay, Hokkaido, Japan. Mar. Mamm. Sci. 14(2): 209-20.

Ovide, B.G. 2017. Using tag data to assess behaviour, vocal sounds, boat noise and potential effects on Humpback whales (Megaptera novaeangliae) in response to whale watching boats in Skjálfandi Bay (Húsavík), Iceland. MSc thesis, University of Akureyri. 147pp.

Owen, K. 2014. The feeding behaviour of humpback whales while on migration: methods, driving factors and its importance to whale ecology. $\mathrm{PhD}$ thesis, University of Queensland. 217pp.

Owen, K., Dunlop, R.A., Monty, J.P., Chung, D., Noad, M.J., Donnelly, D., Goldizen, A.W. and Mackenzie, T. 2016a. Detecting surface-feeding behavior by rorqual whales in accelerometer data. Mar. Mamm. Sci. 32(1): $327-48$

Owen, K., Jenner, C.S., Jenner, M.-N.M. and Andrews, R.D. 2016b. A week in the life of a pygmy blue whale: migratory dive depth overlaps with large vessel drafts. Anim. Biotelemetry 4: 17.

Owen, K., Kavanagh, A.S., Warren, J.D., Noad, M.J., Donnelly, D., Goldizen, A.W. and Dunlop, R.A. 2016c. Potential energy gain by whales outside of the Antarctic: prey preferences and consumption rates of migrating humpback whales (Megaptera novaeangliae). Polar Biol.: 113.

Owen, K., Warren, J.D., Noad, M.J., Donnelly, D., Goldizen, A.W. and Dunlop, R.A. 2015. Effect of prey type on the fine-scale feeding behaviour of migrating east Australian humpback whales. Mar. Ecol. Prog. Ser. 541: 231-44.

Pabst, D.A. 1990. Axial muscles and connective tissues of the bottlenose dolphin. pp.51-67. In: Leatherwood, S. and Reeves, R.R. (eds). The Bottlenose Dolphin. Academic Press. 653pp.

Palmer, C., Baird, R.W., Webster, D.L., Edwards, A.C., Patterson, R., Withers, A., Withers, E., Groom, R. and Woinarski, J.C.Z. 2017. A preliminary study of the movement patterns of false killer whales (Pseudorca crassidens) in coastal and pelagic waters of the Northern Territory, Australia. Mar. Freshw. Res. 68(9): 1726-33.

Panigada, S., Donovan, G.P., Druon, J.-N., Lauriano, G., Pierantonio, N., Pirotta, E., Zanardelli, M., Zerbini, A.N. and di Sciara, G.N. 2017. Satellite tagging of Mediterranean fin whales: working towards the identification of critical habitats and the focussing of mitigation measures Sci. Rep. 7(1): 3365 .

Panigada, S., Pesante, G., Zanardelli, M. and Oehen, S. 2003. Day and night-time diving behavior of fin whales in the Western Ligurian Sea Paper read at Proceedings OCEANS 2003

Panigada, S., Zanardelli, M., Canese, S. and Jahoda, M. 1999. How deep can baleen whales dive? Mar. Ecol. Prog. Ser. 187: 309-11.

Parks, S.E., Cusano, D.A., Stimpert, A.K., Weinrich, M.T., Friedlaender, A.S. and Wiley, D.N. 2014. Evidence for acoustic communication among bottom foraging humpback whales. Sci. Rep. 4: 7508

Parks, S.E., Johnson, M., Nowacek, D. and Tyack, P.L. 2011a. Individual right whales call louder in increased environmental noise. Biol. Lett. 7(1) $33-35$.

Parks, S.E., Searby, A., Célérier, A., Johnson, M.P., Nowacek, D.P. and Tyack, P.I. 2011b. Sound production behavior of individual North Atlantic right whales: implications for passive acoustic monitoring. Endanger Spec. Res. 15(1): 63-76

Parks, S.E., Warren, J.D., Stamieszkin, K., Mayo, C.A. and Wiley, D. 2012 Dangerous dining: surface foraging of North Atlantic right whales increases risk of vessel collisions. Biol. Lett. 8(1): 57-60.

Pavlov, V.V. and Rashad, A.M. 2012. A non-invasive dolphin telemetry tag: Computer design and numerical flow simulation. Mar. Mamm. Sci. 28(1): E16-E27.

Pavlov, V.V., Wilson, R.P. and Lucke, K. 2007. A new approach to tag design in dolphin telemetry: Computer simulations to minimise deleterious effects. DSR 54(3-4): 404-14.

Pearson, H.C., Jones, P.W., Srinivasan, M., Lundquist, D., Pearson, C.J., Stockin, K.A. and Machovsky-Capuska, G.E. 2017. Testing and deployment of C-VISS (cetacean-borne video camera and integrated sensor system) on wild dolphins. Mar. Biol. 164(3): 42.

Pérez, J.M., Jensen, F.H., Rojano-Doñate, L. and Soto, N.A.d. 2017. Different modes of acoustic communication in deep-diving short-finned pilo whales (Globicephala macrorhynchus). Mar. Mamm. Sci. 33(1): 59-79.

Pettis, H.M., Rolland, R.M., Hamilton, P.K., Brault, S., Knowlton, A.R. and Kraus, S.D. 2004. Visual health assessment of North Atlantic right whales (Eubalaena glacialis) using photographs. Can. J. Zool. 82(1): 8-19.

Pirotta, E., Mangel, M., Costa, D.P., Mate, B., Goldbogen, J.A., Palacios, D.M., Hückstädt, L.A., McHuron, E.A., Schwarz, L. and New, L. 2018a A dynamic state model of migratory behavior and physiology to asses the consequences of environmental variation and anthropogenic disturbance on marine vertebrates. Am. Nat. 191(2): E40-E56.

Pirotta, E., New, L. and Marcoux, M. 2018b. Modelling beluga habitat use and baseline exposure to shipping traffic to design effective protection against prospective industrialization in the Canadian Arctic. Aquat. Conserv. 28(3): 713-22.

Pitman, R.L., Totterdell, J.A., Fearnbach, H., Ballance, L.T., Durban, J.W. and Kemps, H. 2015. Whale killers: Prevalence and ecological implications of killer whale predation on humpback whale calves off Western Australia. Mar. Mamm. Sci. 31(2): 629-57. 
Pomerleau, C., Patterson, T.A., Luque, S., Lesage, V., Heide-Jørgensen, M.P., Dueck, L.I. and Ferguson, S.H. 2011. Bowhead whale Balaena mysticetus diving and movement patterns in the eastern Canadian Arctic: implications for foraging ecology. Endanger. Spec. Res. 15(2): 167-77.

Popov, V., Langrock, R., DeRuiter, S.L. and Visser, F. 2017. An analysis of pilot whale vocalization activity using hidden Markov models. J. Acoust. Soc. Am. 141(1): 159.

Prieto, R., Silva, M.A., Waring, G.T. and Gonalves, J.M.A. 2014. Sei whale movements and behaviour in the North Atlantic inferred from satellite telemetry. Endanger. Spec. Res. 26(2): 103-13.

Pulis, E.E., Wells, R.S., Schorr, G.S., Douglas, D.C., Samuelson, M.M. and Solangi, M. 2018. Movements and Dive Patterns of Pygmy Killer Whales (Feresa attenuata) Released in the Gulf of Mexico Following Rehabilitation. Aquat. Mamm. 43(5): 555-67.

Quakenbush, L., Citta, J., George, J.C., Heide-Jørgensen, M.P., Small, R., Brower, H., Harwood, L., Adams, B., Brower, L., Tagarook, G., Pokiak, C. and Pokiak, J. 2012. Seasonal movements of the Bering-ChukchiBeaufort stock of Bowhead Whales: 2006-2011 satellite telemetry results. Paper SC/64/BRG1 presented to the IWC Scientific Committee, June 2012, Panama City, Panama (unpublished). 22pp. [Paper available from the Office of this Journal].

Quakenbush, L.T., Citta, J.J., George, J.C., Small, R.J. and Heide-Jørgensen, M.P. 2010. Fall and winter movements of bowhead whales (Balaena mysticetus) in the Chukchi Sea and within a potential petroleum development area. Arctic 63(3): 289-307.

Quick, N., Callahan, H. and Read, A.J. 2018. Two-component calls in shortfinned pilot whales (Globicephala macrorhynchus). Mar. Mamm. Sci. 34(1): 155-68.

Quick, N., Scott-Hayward, L., Sadykova, D., Nowacek, D. and Read, A. 2017a. Effects of a scientific echo sounder on the behavior of short-finned pilot whales (Globicephala macrorhynchus). Can. J. Fish. Aquat. Sci. 74(5): 716-26.

Quick, N.J., Cioffi, W.R., Shearer, J. and Read, A.J. 2019. Mind the gap optimizing satellite tag settings for time series analysis of foraging dives in Cuvier's beaked whales (Ziphius cavirostris). Anim. Biotelemetry 7(1): 5.

Quick, N.J., Isojunno, S., Sadykova, D., Bowers, M., Nowacek, D.P. and Read, A.J. 2017b. Hidden Markov models reveal complexity in the diving behaviour of short-finned pilot whales. Sci. Rep. 7: 45765.

Rasmussen, M.H., Akamatsu, T., Teilmann, J., Vikingsson, G. and Miller, L.A. 2013. Biosonar, diving and movements of two tagged white-beaked dolphin in Icelandic waters. DSR 88-89: 97-105.

Ratner, B.D., Hoffman, A.S., Schoen, F.J. and Lemons, J.E. 2013. Biomaterials Science - An Introduction to Materials in Medicine. 3rd ed. Elsevier, Amsterdam. 1,519pp.

Ray, G.C., Mitchell, E.D., Wartzok, D., Kozicki, V.M. and Maiefski, R. 1978. Radio tracking of a fin whale (Balaenoptera physalus). Science 202(4367): 521-24.

Read, A.J., Watkins, W.A. and Westgate, A.J. 1996. Development and testing of tagging and attachment equipment for harbour porpoises in the southwestern Bay of Fundy. Final Report to the Office of Naval Research N00014-94-1-1189.

Read, A.J. and Westgate, A.J. 1997. Monitoring the movements of harbour porpoises (Phocoena phocoena) with satellite telemetry. Mar. Biol. 130: 315-22

Reisinger, R.R., Keith, M., Andrews, R.D. and de Bruyn, P.J.N. 2015. Movement and diving of killer whales (Orcinus orca) at a Southern Ocean archipelago. J. Exp. Mar. Biol. Ecol. 473: 90-102.

Reisinger, R.R., Oosthuizen, W.C., Péron, G., Cory Toussaint, D., Andrews, R.D. and de Bruyn, P.J.N. 2014. Satellite tagging and biopsy sampling of killer whales at subantarctic Marion Island: effectiveness, immediate reactions and long-term responses. PLoS One 9(11): e111835.

Rekdahl, Dunlop, R., Goldizen, A., Garland, E.C., Biassoni, N., Miller, P. and Noad, M. 2015. Non-song social call bouts of migrating humpback whales. J. Acoust. Soc. Am. 137(6): 3042-53.

Richard, G., Bonnel, J., Tixier, P., Arnould, J.P.Y., Janc, A. and Guinet, C. 2019. Evidence of deep-sea interactions between toothed whales and longlines. Ambio: 1-14.

Richard, P.R., Heide-Jørgensen, M.P. and Aubin, D.S. 1998. Fall movements of Belugas (Delphinapterus lencas) with satellite-linked transmitters in Lancaster Sound, Jones Sound, and Northern Baffin Bay. Arctic 51(1) $5-16$.

Richard, P.R., Heide-Jørgensen, M.P., Orr, J.R., Dietz, R. and Smith, T.G. 2001a. Summer and autumn movements and habitat use by belugas in the Canadian High Arctic and adjacent areas. Arctic 54(3): 207-22.

Richard, P.R., Martin, A.R. and Orr, J.R. 2001b. Summer and autumn movements of belugas of the eastern Beaufort Sea Stock. Arctic 54(3): 223-36.

Riekkola, L., Andrews-Goff, V., Friedlaender, A., Constantine, R. and Zerbini, A.N. 2019. Environmental drivers of humpback whale foraging behavior in the remote Southern Ocean. J. Exp. Mar. Biol. Ecol. 517: 112 .
Riekkola, L., Zerbini, A.N., Andrews, O., Andrews-Goff, V., Baker, C.S., Chandler, D., Childerhouse, S., Clapham, P., Dodémont, R., Donnelly, D., Friedlaender, A., Gallego, R., Garrigue, C., Ivashchenko, Y., Jarman, S., Lindsay, R., Pallin, L., Robbins, J., Steel, D., Tremlett, J., Vindenes, S. and Constantine, R. 2018. Application of a multi-disciplinary approach to reveal population structure and Southern Ocean feeding grounds of humpback whales. Ecol. Indicators 89: 455-65.

Risch, D., Gales, N.J., Gedamke, J., Kindermann, L., Nowacek, D.P., Read, A.J., Siebert, U., Van Opzeeland, I.C., Van Parijs, S.M. and Friedlaender, A.S. 2014. Mysterious bio-duck sound attributed to the Antarctic minke whale (Balaenoptera bonaerensis). Biol. Lett. 10(4): 20140175.

Robbins, J., Zerbini, A.N., Gales, N., Gulland, F.M.D., Double, M., Clapham, P.J., Andrews-Goff, V., Kennedy, A.S., Landry, S., Mattila, D.K. and Tackaberry, J. 2013. Satellite tag effectiveness and impacts on large whales: preliminary results of a case study with Gulf of Maine humpback whales. Paper SC/65a/SH05 presented to the IWC Scientific Committee, June 2013, Jeju, Republic of Korea (unpublished). 10pp. [Paper available from the Office of this Journal].

Rockwood, R.C., Calambokidis, J. and Jahncke, J. 2017. High mortality of blue, humpback and fin whales from modeling of vessel collisions on the U.S. West Coast suggests population impacts and insufficient protection. PLoS One 12(8): e0183052.

Rojano-Doñate, L., McDonald, B.I., Wisniewska, D.M., Johnson, M., Teilmann, J., Wahlberg, M., Højer-Kristensen, J. and Madsen, P.T. 2018. High field metabolic rates of wild harbour porpoises. J. Exp. Biol. 221(23): jeb185827.

Roos, M.M.H., Wu, G.-M. and Miller, P.J.O. 2016. The significance of respiration timing in the energetics estimates of free-ranging killer whales (Orcinus orca). J. Exp. Biol. 219(13): 2066-77.

Root-Gutteridge, H., Cusano, D.A., Shiu, Y., Nowacek, D.P., Van Parijs, S.M. and Parks, S.E. 2018. A lifetime of changing calls: North Atlantic right whales, Eubalaena glacialis, refine call production as they age. Anim. Behav. 137: 21-34.

Rosenbaum, H.C., Maxwell, S.M., Kershaw, F. and Mate, B. 2014. Longrange movement of humpback whales and their overlap with anthropogenic activity in the South Atlantic Ocean. Conserv. Biol. 28(2): $604-15$

Russell, W. and Burch, R. 1959. The Principles of Humane Experimental Technique. Methuen, London. xiv $+238 \mathrm{pp}$.

Rutala, W., Weber, D. and the HICPAC. 2008. Guideline for disinfection and sterilization in healthcare facilities. Last updated 15 February 2017. [Available at: https://www.cdc.gov/infectioncontrol/guidelines/ disinfection/]

Saddler, M.R., Bocconcelli, A., Hickmott, L.S., Chiang, G., Landea-Briones, R., Bahamonde, P.A., Howes, G., Segre, P.S. and Sayigh, L.S. 2017. Characterizing Chilean blue whale vocalizations with DTAGs: a test of using tag accelerometers for caller identification. J. Exp. Biol. 220.

Sakai, M., Aoki, K., Sato, K., Amano, M., Baird, R.W., Webster, D.L., Schorr, G.S. and Miyazaki, N. 2011a. Swim speed and acceleration measurements of short-finned pilot whales (Globicephala macrorhynchus) in Hawai'i. Mamm. Study 36(1): 55-59.

Sakai, M., Karczmarski, L., Morisaka, T. and Thornton, M. 2011 b. Reactions of Heaviside's dolphins to tagging attempts using remotelydeployed suction-cup tags. S. Afr. J. Wildl. Res. 41(1): 134-38.

Samarra, F.I.P. and Miller, P.J.O. 2015. Prey-induced behavioural plasticity of herring-eating killer whales. Mar. Biol. 162(4): 1-13.

Sampson, K., Merigo, C., Lagueux, K., Rice, J., Cooper, R., Weber III, E.S., Kass, P., Mandelman, J. and Innis, C. 2012. Clinical assessment and postrelease monitoring of 11 mass stranded dolphins on Cape Cod, Massachusetts. Mar. Mamm. Sci. 28(4): E404-E25.

Sato, K., Watanuki, Y., Takahashi, A., Miller, P.J.O., Tanaka, H., Kawabe, R., Ponganis, P.J., Handrich, Y., Akamatsu, T., Watanabe, Y., Mitani, Y., Costa, D.P., Bost, C.-A., Aoki, K., Amano, M., Trathan, P., Shapiro, A. and Naito, Y. 2007. Stroke frequency, but not swimming speed, is related to body size in free-ranging seabirds, pinnipeds and cetaceans. Proc. R. Soc. B Biol. Sci. 274(1609): 471-77.

Sayigh, L., Quick, N., Hastie, G. and Tyack, P. 2013. Repeated call types in short-finned pilot whales, Globicephala macrorhynchus. Mar. Mamm. Sci. 29(2): 312-24

Scales, K.K., Hazen, E.L., Jacox, M.G., Edwards, C.A., Boustany, A.M., Oliver, M.J. and Bograd, S.J. 2016. Scale of inference: on the sensitivity of habitat models for wideranging marine predators to the resolution of environmental data. Ecography 39: 1-11.

Scales, K.L., Schorr, G.S., Hazen, E.L., Bograd, S.J., Miller, P.I., Andrews, R.D., Zerbini, A.N. and Falcone, E.A. 2017. Should I stay or should I go? Modelling year-round habitat suitability and drivers of residency for fin whales in the California Current. Divers. Distrib. 23(10): 1204-15.

Schmidt, V., Weber, T.C., Wiley, D.N. and Johnson, M.P. 2010. Underwater tracking of humpback whales (Megaptera novaeangliae) with highfrequency pingers and acoustic recording tags. IEEE J. Oceanic Eng. 35(4): 821-36. 
Schneider, K., Baird, R.W., Dawson, S., Visser, I. and Childerhouse, S. 1998. Reactions of bottlenose dolphins to tagging attempts using a remotely-deployed suction-cup tag. Mar. Mamm. Sci. 14(2): 316-24.

Scholander, P.F. 1940. Experimental investigations on the respiratory function in diving mammals and birds. Hvalrådets Skrifter 22: 1-131.

Schorr, G.S., Baird, R.W., Hanson, M.B., Webster, D.I., McSweeney, D.J. and Andrews, R.D. 2009. Movements of satellite-tagged Blainville's beaked whales off the island of Hawai'i. Endanger. Spec. Res. 10: 203-13.

Schorr, G.S., Falcone, E.A., Moretti, D.J. and Andrews, R.D. 2014. First Long-Term Behavioral Records from Cuvier's Beaked Whales (Ziphius cavirostris) Reveal Record-Breaking Dives. PLoS One 9(3): e92633.

Scott, M.D. and Chivers, S.J. 2009. Movements and diving behavior of pelagic spotted dolphins. Mar. Mamm. Sci. 25(1): 137-60.

Scott, M.D., Hohn, A.A., Westgate, A.J., Nicolas, J.R., Whitaker, B.R. and Campbell, W.B. 2001. A note on the release and tracking of a rehabilitated pygmy sperm whale (Kogia breviceps). J. Cetacean Res. Manage. 3(1): $87-94$.

Scott, M.D., Wells, R.S., Irvine, A.B. and Mate, B.R. 1990. Tagging and marking studies on small cetaceans. pp.489-514. In: Leatherwood, S. and Reeves, R.R. (eds). The Bottlenose Dolphin. Academic Press, San Diego.

Segre, P.S., Cade, D.E., Fish, F.E., Potvin, J., Allen, A.N., Calambokidis, J., Friedlaender, A.S. and Goldbogen, J.A. 2016. Hydrodynamic properties of fin whale flippers predict maximum rolling performance. J. Exp. Biol. 219(21): 3315-20.

Segre, P.S., Mduduzi Seakamela, S., Meÿer, M.A., Findlay, K.P. and Goldbogen, J.A. 2017. A hydrodynamically active flipper-stroke in humpback whales. Curr. Biol. 27(13): R636-R37.

Sepúlveda, M., Pérez-Álvarez, M.J., Santos-Carvallo, M., Pavez, G., Olavarría, C., Moraga, R. and Zerbini, A.N. 2018. From whaling to whale watching: Identifying fin whale critical foraging habitats off the Chilean coast. Aquat. Conserv. 28(4): 821-29.

Sequeira, A.M.M., Rodríguez, J.P., Eguíluz, V.M., Harcourt, R., Hindell, M., Sims, D.W., Duarte, C.M., Costa, D.P., Fernández-Gracia, J., Ferreira, L.C., Hays, G.C., Heupel, M.R., Meekan, M.G., Aven, A., Bailleul, F., Baylis, A.M.M., Berumen, M.L., Braun, C.D., Burns, J., Caley, M.J., Campbell, R., Carmichael, R.H., Clua, E., Einoder, L.D., Friedlaender, A., Goebel, M.E., Goldsworthy, S.D., Guinet, C., Gunn, J., Hamer, D., Hammerschlag, N., Hammill, M., Hückstädt, L.A., Humphries, N.E., Lea, M.-A., Lowther, A., Mackay, A., McHuron, E., McKenzie, J., McLeay, L., McMahon, C.R., Mengersen, K., Muelbert, M.M.C., Pagano, A.M., Page, B., Queiroz, N., Robinson, P.W., Shaffer, S.A., Shivji, M., Skomal, G.B., Thorrold, S.R., Villegas-Amtmann, S., Weise, M., Wells, R., Wetherbee, B., Wiebkin, A., Wienecke, B. and Thums, M. 2018. Convergence of marine megafauna movement patterns in coastal and open oceans. Proc. Natl Acad. Sci. 115(12): 3072-77.

Shaffer, J.W., Moretti, D., Jarvis, S., Tyack, P. and Johnson, M. 2013. Effective beam pattern of the Blainville's beaked whale (Mesoplodon densirostris) and implications for passive acoustic monitoring. J. Acoust Soc. Am. 133(3): 1770-84.

Shaffer, S.A., Costa, D.P., Williams, T.M. and Ridgway, S.H. 1997. Diving and swimming performance of white whales, Delphinapterus leucas: An assessment of plasma lactate and blood gas levels and respiratory rates. J. Exp. Biol. 200: 3091-99.

Shapiro, A.D. 2006. Preliminary evidence for signature vocalizations among free-ranging narwhals (Monodon monoceros). J. Acoust. Soc. Am. 120(3): 1695-705.

Shapiro, A.D., Tyack, P.L. and Seneff, S. 2011. Comparing call-based versus subunit-based methods for categorizing Norwegian killer whale, Orcinus orca, vocalizations. Anim. Behav. 81(2): 377-86.

Sharp, S.M., Harry, C.T., Hoppe, J.M., Moore, K.M., Niemeyer, M.E., Robinson, I., Rose, K.S., Sharp, W.B., Landry, S., Richardson, J. and Moore, M.J. 2016. A comparison of postrelease survival parameters between single and mass stranded delphinids from Cape Cod, Massachusetts, USA. Mar. Mamm. Sci. 32(1): 161-80.

Shorter, A.K., Murray, M.M., Johnson, M., Moore, M. and Howle, L.E. 2014. Drag of suction cup tags on swimming animals: Modeling and measurement. Mar. Mamm. Sci. 30(2): 726-46.

Shorter, K.A., Shao, Y., Ojeda, L., Barton, K., Rocho-Levine, J., van der Hoop, J. and Moore, M. 2017. A day in the life of a dolphin: Using biologging tags for improved animal health and well-being. Mar. Mamm. Sci. 33(3): 785-802.

Shpak, O.V., Andrews, R.D., Glazov, D.M., Litovka, D.I., Hobbs, R.C. and Mukhametov, L.M. 2010. Seasonal migrations of Sea of Okhotsk beluga whales (Delphinapterus leucas) of the Sakhalin-Amur summer aggregation. Russ. J. Mar. Biol. 36(1): 56-62.

Silva, M.A., Jonsen, I., Russell, D.J.F., Prieto, R., Thompson, D. and Baumgartner, M.F. 2014. Assessing performance of Bayesian state-space models fit to Argos satellite telemetry locations processed with Kalman filtering. PLoS One 9(3): e92277.

Silva, M.A., Prieto, R., Jonsen, I., Baumgartner, M.F. and Santos, R.S. 2013. North Atlantic blue and fin whales suspend their spring migration to forage in middle latitudes: building up energy reserves for the journey? PLoS One 8(10): e76507.

Silva, T.L., Mooney, T.A., Sayigh, L.S., Baird, R.W. and Tyack, P.L. 2017. Successful suction-cup tagging of a small delphinid species, Stenella attenuata: Insights into whistle characteristics. Mar. Mamm. Sci. 33(2): 653-68.

Silva, T.L., Mooney, T.A., Sayigh, L.S., Tyack, P.L., Baird, R.W. and Oswald, J.N. 2016. Whistle characteristics and daytime dive behavior in pantropical spotted dolphins (Stenella attenuata) in Hawai'i measured using digital acoustic recording tags (DTAGs). J. Acoust. Soc. Am. 140(1): 421-29.

Simon, M., Hanson, M.B., Murrey, L., Tougaard, J. and Ugarte, F. 2009a. From captivity to the wild and back: An attempt to release Keiko the killer whale. Mar. Mamm. Sci. 25(3): 693-705.

Simon, M., Johnson, M. and Madsen, P.T. 2012. Keeping momentum with a mouthful of water: behavior and kinematics of humpback whale lunge feeding. J. Exp. Biol. 215(21): 3786-98.

Simon, M., Johnson, M., Tyack, P. and Madsen, P.T. 2009b. Behaviour and kinematics of continuous ram filtration in bowhead whales (Balaena mysticetus). Proc. R. Soc. B Biol. Sci. 276(1674): 3819-28.

Sivle, L.D., Kvadsheim, P.H., Cure, C., Isojunno, S., Wensveen, P., Lam, F.A., Visser, F., Kleivane, L., Tyack, P.L., Harris, C.M. and Miller, P.J.O 2015. Severity of expert-identified behavioural responses of humpback whale, minke whale, and northern bottlenose whale to naval sonar. Aquat. Mamm. 41(4): 469-502.

Sivle, L.D., Kvadsheim, P.H., Fahlman, A., Lam, F.P.A., Tyack, P.L. and Miller, P.J.O. 2012. Changes in dive behavior during naval sonar exposure in killer whales, long-finned pilot whales, and sperm whales. Front. Physiol. 3(400): 1-11.

Sivle, L.D., Wensveen, P.J., Kvadsheim, P.H., Lam, F.A., Visser, F., Cure, C., Harris, C.M., Tyack, P.L. and Miller, P.J.O. 2017. Naval sonar disrupts foraging in humpback whales. Mar. Ecol. Prog. Ser. 562 211-20.

Skrovan, R.C., Williams, T.M., Berry, P.S., Moore, P.W. and Davis, R.W. 1999. The diving physiology of bottlenose dolphins (Tursiops truncatus) II. Biomechanics and changes in buoyancy at depth. J. Exp. Biol. 202 2749-61.

Smith, A.J., Higdon, J.W., Richard, P., Orr, J., Bernhardt, W. and Ferguson, S.H. 2017. Beluga whale summer habitat associations in the Nelson River estuary, western Hudson Bay, Canada. PLoS One 12(8): e0181045.

Smith, J.N., Grantham, H.S., Gales, N., Double, M.C., Noad, M.J. and Paton, D. 2012. Identification of humpback whale breeding and calving habitat in the Great Barrier Reef. Mar. Ecol. Prog. Ser. 447: 259-72.

Smith, T.G. and Martin, A.R. 1994. Distribution and movements of belugas, Delphinapterus leucas, in the Canadian high Arctic. Can. J. Fish. Aquat. Sci. 51(7): 1653-63.

Solsona Berga, A., Wright, A.J., Galatius, A., Sveegaard, S. and Teilmann, J. 2014. Do larger tag packages alter diving behavior in harbor porpoises? Mar. Mamm. Sci. 31(2): 756-63.

Sonne, C., Teilmann, J., Wright, A.J., Dietz, R. and Leifsson, P.S. 2012. Tissue healing in two harbor porpoises (Phocoena phocoena) following long-term satellite transmitter attachment. Mar. Mamm. Sci. 28(3): E316E24.

Sørensen, P.M., Wisniewska, D.M., Jensen, F.H., Johnson, M., Teilmann, J and Madsen, P.T. 2018. Click communication in wild harbour porpoises (Phocoena phocoena). Sci. Rep. 8(1): 9702.

Southall, B.L., DeRuiter, S.L., Friedlaender, A., Stimpert, A.K., Goldbogen, J.A., Hazen, E., Casey, C., Fregosi, S., Cade, D.E., Allen, A.N., Harris, C.M., Schorr, G., Moretti, D., Guan, S. and Calambokidis, J. 2019. Behavioral responses of individual blue whales (Balaenoptera musculus) to mid-frequency military sonar. J. Exp. Biol. 222(5): jeb190637.

Southall, B.L., Moretti, D., Abraham, B., Calambokidis, J., DeRuiter, S.L. and Tyack, P.L. 2012. Marine mammal behavioral response studies in southern California: Advances in technology and experimental methods. Mar. Technol. Soc. J. 46(4): 46-59.

Southall, B.L., Nowacek, D.P., Miller, P.J.O. and Tyack, P.L. 2016. Experimental field studies to measure behavioral responses of cetaceans to sonar. Endanger. Spec. Res. 31: 293-315.

St. Aubin, D.J., Forney, K.A., Chivers, S.J., Scott, M.D., Danil, K., Romano, T.A., Wells, R.S. and Gulland, F.M.D. 2013. Hematological, serum, and plasma chemical constituents in pantropical spotted dolphins (Stenella attenuata) following chase, encirclement, and tagging. Mar. Mamm. Sci. 29(1): 14-35.

Stafford, K.M., Citta, J.J., Okkonen, S.R. and Suydam, R.S. 2016. Winddependent beluga whale dive behavior in Barrow Canyon, Alaska. Deep Sea Res. Pt. I Oceanogr. Res. Pap. 118: 57-65.

Stafford, K.M., Ferguson, M.C., Hauser, D.D.W., Okkonen, S.R., Berchok, C.L., Citta, J.J., Clarke, J.T., Garland, E.C., Jones, J. and Suydam, R.S 2018. Beluga whales in the western Beaufort Sea: Current state of knowledge on timing, distribution, habitat use and environmental drivers. DSR 152: 182-94. 
Stepanuk, J.E.F., Read, A.J., Baird, R.W., Webster, D.L. and Thorne, L.H. 2018. Spatiotemporal patterns of overlap between short-finned pilot whales and the U.S. pelagic longline fishery in the Mid-Atlantic Bight: An assessment to inform the management of fisheries bycatch. Fish. Res. 208: 309-20.

Stewart, B.S., Harvey, J. and Yochem, P.K. 2001. Post-release monitoring and tracking of a rehabilitated California gray whale. Aquat. Mamm. 27(3): 294.

Stimpert, A.K., Au, W.W.L., Parks, S.E., Hurst, T. and Wiley, D.N. 2011. Common humpback whale (Megaptera novaeangliae) sound types for passive acoustic monitoring. J. Acoust. Soc. Am. 129(1): 476-82.

Stimpert, A.K., DeRuiter, S.L., Falcone, E.A., Joseph, J., Douglas, A.B., Moretti, D.J., Friedlaender, A.S., Calambokidis, J., Gailey, G., Tyack, P.L. and Goldbogen, J.A. 2015. Sound production and associated behavior of tagged fin whales (Balaenoptera physalus) in the Southern California Bight. Anim. Biotelemetry 3: 23

Stimpert, A.K., DeRuiter, S.L., Southall, B.L., Moretti, D.J., Falcone, E.A., Goldbogen, J.A., Friedlaender, A., Schorr, G.S. and Calambokidis, J. 2014. Acoustic and foraging behavior of a Baird's beaked whale, Berardius bairdii, exposed to simulated sonar. Sci. Rep. 4: 7031.

Stimpert, A.K., Mattila, D., Nosal, E. and Au, W.W.L. 2012a. Tagging young humpback whale calves: methodology and diving behavior. Endanger. Spec. Res. 19(1): 11-17.

Stimpert, A.K., Peavey, L.E., Friedlaender, A.S. and Nowacek, D.P. 2012 b. Humpback whale song and foraging behavior on an Antarctic feeding ground. PLoS One 7(12): e51214.

Stimpert, A.K., Wiley, D.N., Au, W.W.L., Johnson, M.P. and Arsenault, R. 2007. 'Megapclicks': acoustic click trains and buzzes produced during night-time foraging of humpback whales (Megaptera novaeangliae). Biol. Lett. 3(5): 467-70.

Stone, G., Goodyear, J., Hutt, A. and Yoshinaga, A. 1994. A new noninvasive tagging method for studying wild dolphins. Mar. Technol. Soc. J. 28(1): 11-16.

Stone, G., Hutt, A., Brown, J., Yoshinaga, A., Joy, L. and Burleigh, R. 1998. Respiration and movement of Hector's dolphin from suction-cup VHF radio tag telemetry data. Mar. Technol. Soc. J. 32(1): 89-93.

Stone, G., Hutt, A., Duignan, P., Teilmann, J., Cooper, R., Geschke, K., Yoshinaga, A., Russell, K., Baker, A., Suisted, R., Baker, S., Brown, J., Jones, G. and Higgins, D. 2005. Hector's dolphin (Cephalorhynchus hectori hectori) satellite tagging, health and genetic assessment project. Report submitted to the Dept. Conservation (DoC) Auckland Conservancy in fulfillment of a contract to New England Aquarium, Boston, MA. 77pp

Straley, J.M., Schorr, G.S., Thode, A.M., Calambokidis, J., Lunsford, C.R., Chenoweth, E.M., O'Connell, V.M. and Andrews, R.D. 2014. Depredating sperm whales in the Gulf of Alaska: local habitat use and long distance movements across putative population boundaries Endanger. Spec. Res. 24(2): 125-35.

Suydam, R.S. 2009. Age, growth, reproduction, and movements of beluga whales (Delphinapterus leucas) from the eastern Chukchi Sea. PhD thesis, University of Washington. 169pp.

Suydam, R.S., Lowry, L.F., Frost, K.J., O'Corry-Crowe, G.M. and Pikok Jr, D. 2001. Satellite tracking of eastern Chukchi Sea beluga whales into the Arctic Ocean. Arctic 54(3): 237-43

Sveegaard, S., Nabe-Nielsen, J., Stæhr, K.J., Jensen, T.F., Mouritsen, K.N. and Teilmann, J. 2012. Spatial interactions between marine predators and their prey: herring abundance as a driver for the distributions of mackerel and harbour porpoise. Mar. Ecol. Prog. Ser. 468: 245-53.

Sveegaard, S., Teilmann, J., Tougaard, J., Dietz, R., Mouritsen, K.N., Desportes, G. and Siebert, U. 2011. High-density areas for harbor porpoises (Phocoena phocoena) identified by satellite tracking. Mar Mamm. Sci. 27(1): 230-46.

Szesciorka, A.R. 2015. Using new tag attachments to study humpback whale fine-scale spatiotemporal dive behavior, habitat use, and reaction to ships off Northern California. MSc thesis, San Jose State University, California.

Szesciorka, A.R., Calambokidis, J. and Harvey, J.T. 2016. Testing tag attachments to increase the attachment duration of archival tags on baleen whales. Animal Biotelemetry 4(1): 18.

Tanaka, S. 1987. Satellite radio tracking of bottlenose dolphins Tursiops truncatus. Nippon Suisan Gakkaishi 53(8): 1327-38.

Teilmann, J., Christiansen, C.T., Kjellerup, S., Dietz, R. and Nachman, G. 2013. Geographic, seasonal, and diurnal surface behavior of harbor porpoises. Mar. Mamm. Sci. 29(2): E60-E76.

Teloni, V., Mark, J.P., Patrick, M.J.O. and Peter, M.T. 2008. Shallow food for deep divers: Dynamic foraging behavior of male sperm whales in a high latitude habitat. J. Exp. Mar. Biol. Ecol. 354(1): 119-31.

Teloni, V., Zimmer, W.M.X. and Tyack, P.L. 2005. Sperm whale trumpet sounds. Bioacoustics 15(2): 163-74.

Tennessen, J.B., Holt, M.M., Hanson, M.B., Emmons, C.K., Giles, D.A. and Hogan, J.T. 2019. Kinematic signatures of prey capture from archival tags reveal sex differences in killer whale foraging activity. J. Exp. Biol. 222(3): jeb191874.

Thorne, L.H., Foley, H.J., Baird, R.W., Webster, D.L., Swaim, Z.T. and Read, A.J. 2017. Movement and foraging behavior of short-finned pilot whales in the Mid-Atlantic Bight: importance of bathymetric features and implications for management. Mar. Ecol. Prog. Ser. 584: 245-57.

Tønnesen, P., Gero, S., Ladegaard, M., Johnson, M. and Madsen, P.T. 2018. First-year sperm whale calves echolocate and perform long, deep dives. Behav. Ecol. Sociobiol. 72(10): 165.

Toosy, A.H., Khan, U., Mahmood, R. and Bhagat, H.B. 2009. First tagging with a radio-transmitter of a rescued Indus river dolphin near Sukkur Barrage, Pakistan. Wildlife Middle East News 3(4): 1-2.

Towers, J.R., Tixier, P., Ross, K.A., Bennett, J., Arnould, J.P.Y., Pitman, R.L. and Durban, J.W. 2019. Movements and dive behaviour of a toothfish-depredating killer and sperm whale. ICES J. Mar. Sci. 76(1): 298-311.

Townsend, F.I., Smith, C.R. and Rowles, T.K. 2018. Health assessment of bottlenose dolphins in capture-release studies. pp.823-33. In: Gulland, F.M.D., Dierauf, L.A. and Whitman, K.L. (eds). CRC Handbook of Marine Mammal Medicine. CRC Press: Taylor and Francis Group, Boca Raton, FL.

Trudelle, L., Cerchio, S., Zerbini, A.N., Geyer, Y., Mayer, F., Jung, J., Hervé, M.R., Pous, S., Sallée, J., Rosenbaum, H.C., Adam, O. and Charrassin, J. 2016. Influence of environmental parameters on movements and habitat utilization of humpback whales (Megaptera novaeangliae) in the Madagascar breeding ground. R. Soc. Open Sci. 3: 160616.

Tsuchiya, K., Tsumaki, Y., Mori, K. and Okamoto, R. 2019. Whale rover moving along the surface of sperm whale. Advanced Robotics 33(3-4): 195-206.

Tyack, P. 2009. Acoustic playback experiments to study behavioral responses of free-ranging marine animals to anthropogenic sound. Mar. Ecol. Prog. Ser. 395: 187-200.

Tyack, P.L., Johnson, M., Soto, N.A., Sturlese, A. and Madsen, P.T. 2006. Extreme diving of beaked whales. J. Exp. Biol. 209(21): 4238-53.

Tyack, P.L., Zimmer, W.M.X., Moretti, D., Southall, B.L., Claridge, D.E., Durban, J.W., Clark, C.W., D’Amico, A., DiMarzio, N., Jarvis, S., McCarthy, E., Morrissey, R., Ward, J. and Boyd, I.L. 2011. Beaked whales respond to simulated and actual navy sonar. PLoS One 6(3): e17009.

Tyson, R.B., Friedlaender, A.S. and Nowacek, D.P. 2016. Does optimal foraging theory predict the foraging performance of a large air-breathing marine predator? Anim. Behav. 116: 223-35.

Tyson, R.B., Friedlaender, A.S., Ware, C., Stimpert, A.K. and Nowacek, D.P. 2012. Synchronous mother and calf foraging behaviour in humpback whales Megaptera novaeangliae: insights from multi-sensor suction cup tags. Mar. Ecol. Prog. Ser. 457: 209-20.

Vacquié-Garcia, J., Lydersen, C., Ims, R.A. and Kovacs, K.M. 2018. Habitats and movement patterns of white whales Delphinapterus leucas in Svalbard, Norway in a changing climate. Mov. Ecol. 6(1): 21.

van Beest, F.M., Teilmann, J., Dietz, R., Galatius, A., Mikkelsen, L., Stalder, D., Sveegaard, S. and Nabe-Nielsen, J. 2018a. Environmental drivers of harbour porpoise fine-scale movements. Mar. Biol. 165(5): 95.

van Beest, F.M., Teilmann, J., Hermannsen, L., Galatius, A., Mikkelsen, Sveegaard, S., Balle, J.D., Dietz, R. and Nabe-Nielsen, J. 2018b. Finescale movement responses of free-ranging harbour porpoises to capture, tagging and short-term noise pulses from a single airgun. R. Soc. Open Sci. 5(1): 170110

van der Hoop, J., Moore, M., Fahlman, A., Bocconcelli, A., George, C., Jackson, K., Miller, C., Morin, D., Pitchford, T., Rowles, T., Smith, J. and Zoodsma, B. 2014a. Behavioral impacts of disentanglement of a right whale under sedation and the energetic cost of entanglement. Mar. Mamm. Sci. 30(1): 282-307.

van der Hoop, J.M., Fahlman, A., Hurst, T., Rocho-Levine, J., Shorter, K.A., Petrov, V. and Moore, M.J. 2014b. Bottlenose dolphins modify behavior to reduce metabolic effect of tag attachment. J. Exp. Biol. 217(23): 422936.

van der Hoop, J.M., Fahlman, A., Shorter, K.A., Gabaldon, J., Rocho-Levine, J., Petrov, V. and Moore, M.J. 2018. Swimming energy economy in bottlenose dolphins under variable drag loading. Front. Mar. Sci. 5: 465.

van der Hoop, J.M., Nowacek, D.P., Moore, M.J. and Triantafyllou, M.S. 2017. Swimming kinematics and efficiency of entangled North Atlantic right whales. Endanger. Spec. Res. 32: 1-17.

Videsen, S.K.A., Bejder, L., Johnson, M. and Madsen, P.T. 2017. High suckling rates and acoustic crypsis of humpback whale neonates maximise potential for mother-calf energy transfer. Funct. Ecol. 31(8): 1561-73.

Víkingsson, G.A. and Heide-Jørgensen, M.P. 2015. First indications of autumn migration routes and destination of common minke whales tracked by satellite in the North Atlantic during 2001-2011. Mar. Mamm. Sci. 31(1): 376-85.

Visser, F. 2012. Diving behavior of Sowerby's beaked whale in the Azores. $5 \mathrm{pp}$. 
Visser, F., Cure, C., Kvadsheim, P.H., Lam, P.A., Tyack, P.L. and Miller, P.J.O. 2016. Disturbance-specific social responses in long-finned pilot whales, Globicephala melas. Sci. Rep. 6: 28641

Visser, F., Kok, A.C.M., Oudejans, M.G., Scott-Hayward, L.A.S., DeRuiter, S.L., Alves, A.C., Antunes, R.N., Isojunno, S., Pierce, G.J., Slabbekoorn, H., Huisman, J. and Miller, P.J.O. 2017. Vocal foragers and silent crowds: context-dependent vocal variation in Northeast Atlantic long-finned pilot whales. Behav. Ecol. Sociobiol. 71: 170

Visser, F., Miller, P.J.O., Antunes, R.N., Oudejans, M.G., Mackenzie, M.L., Aoki, K., Lam, F.A., Kvadsheim, P.H., Huisman, J. and Tyack, P.L. 2014 The social context of individual foraging behaviour in long-finned pilot whales (Globicephala melas). Behaviour 151(10): 1453-77.

von Benda-Beckmann, A.M., Wensveen, P.J., Samara, F.I.P., Beerens, S.P. and Miller, P.J.O. 2016. Separating underwater ambient noise from flow noise recorded on stereo acoustic tags attached to marine mammals. $J$. Exp. Biol. 219: 2271-75.

Wade, P., Heide-Jorgensen, M.P., Shelden, K., Barlow, J., Carretta, J., Durban, J., LeDuc, R., Munger, L., Rankin, S., Sauter, A. and Stinchcomb, C. 2006. Acoustic detection and satellite-tracking leads to discovery of rare concentration of endangered North Pacific right whales. Biol. Lett. 2(3): 417-19.

Walker, K.A., Trites, A.W., Haulena, M. and Weary, D.M. 2012. A review of the effects of different marking and tagging techniques on marine mammals. Wildl. Res. 39(1): 15

Ward, J., Morrissey, R., Moretti, D., DiMarzio, N., Jarvis, S., Johnson, M., Tyack, P. and White, C. 2008. Passive acoustic detection and localization of Mesoplodon densirostris (Blainville's beaked whale) vocalization using distributed bottom-mounted hydrophones in conjunction with a digital tag (DTAG) recording. Can. Acoustics 36(1): 60-66.

Ware, C., Friedlaender, A.S. and Nowacek, D.P. 2011. Shallow and deep lunge feeding of humpback whales in fjords of the West Antarctic Peninsula. Mar. Mamm. Sci. 27(3): 587-605.

Ware, C., Wiley, D.N., Friedlaender, A.S., Weinrich, M., Hazen, E.L., Bocconcelli, A., Parks, S.E., Stimpert, A.K., Thompson, M.A. and Abernathy, K. 2014. Bottom side-roll feeding by humpback whales (Megaptera novaeangliae) in the southern Gulf of Maine, U.S.A. Mar Mamm. Sci. 30(2): 494-511.

Warren, V.E., Marques, T.A., Harris, D., Thomas, L., Tyack, P.L., Aguilar de Soto, N., Hickmott, L.S. and Johnson, M.P. 2017. Spatiotemporal variation in click production rates of beaked whales: Implications for passive acoustic density estimation. J. Acoust. Soc. Am. 141: 1962.

Watanabe, Y.Y., Sato, K., Watanuki, Y., Takahashi, A., Mitani, Y., Amano, M., Aoki, K., Narazaki, T., Iwata, T., Minamikawa, S. and Miyazaki. 2011. Scaling of swim speed in breath-hold divers. J. Anim. Ecol. 80(1) $57-68$.

Watkins, W.A. 1979. A projectile point for penetrating whale blubber. Deep Sea Res. Pt. A Oceanogr. Res. Pap. 26(11): 1301-08.

Watkins, W.A. 1981. Reaction of three species of whales Balaenoptera physalus, Megaptera novaeangliae, and Balaenoptera edeni to implanted radio tags. Deep Sea Res. Pt. A Oceanogr. Res. Pap. 28(6): 589-99.

Watkins, W.A., Daher, M.A., Dimarzio, N.A., Samuels, A., Wartzok, D., Fristrup, K.M., Gannon, D.P., Howey, P.W., Maiefski, R.R. and Spradlin, T.R. 1999. Sperm whale surface activity from tracking by radio and satellite tags. Mar. Mamm. Sci. 15(4): 1158-80.

Watkins, W.A., Daher, M.A., Dimarzio, N.A., Samuels, A., Wartzok, D. Fristrup, K.M., Howey, P.W. and Maiefski, R.R. 2002. Sperm whale dives tracked by radio tag telemetry. Mar. Mamm. Sci. 18(1): 55-68.

Watkins, W.A., Daher, M.A., Fristrup, K.M., Howald, T.J., Sciara, D. and Notarbartolo, G. 1993. Sperm whales tagged with transponders and tracked underwater by sonar. Mar. Mamm. Sci. 9(1): 55-67.

Watkins, W.A., Moore, K.E., Wartzok, D. and Johnson, J.H. 1981. Radio tracking of finback (Balaenoptera physalus) and humpback (Megaptera novaeangliae) whales in Prince William Sound, Alaska. Deep Sea Res. Pt. A Oceanogr. Res. Pap. 28(6): 577-88.

Watkins, W.A. and Schevill, W.E. 1977. The development and testing of a radio whale tag. Report prepared for the Office of Naval Research by Woods Hole Oceanographic Institute. 44pp.

Watkins, W.A., Sigurjónsson, J., Wartzok, D., Maiefski, R.R., Howey, P.W. and Daher, M.A. 1996. Fin whale tracked by satellite off Iceland. Mar. Mamm. Sci. 12(4): 564-69.

Watkins, W.A. and Tyack, P. 1991. Reaction of sperm whales (Physeter catodon) to tagging with implanted sonar transponders and radio tags Mar. Mamm. Sci. 7(4): 409-13.

Watt, C.A., Orr, J.R., Heide-Jørgensen, M.P., Nielson, N.H. and Ferguson, S.H. 2015. Differences in dive behaviour among the world's three narwhal Monodon monoceros populations correspond with dietary differences. Mar. Ecol. Prog. Ser. 525: 273-85.

Watwood, S.L., Miller, P.J.O., Johnson, M., Madsen, P.T and Tyack, P.L. 2006. Deep-diving foraging behaviour of sperm whales (Physeter macrocephalus). J. Anim. Ecol. 75(3): 814-25.
Weinrich, M.T., Lambertsen, R.H., Baker, C.S., Schilling, M.R. and Belt, C.R. 1991. Behavioural responses of humpback whales (Megaptera novaeangliae) in the Southern Gulf of Maine to biopsy sampling. Rep. Int Whaling Comm. (special issue) 13: 91-97.

Weinstein, B.G., Double, M., Gales, N., Johnston, D.W. and Friedlaender, A.S. 2017. Identifying overlap between humpback whale foraging grounds and the Antarctic krill fishery. Biol. Conserv. 210, Part A: 184-91.

Weinstein, B.G. and Friedlaender, A.S. 2017. Dynamic foraging of a top predator in a seasonal polar marine environment. Oecologia 185(3): 42735 .

Weller, D.W. 2008. Report of the Large Whale Tagging Workshop convened by the US Marine Mammal Commission and US National Marine Fisheries Service, 10 December 2005, San Diego, California, USA. Contract Report to the US Marine Mammal Commission. Available from http://www.mmc.gov/pdf/final tagging 82608.pdf. 32pp.

Wells, R.S. 2005. Report to the Marine Mammal Commission on the Small Cetacean Electronic Tag Attachment Workshop. Report (unpublished) on workshop held 11-12 June 2003. 73pp. [Available from the author]

Wells, R.S. 2008. Tagging and tracking of rough-toothed dolphins (Steno bredanensis) from the March 2005 mass stranding in the Florida Keys NOAA Tech. Mem. NMFS-SEFSC-574. 50pp.

Wells, R.S. 2013. Evaluation of tag attachments on small cetaceans. Final Report to the Office of Naval Research for Award Number: N000141210391. 5pp

Wells, R.S., Fauquier, D.A., Gulland, F.M.D., Townsend, F.I. and DiGiovanni, R.A. 2012. Evaluating postintervention survival of freeranging odontocete cetaceans. Mar. Mamm. Sci. 29(4): E463-E83.

Wells, R.S., Fougeres, E.M., Cooper, A.G., Stevens, R.O., Brodsky, M., Lingenfelser, R., Dold, C. and Douglas, D.C. 2013. Movements and dive patterns of short-finned pilot whales (Globicephala macrorhynchus) released from a mass stranding in the Florida Keys. Aquat. Mamm. 39(1) $61-72$

Wells, R.S., Manire, C.A., Byrd, L., Smith, D.R., Gannon, J.G., Fauquier, D. and Mullin, K.D. 2009. Movements and dive patterns of a rehabilitated Risso's dolphin, Grampus griseus, in the Gulf of Mexico and Atlantic Ocean. Mar. Mamm. Sci. 25(2): 420-29.

Wells, R.S., Rhinehart, H.L., Cunningham, P., Whaley, J., Baran, M., Koberna, C. and Costa, D.P. 1999. Long distance offshore movements of bottlenose dolphins. Mar. Mamm. Sci. 15(4): 1098-114.

Wells, R.S., Schwacke, L.H., Rowles, T.K., Balmer, B.C., Zolman, E., Speakman, T., Townsend, F.I., Tumlin, M.C., Barleycorn, A. and Wilkinson, K.A. 2017. Ranging patterns of common bottlenose dolphins Tursiops truncatus in Barataria Bay, Louisiana, following the Deepwater Horizon oil spill. Endanger. Spec. Res. 33: 159-80.

Wensveen, P., Thomas, L. and Miller, P.J.O. 2015a. A path reconstruction method integrating dead-reckoning and position fixes applied to humpback whales. Mov. Ecol. 3: 31 .

Wensveen, P.J., Kvadsheim, P.H., Lam, F.-P.A., Benda-Beckmann, A.M.v., Sivle, L.D., Visser, F., Curé, C., Tyack, P.L. and Miller, P.J.O. 2017. Lack of behavioural responses of humpback whales (Megaptera novaeangliae) indicate limited effectiveness of sonar mitigation. J. Exp. Biol. 220(22) 4150-61.

Wensveen, P.J., von Benda-Beckmann, A.M., Ainslie, M.A., Lam, F.A., Kvadsheim, P.H., Tyack, P.L. and Miller, P.J.O. 2015b. How effectively do horizontal and vertical response strategies of long- finned pilot whales reduce sound exposure from naval sonar? Mar. Environ. Res. 106: 6881.

Werth, A.J., Potvin, J., Shadwick, R.E., Jensen, M.M., Cade, D.E. and Goldbogen, J.A. 2018. Filtration area scaling and evolution in mysticetes: trophic niche partitioning and the curious cases of sei and pygmy righ whales. Biol. J. Linn. Soc. 125(2): 264-79.

West, K.L., Walker, W.A., Baird, R.W., Webster, D.L. and Schorr, G.S. 2018 Stomach contents and diel diving behavior of melon-headed whales (Peponocephala electra) in Hawaiian waters. Mar. Mamm. Sci. 34(4) 1082-96.

Westdal, K.H., Davis, J., MacPherson, A., Orr, J. and Ferguson, S.H. 2016. Behavioural changes in belugas (Delphinapterus leucas) during a killer whale (Orcinus orca) attack in southwest Hudson Bay. Can. Field Nat 130(4): 315-19.

Westdal, K.H., Richard, P.R. and Orr, J.R. 2013. Availability bias in population survey of Northern Hudson Bay narwhal (Monodon monoceros). Polar Biol. 36(9): 1235-41.

Westgate, A.J., Head, A.J., Berggren, P., Koopman, H.N. and Gaskin, D.E 1995. Diving behaviour of harbour porpoises, Phocoena phocoena. Can J. Fish. Aquat. Sci. 52(5): 1064-73.

Westgate, A.J., McLellan, W.A., Wells, R.S., Scott, M.D., Meagher, E.M. and Pabst, D.A. 2007. A new device to remotely measure heat flux and skin temperature from free-swimming dolphins. J. Exp. Mar. Biol. Ecol. 346(1-2): 45-59.

Westgate, A.J. and Read, A.J. 1998. Applications of new technology to the conservation of porpoises. Mar. Technol. Soc. J. 32(1): 70-81. 
Westgate, A.J., Read, A.J., Cox, T.M., Schofield, T.D., Whitaker, B.R. and Anderson, K.E. 1998. Monitoring a rehabilitated harbor porpoise using satellite telemetry. Mar. Mamm. Sci. 14(3): 599-604.

Wiley, D., Ware, C., Bocconcelli, A., Cholewiak, D., Friedlaender, A., Thompson, M. and Weinrich, M. 2011. Underwater components of humpback whale bubble-net feeding behaviour. Behaviour 148(5): 575602 .

Williams, T.M. 2001. Intermittent swimming by mammals: A strategy for increasing energetic efficiency during diving. Am. Zool. 41: 166-76.

Williams, T.M., Blackwell, S.B., Richter, B., Sinding and Heide-Jørgensen, M.P. 2017a. Paradoxical escape responses by narwhals (Monodon monoceros). Science 358: 1328-31.

Williams, T.M., Davis, R.W., Fuiman, L.A., Francis, J., Le, B.J., Boeuf, Horning, M., Calambokidis, J. and Croll, D.A. 2000. Sink or swim: Strategies for cost-efficient diving by marine mammals. Science 288(5463): 133-36

Williams, T.M., Friedl, W.A., Fong, M.L., Yamada, R.M., Sedivy, P. and Haun, J.E. 1992. Travel at low energetic cost by swimming and waveriding bottlenose dolphins. Letters to Nature 355: 821-23.

Williams, T.M., Friedl, W.A. and Haun, J.E. 1993. The physiology of bottlenose dolphins (Tursiops truncatus): Heart rate, metabolic rate and plasma lactate concentration during exercise. J. Exp. Biol. 179: 31-46.

Williams, T.M., Fuiman, L.A., Kendall, T., Berry, P., Richter, B., Noren, S.R., Thometz, N., Shattock, M.J., Farrell, E., Stamper, A.M. and Davis, R.W. 2015. Exercise at depth alters bradycardia and incidence of cardiac anomalies in deep-diving marine mammals. Nat. Commun. 6 : 6055 .

Williams, T.M., Haun, J.E. and Friedl, W.A. 1999a. The diving physiology of bottlenose dolphins (Tursiops truncatus) I. Balancing the demands of exercise for energy conservation at depth. J. Exp. Biol. 202: 273948.

Williams, T.M., Kendall, T.L., Richter, B.P., Ribeiro-French, C.R., John, J.S., Odell, K.L., Losch, B.A., Feuerbach, D.A. and Stamper, M.A. 2017b. Swimming and diving energetics in dolphins: a stroke-by-stroke analysis for predicting the cost of flight responses in wild odontocetes. J. Exp. Biol. 220(6): 1135-45.

Williams, T.M., Noren, D., Berry, P., Estes, J.A., Allison, C. and Kirtland, J. 1999b. The diving physiology of bottlenose dolphins (Tursiops truncatus) III. Thermoregulation at depth. J. Exp. Biol. 202: 2763-69.

Williamson, M.J., Kavanagh, A.S., Noad, M.J., Kniest, E. and Dunlop, R.A. 2016. The effect of close approaches for tagging activities by small research vessels on the behavior of humpback whales (Megaptera novaeangliae). Mar. Mamm. Sci. 32(4): 1234-53

Winn, H.E., Goodyear, J.D., Kenney, R.D. and Petricig, R.O. 1995. Dive patterns of tagged right whales in the Great South Channel. CSR 15(4 5): 593-611.

Winsor, M.H., Irvine, L.M. and Mate, B.R. 2017. Analysis of the spatial distribution of satellite-tagged sperm whales (Physeter macrocephalus) in close proximity to seismic surveys in the Gulf of Mexico. Aquat. Mamm. 43(4): 439-46.

Wisniewska, D.M., Johnson, M., Beedholm, K., Wahlberg, M. and Madsen, P.T. 2012. Acoustic gaze adjustments during active target selection in echolocating porpoises. J. Exp. Biol. 215(24): 4358-73.

Wisniewska, D.M., Johnson, M., Nachtigall, P.E. and Madsen, P.T. 2014 Buzzing during biosonar-based interception of prey in the delphinids Tursiops truncatus and Pseudorca crassidens. J. Exp. Biol. 217(24) 4279-82.

Wisniewska, Danuta M., Johnson, M., Teilmann, J., Rojano-Doñate, L., Shearer, J., Sveegaard, S., Miller, Lee A., Siebert, U. and Madsen, Peter T. 2016a. Ultra-high foraging rates of harbor porpoises make them vulnerable to anthropogenic disturbance. Curr. Biol. 26(11): 1441-46.

Wisniewska, D.M., Johnson, M., Teilmann, J., Siebert, U., Galatius, A., Dietz, R. and Madsen, P.T. 2018. High rates of vessel noise disrupt foraging in wild harbour porpoises (Phocoena phocoena). Proc. R. Soc. B Biol. Sci. 285(1872): 20172314.

Wisniewska, D.M., Teilmann, J., Hermannsen, L., Johnson, M., Miller, L.A., Siebert, U. and Madsen, P.T. 2016b. Quantitative measures of anthropogenic noise on harbor porpoises: testing the reliability of acoustic tag recordings. pp.1236-42. In: Popper, A.N. and Hawkins, A. (eds). The Effects of Noise on Aquatic Life II, Advances in Experimental Medicine and Biology 875. Springer, New York, USA.

Witteveen, B.H., de Robertis, A., Guo, L. and Wynne, K.M. 2015. Using dive behavior and active acoustics to assess prey use and partitioning by fin and humpback whales near Kodiak Island, Alaska. Mar. Mamm. Sci. 31(1): $255-78$
Witteveen, B.H., Foy, R.J., Wynne, K.M. and Tremblay, Y. 2008. Investigation of foraging habits and prey selection by humpback whales (Megaptera novaeangliae) using acoustic tags and concurrent fish surveys. Mar. Mamm. Sci. 24(3): 516-34.

Woodward, B. 2011. Development of a peduncle belt as a medium to longterm tag attachment platform for cetacean studies. Study for Award Number N00014-10-1-0571. 13pp.

Woodward, B.L., Peterson, M.L. and Winn, J.P. 2002. Refining crossbow deployment techniques of suction cup attached tags for cetacean field studies. Mar. Technol. Soc. J. 36(2): 50-57.

Woodward, B.L. and Winn, J.P. 2006. Apparent lateralized behavior in gray whales feeding off the central British Columbia coast. Mar. Mamm. Sci. 22(1): 64-73.

Woodworth, P.A., Schorr, G.S., Baird, R.W., Webster, D.L., McSweeney, D.J., Hanson, M.B., Andrews, R.D. and Polovina, J.J. 2012. Eddies as offshore foraging grounds for melon-headed whales (Peponocephala electra). Mar. Mamm. Sci. 28(3): 638-47.

Wright, A.J., Akamatsu, T., Mouritsen, K.N., Sveegaard, S., Dietz, R. and Teilmann, J. 2017a. Silent porpoise: potential sleeping behaviour identified in wild harbour porpoises. Anim. Behav. 133: 211-22.

Wright, B.M., Ford, J.K.B., Ellis, G.M., Deecke, V.B., Shapiro, A.D., Battaile, B.C. and Trites, A.W. 2017b. Fine-scale foraging movements by fish-eating killer whales (Orcinus orca) relate to the vertical distributions and escape responses of salmonid prey (Oncorhynchus spp.). Mov. Ecol. 5(1): 3 .

Yurkowski, D.J., Auger-Méthé, M., Mallory, M.L., Wong, S.N.P., Gilchrist, G., Derocher, A.E., Richardson, E., Lunn, N.J., Hussey, N.E., Marcoux, M., Togunov, R.R., Fisk, A.T., Harwood, L.A., Dietz, R., Rosing-Asvid, A., Born, E.W., Mosbech, A., Fort, J., Grémillet, D., Loseto, L., Richard, P.R., Iacozza, J., Jean-Gagnon, F., Brown, T.M., Westdal, K.H., Orr, J., LeBlanc, B., Hedges, K.J., Treble, M.A., Kessel, S.T., Blanchfield, P.J., Davis, S., Maftei, M., Spencer, N., McFarlane-Tranquilla, L., Montevecchi, W.A., Bartzen, B., Dickson, L., Anderson, C. and Ferguson, S.H. 2019. Abundance and species diversity hotspots of tracked marine predators across the North American Arctic. Divers. Distrib. 25(3): 32845 .

Zerbini, A.N., Andriolo, A., Heide-Jørgensen, M.P., Moreira, S.C., Pizzorno, J.L., Maia, Y.G., Bethlem, C., VanBlaricom, G.R. and DeMaster, D.P. 2011. Migration and summer destinations of humpback whales (Megaptera novaeangliae) in the western South Atlantic Ocean. J. Cetacean Res. Manage. (special issue 3): 113-18.

Zerbini, A.N., Andriolo, A., Heide-Jørgensen, M.P., Pizzorno, J.L., Maia, Y.G., VanBlaricom, G.R., DeMaster, D.P., Simões-Lopes, P.C., Moreira, S. and Bethlem, C. 2006. Satellite-monitored movements of humpback whales Megaptera novaeangliae in the Southwest Atlantic Ocean. Mar. Ecol. Prog. Ser. 313: 295-304.

Zerbini, A.N., Baumgartner, M.F., Kennedy, A.S., Rone, B.K., Wade, P.R. and Clapham, P.J. 2015a. Space use patterns of the endangered North Pacific right whale Eubalaena japonica in the Bering Sea. Mar. Ecol. Prog. Ser. 532: 269-81.

Zerbini, A.N., Mendez, M., Rosenbaum, H., Sucunza, F., Andriolo, A., Harris, G., Clapham, P.J., Sironi, M. and Uhart, M. 2015b. Tracking southern right whales through the southwest Atlantic: New insights into migratory routes and feeding grounds. Paper SC/66a/BRG22rev1 presented to the IWC Scientific Committee, May 2015, San Diego, CA, USA (unpublished). 9pp. [Paper available from the Office of this Journal].

Zerbini, A.N. and Moore, M.J. 2013. Improving large cetacean implantable satellite tag designs to maximize tag robustness and minimize health effects to individual animals.

Zimmer, W.M.X., Johnson, M.P., D’Amico, A. and Tyack, P.L. 2003. Combining data from a multisensor tag and passive sonar to determine the diving behavior of a sperm whale (Physeter macrocephalus). IJOE 28(1): 13-28.

Zimmer, W.M.X., Johnson, M.P., Madsen, P.T. and Tyack, P.L. 2005a. Echolocation clicks of free-ranging Cuvier's beaked whales (Ziphius cavirostris). J. Acoust. Soc. Am. 117(6): 3919.

Zimmer, W.M.X., Madsen, P.T., Teloni, V., Johnson, M.P. and Tyack, P.L. 2005 b. Off-axis effects on the multipulse structure of sperm whale usual clicks with implications for sound production. J. Acoust. Soc. Am. 118(5): $3337-45$.

Zimmer, W.M.X. and Tyack, P.L. 2007. Repetitive shallow dives pose decompression risk in deep-diving beaked whales. Mar. Mamm. Sci. 23(4): 888-925.

Zimmer, W.M.X., Tyack, P.L., Johnson, M.P. and Madsen, P.T. 2005c. Three-dimensional beam pattern of regular sperm whale clicks confirms bent-horn hypothesis. J. Acoust. Soc. Am. 117(3): 1473-85. 